FERNANDO HENRIQUE JACYNTHO PETENEL

\title{
Análise de Problemas Ligados às Comunicações em Redes Elétricas Inteligentes
}

Dissertação apresentada à Escola Politécnica da Universidade de São Paulo para obtenção do título de Mestre em Engenharia Elétrica

Área de Concentração: Engenharia de Telecomunicações e Controle

Orientador: Prof. Dr. Cristiano Magalhães Panazio

São Paulo

2014 
Este exemplar foi revisado e alterado em relação à versão original, sob responsabilidade única do autor e com a anuência de seu orientador.

São Paulo, 03 de Fevereiro de 2014.

Assinatura do autor

Assinatura do orientador

FICHA CATALOGRÁFICA

Petenel, Fernando Henrique Jacyntho

Análise de Problemas Ligados às Comunicações em Redes Elétricas Inteligentes /

F.H.J. Petenel. -- ed. rev. -- São Paulo, 2014.

p.

Dissertação (Mestrado) - Escola Politécnica da Universidade de São Paulo. Departamento de Engenharia de Telecomunicações e Controle.

1.Automação na distribuição de energia elétrica 2.Redes elétricas inteligentes 3.IEC 61850 4.NS-2 I. Universidade de São Paulo. Escola Politécnica. Departamento de Engenharia de Telecomunicações e Controle II.t. 


\section{RESUMO}

PETENEL, FHJ. Análise de Problemas Ligados às Comunicações em Redes Elétricas Inteligentes. São Paulo: Escola Politécnica da Universidade de São Paulo, 2013. Dissertação de Mestrado em Engenharia Elétrica.

Este estudo é uma análise de interfaces e protocolos de automação que possuem potencial para serem adotados como padrões em redes elétricas inteligentes em um futuro próximo. A fim de verificar a possibilidade de implementar a IEC 61850 em uma aplicação típica de redes deste tipo, é realizada uma simulação usando o software NS-2. Os resultados deste trabalho servirão de orientação para o dimensionamento de redes de automação baseadas em IEC 61850.

Palavras-Chave: Redes elétricas inteligentes, IEC 61850, NS-2. 



\section{ABSTRACT}

PETENEL, FHJ. Analysis of Communication Issues Related to Smart Grids. São Paulo: Escola Politécnica da Universidade de São Paulo, 2013. Dissertação de Mestrado em Engenharia Elétrica.

This study is an analysis of automation interfaces and protocols with the potential to be adopted as standards for smart grids in the near future. In order to verify the feasibility of implementing the IEC 61850 in a typical application of such grids, it is performed a simulation using NS-2 software. The results of this work will be an orientation to dimension automation networks based on IEC 61850.

Keywords: Smart grids, IEC 61850, NS-2. 



\section{LISTA DE ILUSTRAÇÕES}

Figura 1.1 - Geração de energia elétrica mundial, 2010-2040....... 3

Figura 3.1 - Modelagem de dispositivos segundo a IEC 61850..... 41

Figura 3.2 - Modelo de dados da IEC 61850........................... 42

Figura 3.3 - Exemplo de modelo de dados da IEC $61850 \ldots \ldots \ldots \ldots . . . .43$

Figura 3.4 - Consulta dos dados referentes aos LNs CBCSWI120

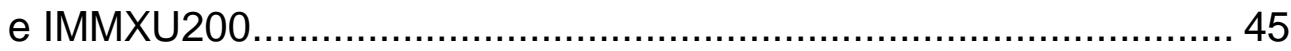

Figura 3.5 - Tempo total de transmissão................................. 50

Figura 3.6 - Modelo de referência OSI e perfis de Aplicação $(A)$ e

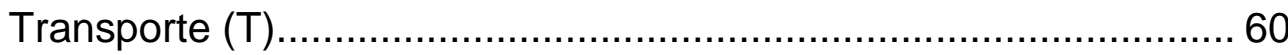

Figura 3.7 - Visão geral dos serviços de comunicação................. 61

Figura 3.8 - Retransmissões de um evento..............................6 63

Figura 3.9 - Compartimento de baixa tensão de um painel de

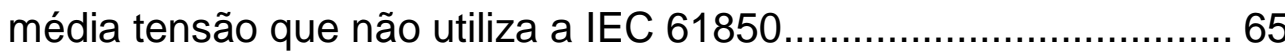

Figura 3.10 - Trecho extraído de um certificado de conformidade.. 66

Figura 3.11 - Teste de conformidade realizado no KEMA.............6 67

Figura 4.1 - Divisão de um SAS por níveis................................ 71

Figura 4.2 - Atualidades e tendências com o uso da IEC 61850 em subestações.................................................................... 72

Figura 4.3 - Diagrama unifilar e estrutura do SAS simulado.......... 79

Figura 4.4 - Topologia de rede de comunicação da simulação...... 79

Figura 4.5 - Equipamentos usados no laboratório para coleta de dados............................................................................................ 81

Figura 4.6 - Número de pacotes na fila.................................. 85

Figura 4.7 - Latência nos enlaces........................................... 86

Figura 4.8 - Vazão de dados.............................................. 86

Figura 4.9 - Latência nos enlaces no caso de curto-circuitos

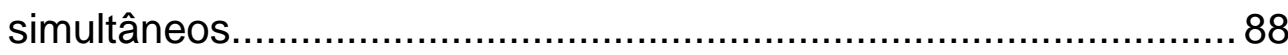


Figura 4.10 - Vazão de dados no caso de curto-circuitos simultâneos... 


\section{LISTA DE TABELAS}

Tabela I - Nós lógicos (LN) ............................................... 43

Tabela II - Restrições funcionais para o LN “CBCSWI120”............ 46

Tabela III - Definição das classes de tempo de sincronização........ 49

Tabela IV - Definição das classes de tempo de transferência......... 53

Tabela V - Classe de desempenho tipo 1A............................... 55

Tabela VI - Classe de desempenho tipo 1B.............................. 55

Tabela VII - Classe de desempenho tipo 2................................ 56

Tabela VIII - Classe de desempenho tipo 3.............................. 57

Tabela IX - Classe de desempenho tipo 4................................ 58

Tabela $X$ - Classe de desempenho tipo 5..................................58

Tabela XI - Classe de desempenho tipo 6....................................59 



\section{LISTA DE ABREVIATURAS E SIGLAS}

$\begin{array}{ll}\text { ACSI } & \text { Abstract Communication Service Interface } \\ \text { A/D } & \text { Analógico/Digital } \\ \text { AMI } & \text { Advanced Metering Infrastructure } \\ \text { ANEEL } & \text { Agência Nacional de Energia Elétrica } \\ \text { ANSI } & \text { American National Standards Institute } \\ \text { AO } & \text { Asset/System Optimization } \\ \text { ASDU } & \text { Application Service Data Unit } \\ \text { BPL } & \text { Broadband over Power Line } \\ \text { CDC } & \text { Commom Data Class } \\ \text { CIM } & \text { Common Information Model } \\ \text { CMV } & \text { Complex measurement value } \\ \text { CS } & \text { Customer Side Systems } \\ \text { DA } & \text { Data Attribute } \\ \text { DARPA } & \text { Defense Advanced Research Projects Agency } \\ \text { DEC } & \text { Duração Equivalente de interrupção por Consumidor } \\ \text { DER } & \text { Distributed Energy Resources } \\ \text { DMS } & \text { Distribution Management System } \\ \text { DO } & \text { Data Object } \\ \text { DPC } & \text { Double Point Controllable } \\ \text { DPS } & \text { Double Point Status } \\ \text { DR } & \text { Demand Response } \\ \text { DSL } & \text { Digital Subscriber Line } \\ \text { EIA } & \text { Estudo de Impacto Ambiental } \\ \text { E/E/PE } & \text { Electrical/Electronic/Programmable Electronic } \\ \text { ERAC } & \text { Esquema Regional de Alívio de Carga } \\ \text { FC } & \text { Functional Restraints } \\ \text { FEC } & \text { Frequência Equivalente de interrupção por Consumidor } \\ \text { GOOSE } & \text { Generic Object Oriented Substation Event } \\ \text { GPS } & \text { Global Positioning System } \\ & \end{array}$




$\begin{array}{ll}\text { ICT } & \text { Information and Communications Integration } \\ \text { IEA } & \text { International Energy Agency } \\ \text { IEC } & \text { International Electrotechnical Comission } \\ \text { IED } & \text { Intelligent Electronic Device } \\ \text { INC } & \text { Integer Controllable } \\ \text { INS } & \text { Integer Status } \\ \text { IP } & \text { Internet Protocol } \\ \text { LAN } & \text { Local Area Network } \\ \text { LD } & \text { Logical Devices } \\ \text { LN } & \text { Logical Nodes } \\ \text { LTE } & \text { Long Term Evolution } \\ \text { MAC } & \text { Media Access Control } \\ \text { MMS } & \text { Manufacturing Message Specification } \\ \text { MV } & \text { Measurement Value } \\ \text { NS-2 } & \text { Network Simulator 2 } \\ \text { OSI } & \text { Open Systems Interconnection } \\ \text { PCH } & \text { Pequena Central Hidroelétrica } \\ \text { PEV } & \text { Plug in Electric Vehicles } \\ \text { PICOM } & \text { Piece of Information for Communication } \\ \text { PLC } & \text { Power Line Carrier } \\ \text { PMU } & \text { Phasor Measuring Unit } \\ \text { QOS } & \text { Quality of Service } \\ \text { RTU } & \text { Remote Terminal Unit } \\ \text { SAS } & \text { Substation Automation System } \\ \text { SCL } & \text { Substation Configuration Language } \\ \text { SDH } & \text { Synchronous Digital Hierarchy } \\ \text { SIN } & \text { Sistema Interligado Nacional } \\ \text { SNTP } & \text { Simple Network Time Protocol } \\ \text { SOA } & \text { Service Oriented Architecture } \\ \text { SONET } & \text { Synchronous Optical Networking } \\ \text { SPC } & \text { Single Point Controllable } \\ \text { SPS } & \text { Single Point Status } \\ & \end{array}$




$\begin{array}{ll}\text { SV } & \text { Sampled Values } \\ \text { TA } & \text { Transmission enhancement Applications } \\ \text { TC57 } & \text { Technical Committee } 57 \\ \text { TCP } & \text { Transmission Control Protocol } \\ \text { UDP } & \text { User Datagram Protocol } \\ \text { UTC } & \text { Coordinated Universal Time } \\ \text { VINT } & \text { Virtual InterNetwork Testbed } \\ \text { VLAN } & \text { Virtual Local Area Network } \\ \text { WAN } & \text { Wide Area Network } \\ \text { WiMAX } & \text { Worldwide Interoperability for Microwave Access }\end{array}$





\section{SUMÁRIO}

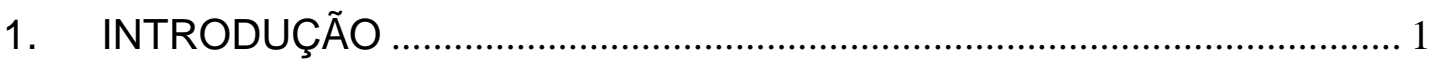

1.1. OBJETIVO, CONTRIBUIÇÕES E ORGANIZAÇÃO DO TEXTO ..............5

2. REDES ELÉTRICAS INTELIGENTES - SMART GRIDS …....................... 7

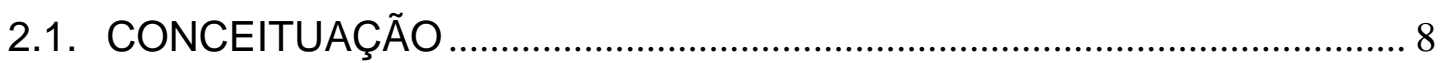

2.2. TÉCNICAS E BENEFÍCIOS DECORRENTES DO USO DE

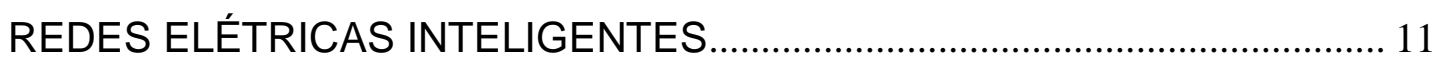

2.3. INICIATIVAS RECENTES DE IMPLANTAÇÃO DE REDES INTELIGENTES NO BRASIL .......................................................................... 22

2.4. INTERFACES DE COMUNICAÇÃO EM REDES ELÉTRICAS

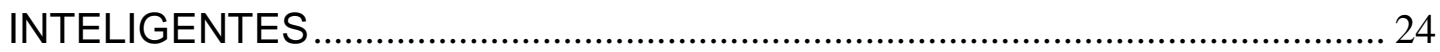

2.5. PROTOCOLOS E NORMAS DE COMUNICAÇÃO ……………………..... 30

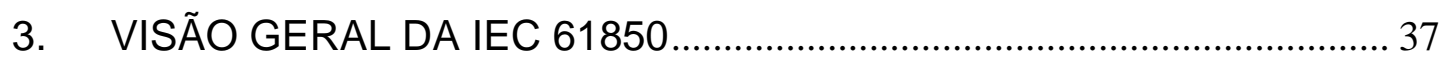

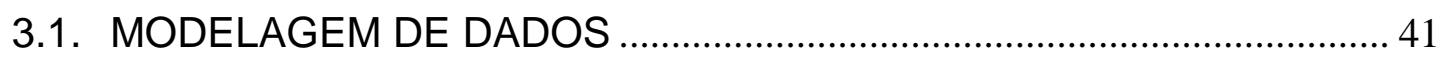

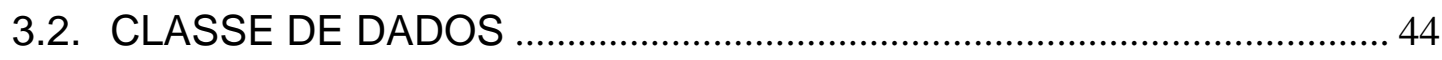

3.3. TIPOS DE MENSAGENS E DEFINIÇÃO DE CLASSES ……………...... 52

3.4. PILHA DE COMUNICAÇÃO E SERVIÇOS ................................................. 60

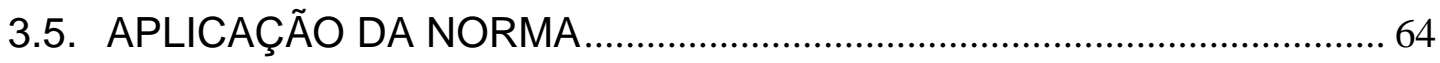

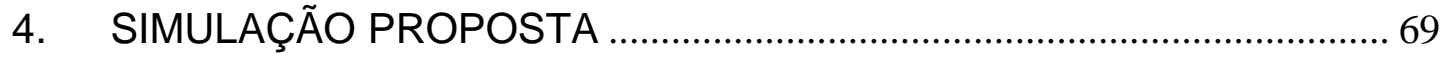

4.1. SISTEMAS DE AUTOMAÇÃO DE SUBESTAÇÕES …………………........ 69

4.2. DEFINIÇÃO DOS CENÁRIOS A SEREM SIMULADOS ……………….... 73

4.3. SOFTWARE DE SIMULAÇÃO DE REDE DE PACOTES ……………..... 77

4.4. DEFINIÇÃO DA ARQUITETURA E PARÂMETROS DA

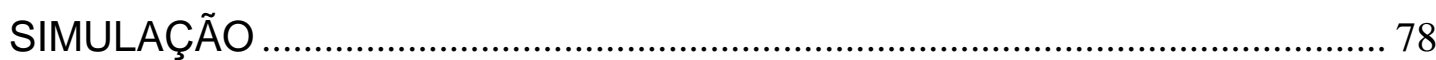


4.5. RESULTADOS DA SIMULAÇÃO

4.6. CONSIDERAÇÕES ADICIONAIS ACERCA DA SIMULAÇÃO................ 89

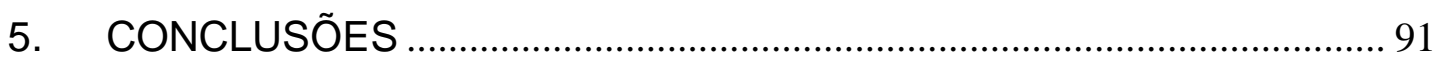

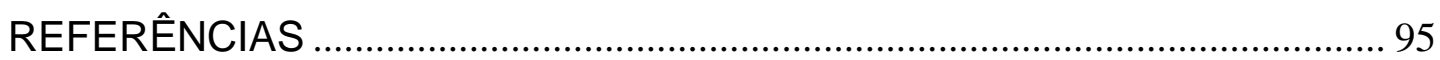




\section{INTRODUÇÃO}

O conceito de rede elétrica, que é utilizado atualmente, foi desenvolvido a mais de 100 anos [1] e a maioria das linhas de transmissão, usinas geradoras e sistemas de distribuição foram construídos a 30 anos atrás ou mais. O modelo usado para o desenvolvimento destes sistemas de geração, transmissão e distribuição, ainda hoje, utiliza muito do que foi proposto no período entre 1890 e 1930 [2], principalmente por Samuel Insull, Thomas Edison, Lucien Gaulard e John Dixon Gibbs, no que diz respeito ao desenvolvimento de subestações, sistemas interligados, transmissão de energia em corrente contínua ou alternada e transformadores. Obviamente surgiram novas tecnologias neste ramo, como, por exemplo, relés de proteção microprocessados, disjuntores a vácuo e painéis fotovoltaicos. No entanto, ainda hoje, o sistema elétrico é baseado no modelo que visa a distribuição da energia produzida em grandes usinas geradoras, geralmente afastadas dos grandes centros consumidores, através da construção de extensas linhas de transmissão.

A construção dos sistemas empregados neste modelo (geração e transmissão) resulta em grandes impactos ambientais e sociais [3]. Nos últimos anos, os grandes empreendimentos de geração de energia têm sido bastante questionados e a legislação ambiental [4] está cada vez mais rigorosa quanto à realização do Estudo de Impacto Ambiental (EIA), o que, na maioria das vezes, resulta no impedimento da construção destes empreendimentos. 
Além do fator ambiental, existem outros problemas, como a capacidade marginal, que se traduz na ineficiência destas redes em suprir o consumo variável em função do tempo utilizando níveis estáveis de geração, a quantidade de perdas técnicas ${ }^{1}$ na transmissão e distribuição, a crescente demanda por energia elétrica para suportar o crescimento populacional e o desenvolvimento das nações, dentre outros.

Dados tais problemas, é preciso encontrar novas soluções para mitigar e/ou contornar estes fatores, tais como:

- o uso de fontes de energia renováveis que reduzam o impacto ambiental.

- o aumento da eficiência energética

- a geração distribuída em áreas mais próximas dos grande centros consumidores.

Segungo a Agência Internacional de Energia (IEA - International Energy Agency), em seu relatório anual International Energy Outlook [5], a demanda global por energia vai crescer cerca de $56 \%$ entre 2010 e 2040. Particularmente no caso da energia elétrica, a elevação será em torno de 93\%. Este aumento deve ocorrer principalmente por causa do crescimento econômico e populacional das nações durante este período. Dos $56 \%$ do crescimento global na demanda de energia, mais de $85 \%$ deste aumento ocorrerá entre os países em desenvolvimento. Para suprir esta nova demanda, serão necessários investimentos da ordem de trilhões de dólares nos sistemas de energia como um todo. A IEA acredita que é preciso investir ao menos 36 trilhões de dólares somente em fontes de

\footnotetext{
${ }^{1}$ Perdas técnicas são perdas inerentes à operação do Sistema Elétrico devido à transmissão (e.g., aquecimento das linhas), transformação, distribuição etc. As perdas não técnicas, também chamadas de perdas comerciais, são aquelas oriundas de fraudes ou furtos.
} 
energia limpa. Apesar de o valor parecer muito alto, este número representa apenas $35 \%$ a mais do valor estimado a ser investido em infraestrutura de energia no mundo até 2050 [6]. De acordo com o relatório da IEA, é esperado que em 2040, 24\% da energia elétrica mundial terá como origem fontes renováveis, um aumento total de 5,4 trilhões de quilowatt-hora ( $\mathrm{kWh}$ ). A Figura 1.1 mostra o prospecto apresentado neste parágrafo.

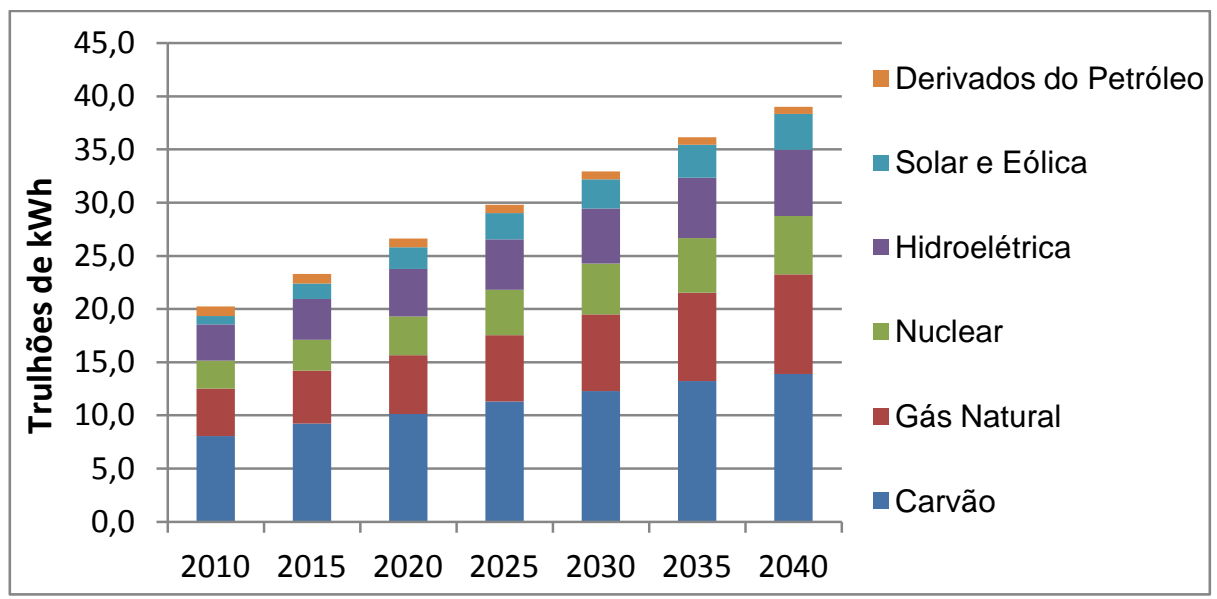

Figura 1.1 - Geração de energia elétrica mundial, 2010-2040. Fonte: [5].

No Brasil, cerca de $79 \%$ da geração de energia é de origem hidráulica [7] e, durante períodos de longa seca, o país ainda sofre com a ameaça de racionamento de energia elétrica. Para contornar este problema, o Plano Nacional Energético 2030 [8] estabelece que, para o período de 2016-2030, a capacidade instalada em usinas térmicas convencionais deverá crescer a uma média anual de $3 \mathrm{GW}$. Para as fontes de energia alternativa, tais como $\mathrm{PCH}^{2}$ (Pequena Central Hidroelétrica), Centrais a biomassa, centrais

\footnotetext{
${ }^{2} \mathrm{PCH}$ - Pequena central hidrelétrica. De acordo com a resolução n ${ }^{\circ} 394$ de 04 de dezembro de 1998 da Agência Nacional de Energia Elétrica (ANEEL), PCH é toda usina hidrelétrica de pequeno porte cuja capacidade instalada seja superior a $1 \mathrm{MW}$ e inferior a $30 \mathrm{MW}$. Além disso, a área do reservatório deve ser inferior a $3 \mathrm{~km}^{2}$.
} 
eólicas e fontes movidas a resíduos urbanos, o aumento total no período é de cerca de 15,35 GW. Ao longo dos 14 anos compreendidos neste período, o crescimento da capacidade instalada em fontes de energia limpa representa somente cerca de um terço da capacidade adicional instalada de fontes de energia com grande impacto ambiental.

No total estaria-se investindo no período de 14 anos quase 3 vezes O Plano Decenal de Expansão de Energia 2011 [9] prevê, para o período de 2012 a 2021, investimentos da ordem de $R \$ 213$ bilhões em geração de energia elétrica. Este valor engloba o já investido em usinas contratadas e autorizadas, e também o valor que será investido em usinas planejadas. Dentre o investimento em usinas planejadas, que será de $R \$ 117,4$ bilhões, $57 \%$ serão destinados a empreendimentos hidroelétricos e $42 \%$ irão para as outras fontes renováveis, como $\mathrm{PCH}$, biomassa e eólica.

Atualmente, a geração de energia elétrica mundial possui grande impacto na emissão de $\mathrm{CO}_{2}$ [10], arcando com cerca de $30 \%$ do total das emissões relacionadas à produção de energia em geral. Para reduzir este impacto, será crucial a transição para fontes de geração renováveis e processos mais inteligentes. No nível de processos, as cidades deverão deixar de ser apenas locais de grande consumo de energia elétrica e se transformar em locais onde a energia é usada, produzida e armazenada. Como consequência, será necessário lançar mão das tecnologias provenientes das redes elétricas inteligentes para implementar sistemas de controle e gerenciar os dados provenientes da penetração maciça de dispositivos de medição e controle. Logo, o sucesso deste novo modelo dependerá da criação de uma estrutura apropriada de comunicação que ofereça disponibilidade e suficiente largura de banda, e da implementação 
de algoritmos de controle que possam ser executados de forma centralizada ou distribuída de acordo com a aplicação a que forem destinados, evitando sobrecarregar as redes de comunicação. A partir daí, com a consolidação dos sistemas de comunicação, gerenciamento e controle, será possível integrar, apesar de sua intermitência, até mesmo as pequenas fontes geradoras de origem renovável nos sistemas de distribuição de energia elétrica de maneira segura e eficiente.

Além disso, a otimização das redes atuais que compõem os sistemas elétricos, a motivação da transição das fontes de energia em busca de opções mais limpas, e os fortes investimentos em eletricidade, não só no Brasil, mas também em todo o mundo, criam um cenário de incentivo ao desenvolvimento das empresas fornecedoras de equipamentos e serviços, destinados a este ramo. Isto favorece a criação de novas tecnologias, normas e padrões para conduzir tal expansão do sistema elétrico, ajudando a atender à crescente demanda por energia elétrica.

\subsection{OBJETIVO, CONTRIBUIÇÕES E ORGANIZAÇÃO DO TEXTO}

O objetivo deste trabalho é fazer a análise de redes elétricas inteligentes através do estudo de interfaces e protocolos de comunicação, porém, dando maior enfoque aos protocolos de 
comunicação utilizados em aplicações de sistemas de automação de subestações, como é caso dos protocolos DNP3 [11] e IEC 60870-5103 [12], além de compará-los à mais nova tendência que é a norma IEC 61850 [13].

Pode-se destacar as seguintes contribuições:

- Conceituação do que são redes elétricas inteligentes, suas possíveis aplicações e desafios;

- Resumo da norma IEC 61850, focando em exemplos de implementação;

- Avaliação do uso da IEC 61850 dando maior segurança para os envolvidos com projetos de automação de subestações quanto ao cumprimento dos requisitos de desempenho da norma, mesmo em condições adversas;

A metodologia utilizada neste último ponto engloba a implementação de um sistema de descarte de cargas em laboratório para coleta de dados que serão base da simulação de um sistema mais amplo, a simulação de redes usadas em sistemas de automação de subestações baseada na norma IEC 61850 .

Essa dissertação está organizada da seguinte maneira. No capítulo 2, o conceito de redes elétricas inteligentes é discutido e são apresentadas as técnicas que envolvem sua implantação, os benefícios decorrentes e as questões ligadas à comunicação de dados em tais redes. Já no capítulo 3, a norma mais relevante para implementação de redes elétricas inteligentes no ambiente de sistemas de automação de subestações, a IEC 61850, é detalhada. O capítulo 4 propõe a simulação de um sistema de automação de subestações, utilizando a norma IEC 61850 . Finalmente, o capítulo 5 apresenta as conclusões. 


\title{
2. REDES ELÉTRICAS INTELIGENTES - SMART GRIDS
}

\begin{abstract}
A definição de redes elétricas inteligentes (Smart Grids), que pode resumir em linhas gerais tal idéia, ainda é tema de discussões. Todavia, uma definição abrangente é a do Departamento de Energia dos Estados Unidos da América [14], que diz que uma rede elétrica inteligente utiliza tecnologia digital para melhorar a confiabilidade, segurança, e eficiência do sistema elétrico. A discussão em torno do assunto se dá devido às várias partes interessadas e seus diversos pontos de vista que enfatizam o interesse de cada uma delas. Apesar da ampla abrangência do tema, todos os conceitos convergem para o uso de sistemas digitais e comunicação em redes elétricas. O uso de sistemas digitais com comunicação ampla e irrestrita permitem que a rede seja inteiramente controlada e que os consumidores possam ser inseridos nesse setor produtivo. A diversas definições e as tecnologias presentes nestas redes serão detalhadas neste capítulo.
\end{abstract}




\subsection{CONCEITUAÇÃO}

A origem do termo Smart Grid é controversa. Alguns dizem que o termo foi usado pela primeira vez no artigo "Reliability demands will drive automation investments" [15] de 2003, com a idéia de diminuir os pontos fracos do sistema elétrico (i.e. ineficiência e falhas operacionais) através da capacidade de transmissão de dados e sistemas de controle da rede, enquanto outros dizem que o termo teve origem no artigo “Toward a Smart Grid" [16] de 2005, usado no sentido de adicionar processamento nos equipamentos do sistema elétrico aliado à comunicação. Existem inclusive autores que remetem o uso do termo ao ano de 1998 [17].

Já [18] considera que uma rede elétrica inteligente é feita pelo uso de sensores, comunicação, computação e controle, de algum modo a incrementar as funcionalidades, do sistema de fornecimento de energia elétrica.

Por sua vez, a visão da European Technology Platform (ETP) [19] diz respeito à uma rede elétrica que inteligentemente integra as ações de todos os usuários conectados a ela - geradores, consumidores e aqueles que são ambos geradores e consumidores - a fim de produzir fontes de energia elétrica sustentáveis, econômicas e seguras. Ainda, segundo a ETP, as redes elétricas inteligentes empregam o uso de produtos e serviços inovadores, em algumas áreas, como monitoramento, controle, comunicação e tecnologias de autorestabelecimento inteligentes. 
Em resumo, as áreas do sistema elétrico que estão no escopo das redes elétricas inteligentes são [14]:

- Coleta de medições ao longo do sistema para determinar o estado da rede elétrica, de modo a coordenar ações para aumentar a eficiência econômica, confiabilidade, o cumprimento dos requisitos ambientais, e/ou responder a distúrbios [20].

- Integração na operação do sistema elétrico [21] de fontes de geração distribuídas [22], armazenamento de energia elétrica, e recursos no lado da demanda. Outros integrantes importantes são eletrodomésticos inteligentes [23], veículos elétricos, pequenos geradores eólicos ou fotovoltaicos.

- Modernização da infraestrutura de transmissão e distribuição. Esta área engloba no nível de transmissão, a automação de subestações, limites dinâmicos, coordenação da proteção dos relés, e todas as ações associadas à comunicação, sensoriamento e gerenciamento [24]. No nível de distribuição engloba 0 balanceamento de carga de alimentadores, chaveamento de banco de capacitores, descarte de cargas, detecção, isolamento e restauração de cargas, e infraestrutura de medição avançada, tais como leitura de medidores, corte e religamento remoto e sistemas de resposta pelo lado da demanda [25].

- Continuação nos avanços dos sistemas de automação da geração para otimizar os custos de produção de forma centralizada e viabilizar investimentos seguros em empreendimentos com menores custos [26].

- Comunicação difundida ao longo da rede elétrica e softwares de gerenciamento da informação. No entanto, os requisitos 
das redes de dados (capacidade e desempenho) são diferentes para cada área e seus atributos incluem interoperabilidade, facilidade de integração dos componentes de automação e segurança cibernética [27].

A grosso modo, o objetivo geral das redes elétricas inteligentes é fazer com que exista a comunicação entre os diversos entes presentes no sistema elétrico, de subestações a eletrodomésticos. Um dos benefícios ao consumidor que pode ser citado com relação a esta tecnologia é a possibilidade de desaceleração nos aumentos no valor da conta de energia através do monitoramento inteligente de dispositivos. Além dos consumidores, as concessionárias de energia também visam a redução dos custos operacionais, fazendo, por exemplo, com que processos simples como o de leitura de consumo dos medidores, corte e religamento possam ser feitos de forma remota.

Embora ainda existam muitos debates sobre a definição exata, de forma geral, as redes elétricas inteligentes abrangem uma vasta gama de soluções de tecnologia que aumentam o lucro da energia. Dependendo de onde e como os participantes operam dentro da cadeia, eles podem se beneficiar implantando certas partes dentre todas as soluções das redes inteligentes.

Em particular, é interessante ressaltar que uma das principais entidades do sistema elétrico, i.e., as concessionárias de energia elétrica, focam atualmente em três aspectos com relação à operação de sua rede [17]: 
- Melhoria da infraestrutura, reforço da rede e instalação de equipamentos.

- Digitalização, através da integração de equipamentos tais como medidores digitais, equipamentos de proteção e controle inteligentes e sistemas supervisores.

- Transformação do processo de negócio, de forma a reunir os recursos necessários para implantação das tecnologias das redes inteligentes (e.g. compra da energia proveniente de consumidores residenciais em determinado período).

Para atingir o que propõe as definições apresentadas até o momento, é crucial empregar soluções tecnológicas inovadoras. Este é o assunto a ser discutido a seguir.

\subsection{TÉCNICAS E BENEFÍCIOS DECORRENTES DO USO DE REDES ELÉTRICAS INTELIGENTES}

A ideia de aplicar comunicação e automação nas redes elétricas foi alavancada como alternativa para atender à crescente demanda por energia dos próximos anos. As primeiras tecnologias de redes inteligentes tiveram como base o uso equipamentos de controle, medição e monitoramento que evoluíram de elementos eletromecânicos. 
A primeira solução em larga escala foi implantada em 2001, na Itália [28]. A concessionária de energia local, Enel, colocou em funcionamento seu sistema chamado Telegestore, que é composto por um conjunto de dispositivos eletrônicos e softwares, cujos principais elementos são:

- medidor eletrônico;

- concentrador, instalado nos transformadores de média para baixa tensão;

- sistema central, usado para gerenciar os dados dos medidores, processar o faturamento e monitorar a qualidade do fornecimento.

A solução Telegestore é um sistema automatizado de leitura de dados de medição de energia. Esta solução não possui precificação dinâmica, mas foi o primeiro passo para evolução aos sistemas de infraestrutura de medição avançada (AMI - Advanced Metering Infrastructure). Esta é apenas uma das várias soluções de tecnologia que geralmente são consideradas em um plano de implantação das redes elétricas inteligentes.

Em geral, as soluções tecnológicas mais consideradas na implementação de redes elétricas inteligentes são:

Distribuição

- Infraestrutura de medição avançada formada por medidores inteligentes e sistemas de precificação dinâmica; 
- Sistemas do lado do consumidor (CS - Customer Side Systems) tais como sistemas de controle residencial para regulação de eletrodomésticos;

- Resposta do lado da demanda (DR - Demand Response) que permite que o consumidor decida em quais horários é mais conveniente utilizar energia elétrica pagando por ela o menor preço;

- Sistemas de automação e gerenciamento da distribuição (DMS - Distribution Management System) que darão as ferramentas adequadas para gerenciar a automação da rede de distribuição de energia elétrica das concessionárias;

- Veículos elétricos plug-in (PEV - Plug in electric vehicles) que propiciarão a redução no impacto ambiental criado por veículos automotores à combustão.

- Integração de tecnologias da informação e comunicação (ICT - Information and Communications Technology) para gerenciar a vasta gama de informações coletadas através da comunicação com os dispositivos eletrônicos presentes no sistema elétrico;

Geração

- Fontes de energia distribuídas (DER - Distributed Energy Resources) possibilitarão trazer a geração para mais próximo das cargas presentes nos grandes centros; 
- TransmissãoAplicações de melhoria da transmissão (TA Transmission Enhancement Applications) que irão permitir aos sistemas de transmissão melhor operação e ação diante de falhas;

Otimização de sistema/ativo (AO - Asset/System Optimization) possibilita adiar investimentos através do uso pleno dos equipamentos;

Tais tecnologias objetivam beneficiar todo o sistema de diversas maneiras, em áreas chaves, descritas a seguir [29]:

- Confiabilidade

Geralmente, uma rede elétrica confiável é aquela que entrega energia elétrica a seus consumidores quando estes desejam ou necessitam, com a qualidade que atenda aos seus requisitos. O aumento na confiabilidade pode, geralmente, ser medido através da redução da freqüência e duração das interrupções no fornecimento $\left(\mathrm{DEC}^{3}\right.$ e $\left.\mathrm{FEC}^{4}\right)$, na redução do número de distúrbios devido à uma má qualidade de energia, e pela eliminação de apagões.

Os benefícios referentes ao aumento da confiabilidade são muitos. Dentre eles está a redução do custo operacional da concessionária, devido a um número menor de deslocamentos de equipes de

\footnotetext{
${ }^{3}$ DEC - Duração equivalente de interrupção por unidade consumidora. Intervalo de tempo que, em média, no período de apuração, em cada unidade consumidora do conjunto considerado ocorreu descontinuidade da distribuição de energia elétrica [63].

${ }^{4}$ FEC - Frequência equivalente de interrupção por unidade consumidora. Número de interrupções ocorridas, em média, no período de apuração, em cada unidade consumidora do conjunto considerado [63].
} 
manutenção, menor demanda dos operadores do call center e da equipe de engenharia e de recursos para resposta a apagões. Além disso, há também o aumento na venda de energia das plantas geradoras, pois uma vez que o cliente está menos tempo desligado, a geração está vendendo mais de seu produto. Também, a redução nos transitórios diminui o desgaste dos geradores que, por sua vez, reduz o tempo de parada da planta em virtude de manutenções.

Para os consumidores residenciais, o aumento na confiabilidade diminui os inconvenientes devido aos apagões e danos em equipamentos eletrônicos decorrentes dos problemas na qualidade de energia. Ainda, o desenvolvimento econômico das nações, dentre outros fatores, depende de fontes confiáveis e no fornecimento de energia elétrica. Uma rede elétrica inteligente robusta cria um ambiente atrativo para novos investimentos no setor industrial, que acarretam benefícios para a sociedade em geral.

A integração de novas tecnologias pode contribuir para o aumento significativo na confiabilidade. Entre elas, é possível destacar a infraestrutura de medição com medidores inteligentes (AMI) que possuam comunicação com a central de medição da concessionária e possibilita a detecção instantânea de problemas de qualidade de energia e perda de potência, habilitando os operadores a diagnosticar e restaurar o fornecimento rapidamente. Com o uso destes medidores, é possível também utilizar programas de resposta pelo lado da demanda ${ }^{5}$ (DR) para reduzir o estresse nos ativos do sistema durante condições de pico, reduzindo a probabilidade de falha.

\footnotetext{
${ }^{5}$ Programas de resposta pelo lado da demanda (DR - Demand Response) são usados para controlar a demanda, movendo o consumo para horários em que a tarifa de energia é mais barata. Apesar de muito utilizado em outros países, no Brasil a tarifa de energia ainda é monômia o que impossibilita a implementação de tais programas.
} 
Além disso, sistemas de gerenciamento da distribuição (DMS), com o uso massivo de sensores, comunicação e controles inteligentes possibilta aos operadores maior visibilidade do sistema de distribuição, permitindo a identificação e troca de equipamentos que apresentam problemas antes do colapso. Em aplicações de transmissão, o emprego de sensores tais como unidades de medição de fasores (PMU - Phasor Measuring Unit) e novas ferramentas de simulação, juntamente com a comunicação em alta velocidade entre subestações e centro de controle do sistema, permitem um gerenciamento dinâmico do sistema de transmissão (TA), podendo assim, evitar situações em que falhas ocorrem em cascata e que levam a apagões.

Por fim, as fontes de energia distribuídas (DER), incluindo geração e armazenamento local, podem atuar como fontes de backup em situações em que distúrbios afetem o suprimento normal do sistema de energia elétrica, aumentando a confiabilidade do sistema elétrico.

\section{- Economia}

O benefício econômico é percebido pelo consumidor diretamente quando a sua conta de energia elétrica pode ter valor inferior a paga em outras situações. A criação de oportunidades para novos produtos e serviços, e a criação de novos empregos são elementos de estímulo ao desenvolvimento da economia. Dentre outros benefícios referentes à economia que podem ser destacados está o aumento do faturamento das concessionárias pela redução das 
perdas não técnicas ${ }^{6}$, devido ao aumento da precisão dos medidores inteligentes em detrimento dos tradicionais, a redução nos apagões, e também, a criação de novas oportunidades de mercado para geração distribuída e armazenamento. Ainda, o aumento da eficiência na operação e comercialização, reduzindo o custo para suprir energia em condições de pico possibilita às concessionárias aumentar sua margem de lucro na operação das redes elétricas.

A integração das tecnologias das redes elétricas inteligentes pode contribuir com melhoras significativas na economia. Dentre elas, pode-se destacar a comunicação bidirecional com os medidores inteligentes (AMI), que permite a precificação em tempo quase real em países onde a tarifa de energia elétrica residencial é variável em função da hora do dia. Este modelo incentiva os consumidores a responderem aos preços da mesma forma que ocorre com outros produtos. É esperado que esta resposta reduza a demanda nos horários de pico, o que resulta em um melhor aproveitamento dos ativos do sistema elétrico, diminuindo a necessidade de capacidade extra no sistema para atender ao consumo marginal.

Além disso, fontes de energia distribuídas (DER), incluindo geração e armazenamento local, podem ser utilizadas para suportar o sistema de DR e em alguns casos, atuar como fontes de venda de energia elétrica para o mercado. Este fato se traduz em benefício ao consumidor residencial que pode obter descontos em sua conta de energia, exportando energia para rede em períodos de baixo consumo, como também traz benefícios para a concessionária de energia que pode utilizar esta capacidade adicional para suprir períodos de maior demanda sem sobrecarregar seus ativos.

\footnotetext{
${ }^{6}$ Perdas não técnicas correspondem à energia efetivamente entregue, mas não faturada.
} 


\section{- Eficiência}

Embora os setores de geração e transmissão sejam bastante eficientes, ainda haveria espaço para melhorias, no entanto, é na distribuição de energia que deve acontecer a maior revolução [18].

O aumento na eficiência reduz o custo da produção e entrega da energia elétrica. Reduzindo os custos de operação, manutenção e capital de investimento, como também a quantidade de energia usada pelos consumidores, pode-se criar uma pressão para reduzir os preços da energia elétrica, além de economizar os recursos utilizados na geração. Dentre os ganhos decorrentes da maior eficiência, pode-se citar o aumento da utilização dos ativos da concessionária de energia local, por ser possível extrair mais dos ativos existentes, como também, a redução na perda proveniente das linhas de distribuição e transmissão de energia elétrica.

Além disso, o deslocamento de parte do consumo para fora dos períodos de pico de consumo permite adiar investimentos futuros, e a redução da sobrecarga nas linhas de transmissão de energia elétrica agrega aos geradores mais competitivos economicamente maior acesso aos mercados.

Tais benefícios podem ser alcançados de inúmeras formas. Dentre elas, pode-se citar a infraestrutura de medição inteligente (AMI), que dá aos consumidores informações de consumo e precificação necessárias para habilitá-los a participar mais efetivamente na redução da carga em horários de pico e ajuda na conservação da energia. Além disso, os programas de DR fornecem incentivos adicionais na redução do nível de consumo residencial tais como o 
acompanhamento da conta em tempo real, de forma que todos os clientes possam participar, e não somente os grandes consumidores comerciais e industriais.

Com relação à otimização dos ativos do sistema elétrico $(A O)$, as aplicações de aprimoramento destes equipamentos, integrando dados da rede com ferramentas de planejamento do sistema, permite aumentar a precisão das previsões quando da necessidade de integração de novos ativos para suportar o aumento da demanda.

- Meio Ambiente

Um dos objetivos para a melhora do meio ambiente é a redução das emissões de carbono e outros gases que contribuem para o efeito estufa. No caso de sistemas elétricos objetiva-se a redução no $\mathrm{CO}_{2}$ proveniente das unidades de geração, como também a redução da emissão de escapamentos com a incorporação de veículos elétricos (PEV) à frota de automóveis. Busca-se alcançar tais metas através de iniciativas, como o aumento da capacidade de integrar fontes de energia renováveis do ponto de vista das concessionárias de energia elétrica, possibilidade criada pela habilidade das redes elétricas inteligentes suportarem níveis maiores de fontes intermitentes.

A implementação de tais iniciativas pode se dar de diversas formas, das quais destacam-se o uso da infraestrutura de medição (AMI), que dá aos consumidores a informação e o controle para gerenciar efetivamente seu consumo de energia, os programas de DR juntamente com o armazenamento de energia, que tornam as fontes de energia renováveis mais viáveis para integração no suprimento 
de energia nacional e as aplicações de otimização de ativos (AO), que dão suporte ao sistema de gerenciamento da distribuição e ao sistema de melhoria da transmissão na redução das perdas, reduzindo emissões de todos os tipos, como, por exemplo, as provenientes de transformadores em chamas e vazamentos de óleo.

Ainda, o uso das fontes distribuídas de energia (DER), que incluem ampla penetração de renováveis, novas tecnologias de armazenamento e unidades que combinam calor e potência com alta eficiência, se tornam tecnicamente possíveis graças às mesmas tecnologias que tornam possíveis as redes elétricas inteligentes.

- Segurança

Os avanços na operação segura do sistema aumentam a robustez e flexibilidade da rede do ponto de vista físico e cibernético, reduzindo assim, a probabilidade de ataques humanos e as consequências decorrentes de desastres naturais. $O$ aumento na segurança pode se dar tanto pela redução nos riscos inerentes em um sistema elétrico energizado, como também pela minimização do tempo de exposição aos riscos. Para isso, objetiva-se reduzir a probabilidade que um ataque intencional físico ou cibernético possa ocorrer e mitigar as consequências de qualquer um que não seja detectado ou prevenido, diminuindo a exposição de plantas de geração a distúrbios potencialmente prejudiciais, aumentando o monitoramento através de sistemas de suporte à decisão que possibilitem a identificação de problemas e riscos mais rapidamente. 
A integração das novas tecnologias das redes elétricas inteligentes permite atingir tais objetivos por meio da implantação de uma infraestrutura de medição (AMI), que possibilite aos operadores uma conexão bidirecional em tempo real, e que traga o status de consumidores de forma individual, incluindo a habilidade para corte e religamento remoto das cargas. Além disso, a disponibilização de sistemas do lado do consumidor (CS) dão aos clientes as ferramentas e recursos necessários para operar de forma autônoma (isolada) quando a rede está danificada, e a implantação de programas de DR, em particular, podem ser extremamente úteis para manter os serviços elétricos quando o sistema está próximo do estresse, reduzindo a probabilidade de apagões ou falhas no sistema.

Os sistemas de otimização de ativos (AO), por sua vez, auxiliam na análise do status da rede e na identificação das condições de operação marginal, através da implementação de equipamentos avançados e monitoramento sofisticado, possibilitando a redistribuição do fluxo de energia para atingir um estado mais seguro da rede. 


\subsection{INICIATIVAS RECENTES DE IMPLANTAÇÃO DE REDES INTELIGENTES NO BRASIL}

A instalação da infraestrutura de medição é certamente a fatia mais atraente do ponto de vista financeiro das redes elétricas inteligentes, pois envolve mais do que a simples substituição de medidores antigos (eletromecânicos) por medidores inteligentes que possibilitem a comunicação remota. Esta infraestrutura abre um leque de possibilidades, tais como a implantação dos programas de DR, localização de falhas na rede elétrica, monitoramento da qualidade de energia e precificação dinâmica. Para isso, estes medidores inteligentes devem ser capazes de trocar dados de forma bidirecional, ou seja, devem possuir capacidade de transmissão e recepção de dados. No Brasil, de acordo com dados publicados em 2012 pela Agência Nacional de Energia Elétrica (ANEEL) [30], existem cerca de 69 milhões de consumidores de energia elétrica, o que resulta em um número semelhante de medidores de energia. Em 2010, a ANEEL promoveu a audiência pública № 043/2010 [31] para debater a modernização do parque de medição instalado para consumidores de baixa tensão. Pela proposta da ANEEL, estes medidores serão capazes de fornecer, além das informações de consumo, informações utilizadas no cálculo dos índices de qualidade do fornecimento de energia ao consumidor. Está previsto também que estes medidores possibilitem a comunicação remota dos medidores de consumo com a concessionária de energia local.

Além do custo de adequação do sistema elétrico, a tecnologia de redes elétricas inteligentes esbarra em alguns entraves que deverão 
ser sanados antes de sua implantação. Tais entraves orbitam principalmente em torno da necessidade da adoção de normas e padrões. O sistema elétrico é formado por diversas instituições, cada qual interessada em suas respectivas metas, percepções e recursos. Assim sendo, as partes interessadas deverão influenciar o desenvolvimento técnico das redes elétricas inteligentes, não somente nos aspectos técnicos, mas também no que diz respeito às normas e regulamentos. No Brasil, já existem movimentos reguladores neste sentido, e a ANEEL já aprovou, no dia 17 de abril de 2012, regras que facilitam a integração de fontes de geração distribuídas no sistema de distribuição de energia elétrica [32]. Esta norma estabelece a criação do Sistema de Compensação de Energia, fazendo com que consumidores possam trocar energia com a distribuidora local através da instalação de pequenos geradores, desde que utilizem fontes renováveis de energia. Esta nova regra é o primeiro passo para integração das DERs nas redes elétricas inteligentes brasileiras.

No Brasil, recentemente, a empresa AES Eletropaulo anunciou, que está investindo mais de $R \$ 70$ milhões em um projeto de redes elétricas inteligentes [33]. A empresa é responsável pela concessão da distribuição de energia elétrica na região metropolitana de São Paulo. Este projeto contempla não somente o investimento na infraestrutura de medição, mas também engloba os softwares de sistemas de gerenciamento da distribuição e gerenciamento das equipes e ocorrências.

O êxito da implantação de redes elétricas inteligentes depende muito da infraestrutura de comunicação para o seu pleno desenvolvimento. Por isso, este é o assunto a ser discutido na sequência. 


\subsection{INTERFACES DE COMUNICAÇÃO EM REDES ELÉTRICAS INTELIGENTES}

Os sistemas elétricos, sejam na distribuição ou na transmissão, na sua ampla maioria, possuem uma infraestrutura complexa e sistemas de automação que refletem necessidades individuais de alguns setores ou negócios. Por este motivo, a implantação de redes de comunicação para atender aos propósitos das redes elétricas inteligentes, certamente será composta por diversos protocolos e interfaces, criando um sistema que incorpora uma vasta diversidade de padrões e normas.

Cada tecnologia de comunicação possui seus prós e contras, e é certo que nenhuma solução será capaz de atender de forma ótima a todos os tipos de ambientes presentes no sistema elétrico. Por exemplo, soluções de comunicação que funcionam bem em ambientes de baixa densidade demográfica não funcionarão a contento em grandes centros urbanos.

A implantação de um sistema comunicação entre os usuários e as centrais de concessionárias de energia com intuito de uso em redes elétricas inteligentes apresenta alguns desafios. Conforme destacado no parágrafo anterior, o primeiro deles é a necessidade desta rede em atender uma vasta área, especialmente na cobertura de clientes residenciais. Um segundo desafio de implantação é balancear o desempenho e o benefício almejado em função do custo. Perder a comunicação com uma pequena porcentagem dos equipamentos de automação da distribuição, ou do sistema de 
leitura automática de medidores por um curto período de tempo não representaria uma ameaça real para a segurança e confiabilidade da operação de todo o sistema, dependendo da aplicação [34]. Seguindo esta lógica, a comunicação com um determinado cliente ou residência não requer a mesma capacidade de transferência e desempenho necessária para o tronco de comunicações (backbone). Assim, dependendo da aplicação, podem ser tolerados dispositivos de baixa taxa de transferência de dados, ou que sofram de um baixo nível de qualidade de sinal, requerendo múltiplas retransmissões para completar a transferência de uma determinada informação. Por outro lado, uma melhor qualidade na comunicação permite implementar programas que demandam maior tráfego tais como precificação dinâmica [34]. Em virtude destas questões levantadas, é preciso fazer a ponderação entre confiabilidade, velocidade de transferência de dados e custos necessários para atender uma determinada aplicação.

A relaxação nas necessidades de desempenho e confiabilidade faz com que se abra um leque de possibilidades no uso de tecnologias de transmissão de dados que podem ser empregadas nas redes WANs (Wide Area Networks). Tecnologias tais como IEEE 802.11s [35] e redes sem fio mesh [36], capazes de armazenar e retransmitir pacotes, são opções viáveis neste caso. Existem vários artigos que avaliam o desempenho destes sistemas. Em [37] é descrita uma metodologia para avaliação do uso destas tecnologias para redes elétricas inteligentes, e como exemplo, o uso da IEEE 802.11s é avaliado para a coleta de dados em uma AMI. A comunicação, neste exemplo, ocorre entre os medidores inteligentes e os concentradores de dados. Para avaliar a quantidade de medidores que pode ser agregada a cada concentrador, os autores trabalham com uma 
probabilidade de falha de um por cento e uma densidade de dois mil medidores inteligentes por quilômetro quadrado. Nestas condições, concluem que uma taxa de dados de um megabit por segundo é mais do que suficiente para a transmissão dos dados gerados na leitura automatizada dos medidores. No entanto, se programas de precificação dinâmica forem implantados, o intervalo entre as coletas de dados se torna menor o que resultaria neste caso, na necessidade de uma taxa de transmissão de dados maior.

Atualmente, mais de 10 milhões de pontos de medição são gerenciados utilizando a tecnologia de transmissão de dados sem fio tipo mesh, de acordo com [38]. Neste artigo, é afirmado que a referida tecnologia é adequada para aplicações de redes elétricas inteligentes devido à habilidade de formar enlaces ad-hoc com nós vizinhos, aumentando o alcance da comunicação através do salto de informações nó a nó até o destino. Esta característica permite contornar problemas de variação nas condições de propagação, fazendo com que o sistema detecte automaticamente rotas alternativas para trafegar as informações. A simulação proposta pelo autor utiliza medidores, concentradores e roteadores em sua topologia de rede. Os medidores, que estão interligados em rede mesh, geram os dados de simulação que são conduzidos até os roteadores. Estes roteadores estão ligados aos concentradores ou a outros roteadores através de enlaces sem fio com capacidade de vazão de dados duas vezes maior do que a dos medidores. Os concentradores, por sua vez, possuem conexão direta com a central de coleta de dados da concessionária através de uma conexão de banda larga cabeada. No intuito de avaliar o desempenho do sistema, foram criados dois cenários de simulação, um de pequena escala, com 350 medidores, e outro cenário de larga escala, 
utilizando 17181 medidores. Como resultado das simulações, para ambos os cenários, foi obtido um índice de 99,99\% de taxa de sucesso no recebimento diário de dados de medição, considerando uma frequência de envio de uma mensagem a cada quatro horas, índice que, segundo o autor, é suficiente para coleta de dados de medição e possibilita a definição dos perfis de consumo.

Outros autores também avaliaram o uso de tecnologias mesh para aplicações de redes elétricas inteligentes. Em [39], os autores avaliam o uso de diferentes sistemas de transmissão de dados sem fio, que coexistem na mesma faixa de frequências de operação, no caso a Wi-Fi (IEEE 802.11b) [35] e a ZigBee (IEEE 802.15.4) [40]. Foi encontrada a distância e offset de frequência seguros para evitar interferências severas entre ambos, sendo que os resultados foram obtidos através de simulações e testes empíricos. Este resultado tem uma grande contribuição para redes elétricas inteligentes no que tange aos sistemas residenciais (CS).

Em geral, o emprego de sistemas de transmissão de dados sem fio mesh é uma das opções que tem sido utilizadas em aplicações de redes elétricas inteligentes, principalmente para infraestrutura de medição. Estes sistemas são utilizados em concessionárias de energia [33] como forma de obter a leitura de medidores de energia. Inclusive, tem-se como perspectiva a utilização desses dados para implementar programas de resposta pelo lado da demanda [41]. Entretanto, para tal finalidade, é necessário que haja uma forma de comunicação bidirecional.

A iniciativa a ser utilizada pela AES Eletropaulo [33], citada no item 2.3, será composta por um misto de tecnologias. Neste caso, para a fatia dos medidores, será utilizada a tecnologia de transmissão de 
dados sem fio mesh, e para a comunicação com os equipamentos presentes na rede de distribuição, tais como relés de religadores automáticos, será utilizada uma rede WiMAX [42]. Segundo cronograma da empresa, a rede WiMAX será implementada até o final de 2013, e o sistema de controle da operação será integrado com o centro de medição.

Uma outra tecnologia, bastante utilizada na Europa, é a banda larga via rede elétrica (BPL - Broadband over Power Line) [43]. Em [44] é feita uma análise de uma AMI implantada na Alemanha, utilizada para precificação dinâmica, com cerca de 120 mil medidores, 10 mil repetidores e 550 concentradores. Ao final da análise, conclui-se que lançando mão desta interface de comunicação e também de protocolos de transporte, padrões de encriptação e sincronismo de tempo, é possível estabelecer uma infraestrutura de comunicação para atender aos desafios de implantação da AMI em redes elétricas inteligentes.

No entanto, de acordo com [38], os sistemas smart grid europeus já implementados têm êxito ao utilizar a tecnologia BPL devido ao fato daquelas redes de distribuição serem em sua maioria subterrâneas. Nestes tipos de redes, um único transformador de distribuição atende à centenas de residências. Na América do Norte, por outro lado, as redes de distribuição são predominante aéreas, e, portanto, a solução BPL não atende ao mercado local, uma vez que os transformadores de distribuição atendem a um conjunto menor de consumidores, tornando a adoção desta tecnologia economicamente inviável. No Brasil, uma vez que o sistema de distribuição se assemelha muito mais com o padrão norte americano do que com o padrão europeu, dificilmente a BPL será a opção ideal a ser adotada. 
Outras opções de comunicação viáveis para a referida aplicação seriam DSL (Digital Subscriber Line) [45], cabo de empresas de TV [46], LTE [47] e telefonia celular GSM [48], caso possam ser negociadas em larga escala com os respectivos provedores de serviços, tornando o custo, nestes casos, atrativo.

Certamente, o uso massivo de medidores inteligentes, dispositivos e sensores espalhados ao longo da rede de distribuição é o aspecto mais desafiador para as interfaces de comunicações, pois exige a criação de uma infraestrutura de comunicação de dados que até então não havia sido implantada. Já para aplicações que residem dentro das subestações de energia elétrica por exemplo, o cenário não é tão desafiador no que tange às interfaces de comunicações. Isso se deve ao fato de que, atualmente, a maioria das subestações de energia elétrica já possui algum tipo de estrutura de comunicação com o centro de controle do sistema (COS) [49] que atende satisfatoriamente às suas necessidades, sendo que, na maioria das vezes, são utilizados cabos de fibra óptica (e.g. $\mathrm{SDH}^{7}, \mathrm{SONET}^{8}$, Ethernet over fiber [40]) ou enlaces de rádio ponto a ponto, preferencialmente, em banda licenciada. Neste caso, o desafio do ponto de vista das redes inteligentes reside na modernização dos dispositivos utilizados para proteção e controle e em como usar a estrutura de comunicação pré-existente para acomodar novas tecnologias.

\footnotetext{
${ }^{7}$ SDH - Synchronous Digital Hierarchy é um padrão de multiplexação baseado em divisão do tempo (TDM - Time Division Multiplexing) usado para transmissão de dados. Este padrão é definido pela International Telecommunication Union (ITU).

${ }^{8}$ SONET - Synchronous Optical Networking é um padrão semelhante ao SDH, porém, definido pela American National Standards Institute (ANSI).
} 


\subsection{PROTOCOLOS E NORMAS DE COMUNICAÇÃO}

Além das interfaces, os protocolos e normas de comunicação a serem adotados também são assunto de muita discussão.

Para a AMI, um dos principais entraves na criação da estratégia de implantação deste sistema por parte das empresas ligadas a este setor é a existência de uma grande quantidade de padrões distintos. No entanto, alguns tem sido destacados por entidades internacionais, como é o caso da IEC 62056, que foi identificada pela International Electrotechnical Comission (IEC) como uma das sete normas mais relevantes para aplicação em redes elétricas inteligentes, no que tange a troca de dados para leitura, tarifação e controle de cargas em medidores de energia elétrica. Similar em aplicação a IEC 62056 [50] é a ANSI C12.18 [51]. Estes padrões utilizam interfaces ópticas ou seriais a dois fios baseados em comunicação half-duplex EIA RS-232 [52]. Além destas duas normas, existe também a IEC 61850 [13], que teve foco inicial na automação de subestações e, atualmente, está sendo expandida para aplicações fora deste escopo. Existem vários artigos que tratam os protocolos mais utilizados para esta finalidade. Em [53], é feita uma análise do estado da arte em normas de comunicação para aplicações de Smart Metering, e conclui o artigo dizendo que muitas tecnologias estão disponíveis no mercado, mas que a maioria delas falha nos quesitos aceitação, flexibilidade, ou que estão em estágio inicial ou, ainda, que são controladas por um vendedor específico. Já em [54], o autor faz um comparativo entre os protocolos DLMS/COSEM e SML, que estão definidos na IEC 62056 e a norma 
IEC 61850 para aplicações de Smart Metering. Ao final do texto, o mesmo conclui que nenhuma das opções analisadas é superior em todos os aspectos.

Segundo levantamento da IEC [55], além das normas, IEC 62056 e IEC 61850, existem ainda outras cinco de grande importância para a implantação das redes elétricas inteligentes. Dentre elas está a IEC/TR 62357 - Service Oriented Architecture (SOA) [56]. Esta norma descreve o conceito SOA e cria uma arquitetura de software que facilita a integração de sistemas independentes (aplicações), através de um protocolo de comunicação comum.

Também inclusa no levantamento da IEC está a IEC 61970 Common Information Model (CIM) / Energy Management [57] que introduz um modelo semântico para descrever os componentes do sistema de potência no nível elétrico e as relações entre cada componente. Nela é definido o modelo CIM que possui duas funções: facilitar a troca de dados em redes de sistemas elétricos entre companhias distintas e permitir a troca de dados entre aplicações dentro de uma mesma companhia.

Outra norma citada é a IEC 61968 - Common Information Model (CIM) / Distribution Management [58], que estende o modelo da IEC 61970 para cobrir outros aspectos de troca de dados de softwares para sistemas de potência, tais como rastreamento de ativos, agenda de trabalhos e tarifação de consumidores.

Como não poderia faltar, a IEC 62351 - Security [59] que trata da segurança da informação para as operações de controle do sistema de potência, e, finalmente, a IEC 61508 - Functional safety of electrical/electronic/programmable electronic safety-related systems (E/E/PE) [60], que traz uma abordagem funcional para todas as 
atividades ligadas ao ciclo de vida de sistemas compostos por elementos E/E/PE que são utilizados para realizar alguma tarefa ligada à segurança.

Em conjunto, as sete normas recebem a classificação core, que indica o maior grau de importância para aplicação em smart grids.

Para comunicação em sistemas de automação de subestações, há um grande número de protocolos disponíveis. Dentre eles, pode-se ressaltar o DNP3 [11]. Este protocolo foi desenvolvido pela Westronic baseado nas primeiras versões do IEC 60870-5. Atualmente a especificação do protocolo é controlada pelo DNP Users Group [61] e sua implementação foi padronizada pelo IEEE Std $1815^{\mathrm{TM}}-2012$ [11]. Este protocolo é baseado em um modelo simplificado do modelo OSI (Open Systems Interconnection) [62]. Este modelo simplificado especifica a camada de enlace de dados, a camada de aplicação e uma pseudo-camada de transporte. Para suportar funções avançadas de unidades terminais remotas (RTUs Remote Terminal Units) e também suportar mensagens maiores que o comprimento máximo de frame, assim como definido pelo documento IEC 60870-5-1, o enlace de dados do DNP3 é destinado a ser usado com a pseudo-camada de transporte mencionada. Ainda que o padrão DNP3 não especifique a camada física, ele especifica como operar em um ambiente de rede e também sugere como evitar colisões entre dispositivos transmitindo simultaneamente. Muitas implementações utilizam comunicação serial baseada em RS-232, RS-485 [63], ou mesmo fibra óptica. No entanto, o DNP3 também pode ser usado com os protocolos TCP/IP [64] e UDP/IP [65], no qual, por exemplo, a Ethernet [40] pode ser utilizada. Neste caso, é dito que o DNP3 é encapsulado sobre TCP/IP ou UDP/IP. O DNP3 tem como objetivo transmitir pacotes relativamente pequenos e de 
forma confiável. Suporta os modos de comunicação mestre/escravo, ponto a ponto, múltiplos mestres, múltiplos escravos ou modo hierárquico. Também fornece suporte a polling ${ }^{9}$ e reporte automático. Uma vez que o protocolo é baseado em nós com baixos requisitos e em canais de comunicação de pouca vazão, o DNP3 não é totalmente capaz de permitir o desenvolvimento de todas as possibilidades das redes inteligentes baseadas em canais de comunicação de alta vazão [66].

Outra norma para comunicação em subestações de grande destaque é a IEC 60870-5, que tem sido, e ainda é, bastante utilizada. Esta norma foi introduzida no início dos anos 1990 e é tida como precursora da IEC 61850. É construída de acordo com um modelo de três camadas, baseado no modelo OSI, contendo: camada física, camada de enlace e camada de aplicação.

A norma IEC 60870-5-103 é uma das normas associadas à IEC 60870-5, e possui sua camada de aplicação designada para comunicação com dispositivos de proteção. A norma somente define, como padrão a comunicação serial para enlaces desbalanceados. A velocidade de comunicação pode ser de 9600 ou 19200 baud. O documento da IEC 60870-5 possui seis partes básicas, comuns também a IEC 60870-5-101 e a IEC 60870-5-104. Estas seis partes definem assuntos, tais como o formato do frame, os procedimentos de transmissão, a estrutura dos dados de aplicação, definição e codificação dos elementos de informação, funções de aplicação básicas e testes de conformidade.

Um dispositivo IEC 60870-5-103 pode ser interoperável e intercambiável, ou somente interoperável. Interoperabilidade

\footnotetext{
${ }^{9}$ Polling se refere à atividade de amostrar o status de um dispositivo de forma síncrona.
} 
significa que qualquer dado de aplicação requerido no dispositivo, o qual pode ser codificado por um tipo de dados IEC 60870-5-103, pode ser mapeado no espaço de endereços do protocolo. Assim, estes dados são reconhecidos por qualquer mestre IEC 60870-5-103 [67]. Em outras palavras, a norma estabelece uma lista de interoperabilidade que deve ser seguida para cada dispositivo.

Intercambiabilidade significa suportar os dados de aplicação (elementos informativos), cujas semânticas estão pré-definidas pela norma. Contudo, somente um conjunto muito limitado de dados de aplicação está definido pela norma. É interessante também ressaltar que estes conjuntos de dados estão definidos essencialmente por um IED (Intelligent Electronic Device) com uma única aplicação de proteção. Atualmente, os IEDs dedicados à proteção são dispositivos multifuncionais e, grande parte tem sido desenvolvida com um modelo de dados internos baseado na norma IEC 61850. De acordo com a IEC 60870-5-103, são definidos dois métodos diferentes para troca de informações. O primeiro método é baseado nas ASDUs (Application Service Data Units) e nos procedimentos de aplicação utilizados para transmissão de mensagens padrão. O outro método é baseado em serviços genéricos para transmissão de todos os tipos de mensagens. Apesar de bem estruturado, o padrão possui várias limitações. Um delas é a limitação de 255 tipos de dados, sendo que somente 31 destes estão padronizados. Quando os fabricantes definem seus próprios tipos de dados, a interoperabilidade e compatibilidade entre dispositivos de diferentes fabricantes fica comprometida.

Já a norma IEC 61850 é o mais recente padrão internacional para sistemas de automação de subestações. Atualmente, é o primeiro e único padrão a cobrir todas as necessidades de comunicação em 
subestações, e também foi feito para ser uma solução resistente ao tempo para os problemas de automação de subestações. O principal objetivo da norma é prover a interoperabilidade entre os dispositivos de uma subestação. Além do uso em sistemas de automação de subestações e em AMI, a mesma tem sido indicada para monitoramento e controle de sistemas de DERs. Nos artigos [68] e [69], os autores destacam o modelo de dados bem definido e a capacidade de criar plantas de geração virtuais (Virtual Power Plants - VPP) para facilitar a integração de pequenos geradores no sistema elétrico e no mercado de energia elétrica.

Dado o potencial da norma IEC 61850 em diversas aplicações, ela já está substituindo os outros padrões em alguns casos. Por exemplo, em pesquisa realizada em 2011 [49], mais de cem concessionárias de energia elétrica provenientes de mais de vinte e seis países foram questionadas com relação a quais protocolos de comunicação estavam sendo utilizados em suas subestações. Com o resultado da pesquisa $^{10}$, apontou-se que o protocolo IEC 60870-5-103 é o mais utilizado para comunicação dentro das subestações, presente em $40 \%$ das empresas, enquanto que o protocolo DNP3 é uma das opções em 33\% das empresas. Já a norma IEC 61850 foi apontada como sendo empregada em $31 \%$ das empresas. No entanto, $24 \%$ das empresas indicaram que possuem planos para implantar a IEC 61850 até o final de 2013. Se concretizados, estes planos farão com que a referida norma venha a ser a opção mais utilizada para comunicação dentro de subestações em todo o mundo. A pesquisa também apontou que para comunicação de subestações com serviços externos, tais como centros de controle, a norma IEC

\footnotetext{
10 Nesta pesquisa algumas concessionárias disseram que fazem uso de mais de um protocolo de comunicação. Logo, é importante ressaltar que por este motivo a soma dos percentuais extrapola $100 \%$.
} 
60870-5-101 é de longe a mais difundida, citada por $45 \%$ das empresas e, em segundo lugar, a norma IEC 60870-5-104, presente em 29\% delas. Assim como para as aplicações internas às subestações, há também uma tendência de substituir parte dos sistemas atuais por sistemas que utilizam a IEC 61850, algo que foi previsto a ser feito até o final de 2013 por cerca de $12 \%$ das concessionárias. Por tais motivos, uma visão mais detalhada sobre a IEC 61850, descrevendo a norma e suas características, será feita no capítulo 3. 


\section{VISÃO GERAL DA IEC 61850}

Este capítulo objetiva dar uma visão geral e caracterizar os conceitos essenciais de comunicação de dados definidos pela norma IEC 61850.

A norma IEC 61850 foi desenvolvida pelo comitê TC57 da IEC em 2003 [70] e, atualmente, está em sua segunda edição, tendo sido esta publicada em 2008 [13]. O objetivo principal da norma foi estabelecer a interoperabilidade, cuja vantagem está no próprio nome, entre dispositivos eletrônicos inteligentes de diversos fabricantes, com foco na comunicação em redes e sistemas de subestações [71]. A interoperabilidade permite a simplificação da configuração dos dispositivos do sistema de automação de subestações (SAS - Substation Automation Systems), o aumento da confiabilidade, a redução de custos e uma maior segurança.

Para alcançar tal interoperabilidade, a IEC 61850 define um padrão para o desenvolvimento de dispositivos e como se dá a comunicação entre eles em uma rede. Tal descrição é feita na forma orientada a objetos. Estes objetos são fundamentados em um modelo de comunicação independente da plataforma de hardware chamado de ACSI (Abstract Communication Service Interface). Esta característica faz com que a norma se torne resistente às alterações de protocolos de comunicação, e permite o uso da mesma em qualquer meio de transmissão que atenda aos requisitos de desempenho. Na edição atual, o uso do padrão Ethernet IEEE 802.3 
é sugerido, mas, no entanto, a norma deixa abertura às futuras tecnologias de comunicação.

Todo o sistema de automação de subestações e cada dispositivo de rede na IEC 61850 é descrito através da linguagem de configuração de subestações (SCL - Substation Configuration Language) com base na XML (eXtensible Markup Language) [72].

A norma está divida em dez partes conforme apresentado a seguir.

- IEC61850-1: Introdução e visão geral

- Introdução e visão geral da norma

- IEC61850-2: Glossário

- Coleção de termos

- IEC61850-3: Requisitos gerais

- Requisitos de qualidade (confiabilidade, manutenção, disponibilidade, etc)

- Condições ambientais

- Serviços auxiliares

- Outros padrões e especificações

- IEC61850-4: Gerenciamento do projeto

- Requisitos de engenharia (parâmetros, ferramentas, documentação)

- Ciclo de vida (versões de produtos, descontinuações, suporte)

- Garantia de qualidade (responsabilidades, equipamentos de testes, testes de aceitação em fábrica e em campo)

- IEC61850-5: Requisitos de comunicação

- Requisitos básicos

- Nós lógicos 
- Canais de comunicação lógicos

- Conceito PICOM (Piece of Information for Communication)

- Desempenho e funções

- Cenários dinâmicos

- IEC61850-6: Linguagem de configuração de subestação $(\mathrm{SCL})$

- Visão geral do processo de engenharia

- Definição do sistema e configuração do formato do arquivo de troca de parâmetros baseado em XML

- Descrição esquemática (unifilar)

- Descrição da conexão de comunicação

- Capacidades dos IEDs

- Alocação dos nós lógicos dos IEDs ao sistema primário

- IEC61850-7-1: Estrutura de comunicação básica - princípios e modelos

- Introdução a IEC61850-7-x

- Modelos e princípios de comunicação

- IEC61850-7-2: Interface de Serviço de Comunicação Abstrata (ACSI)

- Descrição da ACSI

- Especificação dos serviços de comunicação abstrata

- Modelo da estrutura de base de dados de dispositivo

- IEC61850-7-3: Classe de dados comuns

- Classe de dados comuns e atributos relacionados

- IEC61850-7-4: Classe de nós lógicos

- Definições das classes de nós lógicos e classes de dados

- IEC61850-7-410: Plantas de energia hidroelétrica 
- Comunicação para monitoramento e controle destas plantas

- IEC61850-8-1: Mapeamento de serviço de comunicação específico - Mapeamento para MMS e ISO/IEC 8802-3

- Mapeamento de serviços comumente usados para comunicação na subestação

- IEC61850-9-1: Mapeamento de serviço de comunicação específico - valores amostrados sobre interfaces ponto a ponto

- Mapeamento de serviços para transmissão de valores analógicos amostrados, principalmente para corrente e tensão, para interfaces ponto a ponto

- IEC61850-9-2: Mapeamento de serviço de comunicação específico - Valores amostrados sobre ISO/IEC 8802-3

- Mapeamento de serviços para transmissão de valores analógicos amostrados sobre ISO/IEC 8802-3

- IEC61850-10: Testes de conformidade

- Procedimentos de testes de conformidade

- Garantia de qualidade e testes

- Documentação exigida

- Certificação, requisitos e validação do equipamento de teste

Neste trabalho, o foco no estudo da norma IEC 61850 dar-se-á nas partes 5, 7-2, 7-3, 7-4, 8-1 e 10. A razão disto decorre do fato de que a simulação proposta no Capítulo 4 fará uso da parte 5 , no que diz respeito ao desempenho da comunicação, e da parte 8-1, no que diz respeito ao funcionamento e formato de mensagem utilizada. Já as partes, 7-2, 7-3, 7-4 e 10 são importantes para o entendimento dos 
conceitos, definições e estrutura da norma para o contexto deste trabalho.

\subsection{MODELAGEM DE DADOS}

A IEC 61850 modela através de nós lógicos (LN - Logical Nodes) as funcionalidades desempenhadas por dispositivos reais presentes em sistemas de automação de subestações. A Figura 3.1 ilustra este conceito.

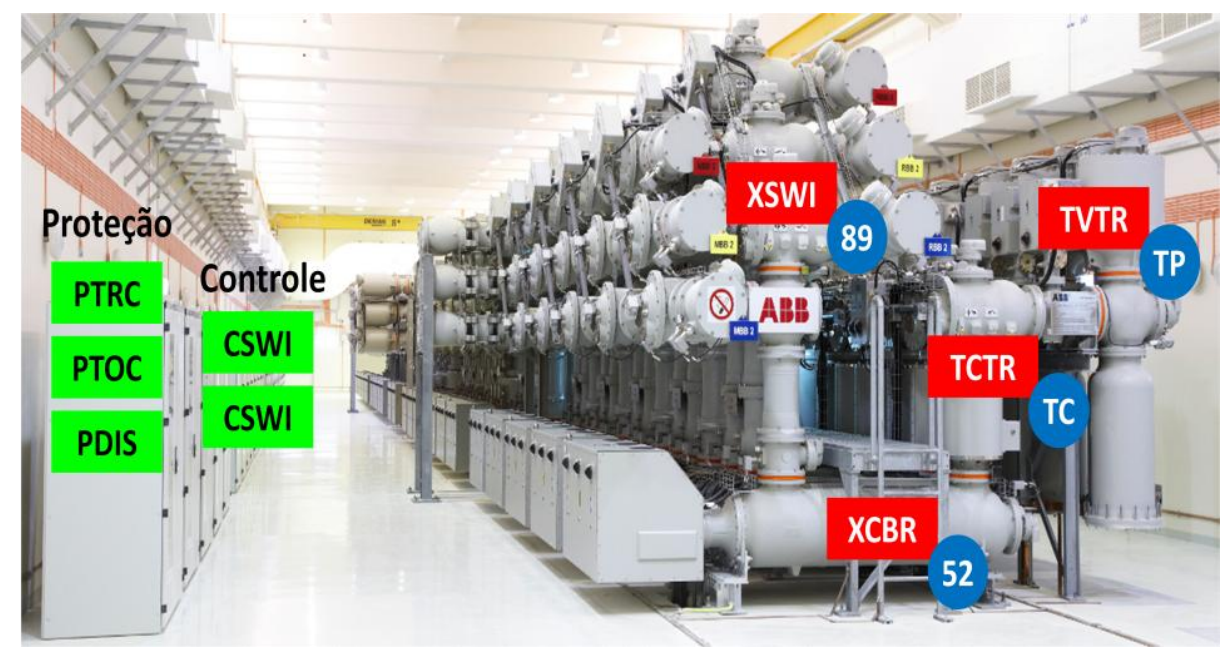

Figura 3.1 - Modelagem de dispositivos segundo a IEC 61850. Fonte [73].

No exemplo da Figura 3.1, os dispositivos tais como disjuntor (XCBR), seccionadora (XSWI), transformador de corrente (TCTR) e 
transformador de potencial (TVTR) são modelados como nós lógicos juntamente com a parte relacionada à proteção (Master Trip PTRC, Sobrecorrente - PTOC, Distância - PDIS) e controle (Chave - CSWI). A Tabela I apresentará os tipos de nós lógicos definidos pela norma. Estes nós lógicos podem estar localizados em um ou mais dispositivos físicos (LD - Logical Devices). Cada LN contém uma lista de dados e seus respectivos atributos, como para o caso do LN do disjuntor (XCBR), em que existe uma classe de dados (DO - Data Object) que é usada para indicar a posição do dispositivo, que pode assumir os atributos aberto/fechado (DA - Data Attributes) usando, por exemplo, valores booleanos. Esta estruturação dos modelos de dados está resumida nas Figuras 3.2 e 3.3 .

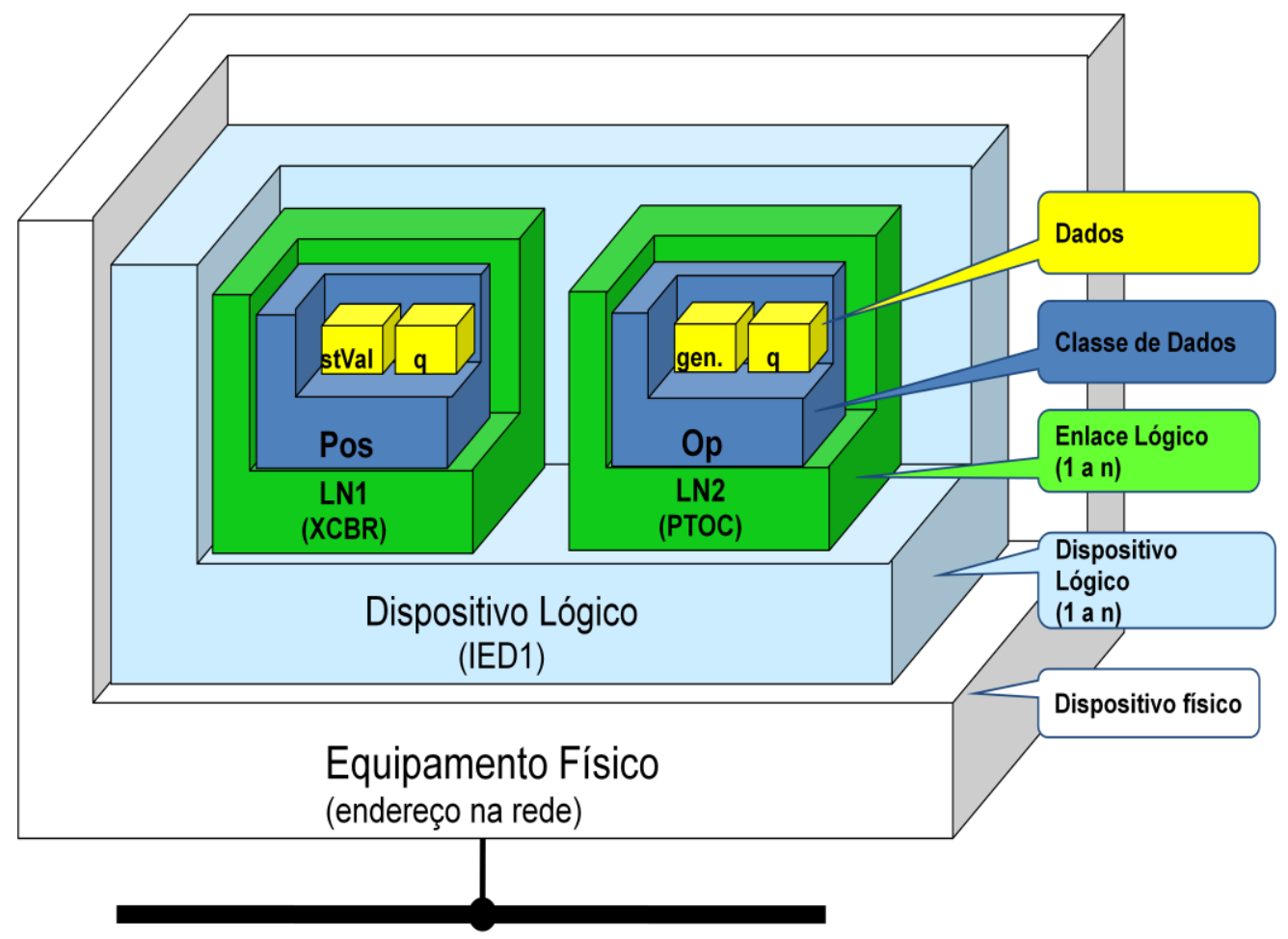

Figura 3.2 - Modelo de dados da IEC 61850. Fonte [13]. 


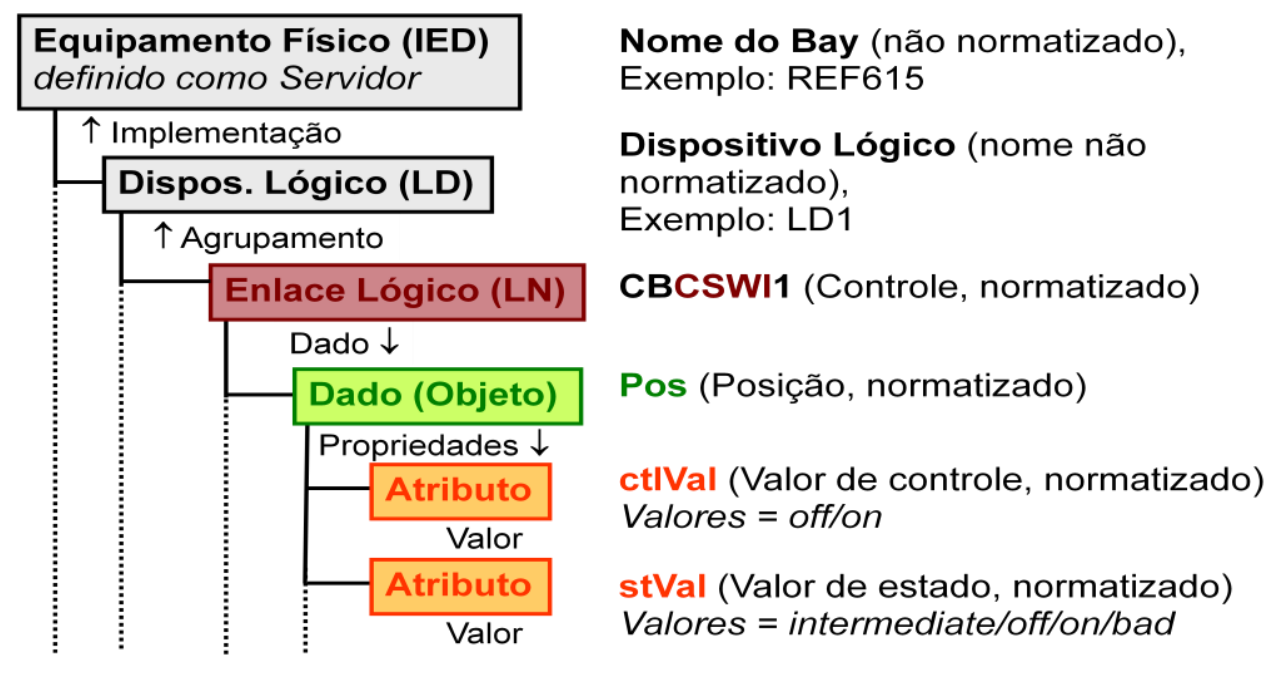

Figura 3.3 - Exemplo de modelo de dados da IEC 61850. Fonte [73].

$\mathrm{Na}$ parte 5 da norma, são definidos os nós lógicos com suas respectivas funções dentro de uma subestação e numeração IEEE C37.2-1996 [74], quando aplicável. Estes nós são agrupados em categorias segundo a letra inicial que Ihes foi atribuída de acordo com a Tabela I, onde o número entre parênteses indica a quantidade de LNs para cada categoria mencionada.

Tabela I - Nós lógicos (LN).

L Sistema de nós lógicos (2) M Medição (8)

P Proteção (28) S Sensor e monitoramento (4)

R Relacionados a proteção (10) X Manobra (2)

C Controle (5) T T Transformadores de instrumento (2)

G Genérico (3) Y Y Y Transformadores de potência (4)

I Interface e arquivamento (4) Z Equipamento de potência adicional (15)

A Controle automático (4)

Alguns LNs são obrigatórios em cada dispositivo físico, como é o caso do LLNO (LN principal), que possui funções de gerenciamento 
comum a todos os LNs contidos em um mesmo LD, e do LPHD (LN do dispositivo físico), que é utilizado para modelar o dispositivo físico. Estes nós possuem informações comuns do dispositivo em si, como, por exemplo, identificação do dispositivo (LLNO.NamPIt), status do IED (LPHD.PhyHealth) e estado local/remoto (LLN0.Loc).

\subsection{CLASSE DE DADOS}

Para cada DO é atribuída uma classe de dados comum (CDC Commom Data Class) definida na norma. Esta definição determina como os atributos devem ser tratados. Por exemplo, para a posição de um disjuntor, o valor pode ser um SPS (Single Point Status) que pode assumir dois valores, em que um deles serve para indicação de aberto e o outro, para posição de fechado. Uma outra forma de indicação seria o uso de um DPS (Double Point Status). Neste caso, a posição do disjuntor poderia ser indicada por 4 estados diferente: aberta, fechada, intermediária e falha. As classes de dados definidas pela norma são:

- $\mathrm{SPS}=$ Single point status (somente leitura 1-bit)

- INS = Integer status (valor inteiro, somente leitura)

- $\mathrm{SPC}=$ Controllable single point with status (leitura/gravação 1-bit)

- $\quad \mathrm{INC}=$ Controllable Integer with status (leitura/gravação)

- DPS = Double point status (somente leitura 2-bits)

- $\mathrm{DPC}=$ Controllable Double point status (leitura/gravação 2bits) 
- $\mathrm{ACD}=$ Directional protection activation information $\left(S T A R T^{11}\right)$

- $\mathrm{ACT}=$ Protection activation information $\left(T R I P^{12}\right)$

- $\mathrm{MV}=$ Measurement value (amplitude)

- $\mathrm{CMV}=$ Complex measurement value (amplitude e ângulo)

- $\mathrm{WYE}=$ Phase-To-Ground measurement (6 $\mathrm{x}$ objetos CMV)

- $\mathrm{DEL}=$ Phase-To-Phase measurement $(3 \times$ objetos CMV)

A Figura 3.4 apresenta um exemplo de consulta de dados para os LNs de medição de corrente trifásica (IMMXU200) e controle de chaves com os respectivos DOs e sua classificação CDC.

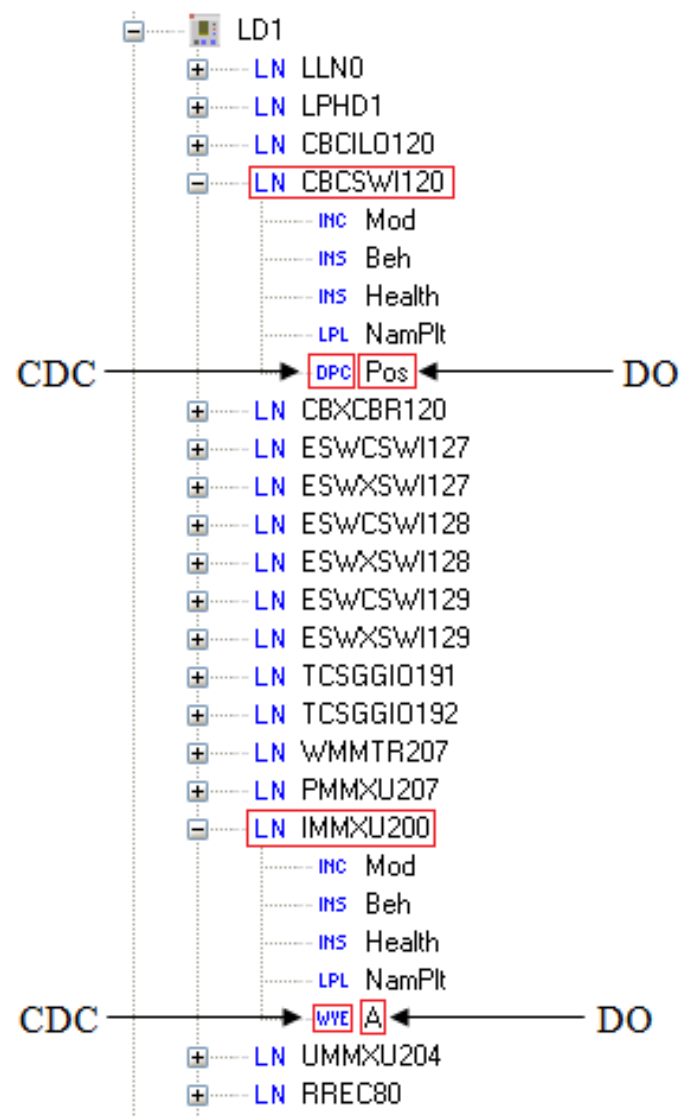

Figura 3.4 - Consulta dos dados referentes aos LNs CBCSWI120 e IMMXU200. Fonte [73].

\footnotetext{
${ }^{11}$ Partida de uma função de proteção temporizada, ou seja, é o início de contagem de tempo até o disparo.

${ }^{12}$ Sinal que indica o disparo de uma função de proteção indicando que determinado circuito deve ser aberto a fim de interromper uma falha.
} 
Destacado na Figura 3.4, o DO A, pertencente ao LN IMMXU200, possui classificação CDC WYE e é utilizado para informar os valores das correntes de fase trifásicas, incluindo amplitude e ângulo. Ainda na mesma figura, o outro DO destacado é o Pos, pertencente ao LN CBCSWI120, utilizado para indicação da posição de chaves. Este DO possui CDC do tipo DPC, e pode assumir os valores binários de dois dígitos 10 (fechado), 01 (aberto), 00 (intermediário) e 11 (falha).

Os atributos relacionados aos objetos de dados, por sua vez, são classificados segundo suas restrições funcionais (FC - Functional Restraints), o que permite saber, por exemplo, se um determinado atributo indica apenas o status, ou ainda, se permite o controle de um certo dispositivo. Tome-se como exemplo prático o caso dos Atributos do DO Pos no LN CBCSWI120 (controle de chaves) que são agrupados com as seguintes restrições funcionais mostradas na Tabela II.

Tabela II - Restrições funcionais para o LN “CBCSWI120".

$\begin{array}{lll}\text { Atributo } & \text { FC } & \text { Descrição } \\ \text { Pos.stVal } & \text { ST } & \text { Estado (Aberto/Fechado) } \\ \text { Pos.Oper } & \text { CO } & \text { Controle (Abrir/Fechar) } \\ \text { Pos.ctIModel } & \text { CF } & \text { Configuração (Status/Comando Direto/...) } \\ \text { Pos.d } & \text { DC } & \text { Texto descritivo }\end{array}$

Segundo a norma, cada DO possui atributos que podem ser classificados em mandatórios ou opcionais. Ou seja, os atributos classificados como mandatórios pela norma estarão sempre presentes em um DO, independentemente da implementação. Por outro lado, os classificados como opcionais estarão à disposição 
somente em casos que o fabricante julgar necessário. No caso do DO, PTOC.Op (utilizado para indicar a operação da função de sobrecorrente), o atributo general (indica operação geral) é classificado como mandatório enquanto que o atributo phsA (indica operação na fase A) é considerado opcional.

Na parte 7-2 da norma, é definida a estrutura de comunicação e informações ACSI. Através dela, é definida a interface entre cliente e servidor utilizada para transferência de dados em tempo real, transferência de arquivos, pesquisa de tipos de dados, controle de grupo, relatório de eventos e controle remoto de dispositivos.

O modelo de comunicação ACSI determina as CDCs na parte 7-3 e os LNs na parte 7-4. Cada modelo possui requisitos diferentes sobre o método de transmissão, tempo de entrega e tamanho do dado. Deste modo, cada modelo está mapeado em diferentes protocolos de comunicação.

Antes de definir o método de transmissão e o protocolo a ser utilizado, a norma define, na parte 5, o conceito de PICOM (Piece of Information for Communication), o tempo de transferência e os tipos de mensagens com suas respectivas classes de desempenho.

O PICOM define a troca de dados entre $L N s$ de acordo com a função que desempenham. Dentre os dados contidos no PICOM estão:

- dados de informação, com sua respectiva identificação necessária para execução da função;

- conexão lógica entre o transmissor e receptor;

- estrutura de dados (i.e. se é valor analógico ou binário, se é um valor único ou um conjunto de dados); 
- tempo permitido de transmissão, integridade de dados e método ou causa da transmissão (e.g. periódico, devido a um evento particular, ou decorrente de uma requisição).

Alguns atributos que sempre devem estar presentes para qualquer tipo de mensagem são: valor, nome, transmissor, receptor, estampa de tempo, prioridade de transmissão e requisitos de tempo.

Após definirem todos os pedaços de comunicação (PICOM) para as diferentes funções, os desenvolvedores da norma concluíram que muitos deles eram similares, e, deste modo, poderiam ser classificados de acordo com suas aplicações, o que facilita a implementação e permite estabelecer requisitos de desempenho mensuráveis. Assim, os PICOMs foram condensados em vários tipos de mensagens, que serão listados no item 3.3. Um outro ponto observado foi que a norma não padronizava a forma como as funções são implementadas (i.e. algoritmo de proteção), mas sim como se dá a comunicação entre elas. Sendo assim, surgiu a definição de tempo de transferência total (overall transfer time). Para definir tal tempo, é necessário primeiramente falar sobre sincronização de tempo, pois dispositivos compatíveis com a IEC 61850 podem estar em qualquer lugar em um sistema elétrico (e.g. PMU) e não somente dentro de uma subestação. Desta maneira, é necessário que os relógios destes equipamentos estejam sincronizados, de modo a permitir a comparação temporal de uma determinada sequência de eventos. Para tanto, são utilizadas estampas de tempo, que devem ser baseadas em um padrão de tempo definido, que é geralmente o UTC (Coordinated Universal Time) [75], obtido a partir de dispositivos comerciais, tais como o GPS (Global Positioning System) [76] e segundo a norma esta informação deve ser obrigatoriamente trafegada na rede através do 
protocolo SNTP (Simple Network Time Protocol). Assim, a precisão é calculada como a diferença entre o tempo do dispositivo mestre, que utiliza o relógio do GPS como referência de tempo, e o tempo do dispositivo escravo, no caso, o IED, como mostra a Equação 3.1.

$$
\Delta t_{\text {precisão }}=\left|t_{\text {publicador }}-t_{\text {assinante }}\right|
$$

Para que se possa criar uma sequência dos eventos ocorridos em diferentes lugares do sistema de potência, é necessário que estes eventos possuam estampas de tempo precisas e sincronizadas em um mesmo relógio global. A Tabela III apresenta as diversas classes de sincronismo de tempo para as aplicações de um IED e o erro de precisão de sincronismo associado a elas, que é calculado como definido pela Equação 3.1.

Tabela III - Definição das classes de tempo de sincronização. Fonte [13].

\begin{tabular}{|c|c|l|}
\hline $\begin{array}{c}\text { Classe de } \\
\text { tempo de } \\
\text { sincronização }\end{array}$ & $\begin{array}{c}\text { Erro de precisão } \\
\text { de sincronismo } \\
{[\mu \mathrm{s}]}\end{array}$ & \multicolumn{1}{|c|}{ Aplicação } \\
\hline TL & $>10000$ & Baixa precisão de sincronização \\
\hline T0 & 10000 & Eventos com precisão de 10 ms \\
\hline T1 & 1000 & Eventos com precisão de 1 ms \\
\hline T2 & 100 & $\begin{array}{l}\text { Aplicações de sincronismo } \\
\text { distribuídas }\end{array}$ \\
\hline T3 & 25 & Miscelânea \\
\hline T4 & 4 & Registro de tempo de amostras \\
\hline T5 & 1 & Alta precisão no registro de amostras \\
\hline
\end{tabular}

Segundo a norma, é sugerido na parte 5 que as mensagens para sincronização de tempo entre os dispositivos devem utilizar a 
mesma infraestrutura de comunicação usada para troca de dados, de modo a facilitar o desenvolvimento do sistema de comunicação.

Em seguida, ainda na parte 5, a norma define que o tempo de transferência total é contabilizado a partir do momento em que o ente transmissor coloca uma mensagem no topo da sua pilha de transmissão, até o momento em que o receptor extrai os dados da mensagem da sua pilha de recepção. A Figura 3.5 apresenta esta definição e os tempos envolvidos no processo.

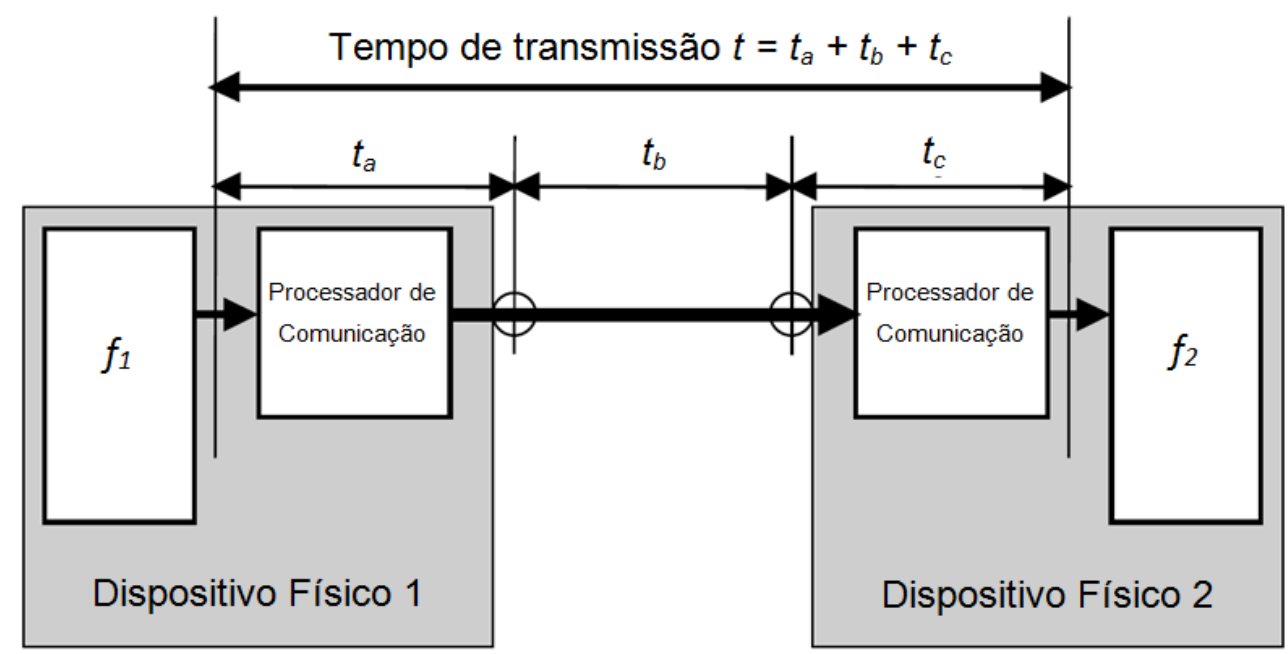

Figura 3.5 - Tempo total de transmissão.

Na Figura 3.5, o tempo de transmissão total $t$ consiste dos tempos de processamento da fila de mensagens $\left(t_{a}\right.$ e $\left.t_{c}\right)$ e do tempo de transferência na rede $\left(t_{b}\right)$. O tempo de transferência na rede inclui tempos de espera e atrasos causados por roteadores e outros equipamentos de comunicação presentes no caminho entre os dispositivos físicos. 
No processador de comunicação estão os processos de codificação e decodificação das mensagens. Ou seja, a conversão de um contato de posição de binário para digital (conversão B/D), ou considerando um valor analógico, a conversão deste em dado digital (conversão $A / D$ ). Se durante a transmissão ocorrem colisões ou perdas, e se for necessária a retransmissão dos sinais, então o tempo atribuído a este evento também é contabilizado no tempo total, acarretando em uma distribuição estatística do tempo de transferência. É importante ressaltar que para alguns tipos de mensagens não existe retransmissão devido a perdas no canal de transmissão. Neste caso, a norma cria um mecanismo para tornar a comunicação deste tipo de mensagem mais confiável. Este mecanismo de retransmissão e o tipo de mensagem a ele relacionado serão apresentados no capítulo 3.4 através da Figura 3.8.

Um fato que deve ser levado em conta é que o tempo de transferência na rede deve ser razoavelmente menor que o tempo de processamento de uma determinada função, e.g. teleproteção. Os sistemas de teleproteção anteriores à norma IEC 61850 utilizavam sistemas de comunicação PLC (Power Line Carrier) [77] onde a velocidade de propagação do sinal é de aproximadamente dois terços da velocidade da luz no vácuo. Assim, o tempo de propagação, considerando uma distância de 1000 km entre transmissor e receptor, seria de cerca de cinco milissegundos [78]. Devido a isto, a norma declara que os tempos de transferência são definidos de acordo com os requisitos das funções, e estes devem ser respeitados em qualquer caso. 


\subsection{TIPOS DE MENSAGENS E DEFINIÇÃO DE CLASSES}

Os requisitos de desempenho são definidos de acordo com o tipo de mensagem e são válidos independentemente do tamanho do sistema. No entanto, o tamanho do sistema pode impactar na forma como os requisitos são satisfeitos, sendo necessário dar prioridade a algumas mensagens em detrimento das outras. Assim, em condições de avalanche de mensagens, o tempo de transferência de algumas delas pode aumentar.

Em uma subestação, nem todos os enlaces de comunicação devem suportar os mesmos requisitos de desempenho. Como referência, a norma estabelece o requisito de tempo de transferência total para as mensagens de maior prioridade em analogia ao menor tempo de atuação dos contatos de disparo (trip) de relés eletromecânicos (5 $\mathrm{ms})$.

Uma vez que o tempo de processamento da comunicação e o tempo de transferência das mensagens no meio físico ( $t_{a}$ e $t_{b}$ na Figura 3.5) é o mesmo, independentemente do tipo de mensagem, é necessário criar pilhas e filas diferentes com prioridades distintas para atender aos requisitos de todas as aplicações. As características para implementação destes esquemas é descrita nas parte 8 e 9 da norma.

O tempo de transferência das mensagens deve ser pequeno, de forma que não influencie no tempo de operação das funções. O tempo de operação das funções, por sua vez, depende de diversos 
fatores como: o nível de tensão, o papel da subestação (distribuição ou transmissão), a implementação do algoritmo, etc. Se for considerada a herança dos sistemas antigos, em que as informações trafegavam em cabos de cobre, o tempo de transmissão de uma mensagem é o mesmo para os níveis de tensão de distribuição e transmissão, e, portanto, o atraso aceitável dos sinais depende da função a ser utilizada e não, especificamente, do nível de tensão. A Tabela IV define as classes de tempo para uso em funções de proteção e controle.

Tabela IV - Definição das classes de tempo de transferência. Fonte [13].

\begin{tabular}{|c|c|l|}
\hline $\begin{array}{c}\text { Classe de } \\
\text { tempo de } \\
\text { transferência }\end{array}$ & $\begin{array}{c}\text { Tempo de } \\
\text { transferência } \\
{[\mathrm{ms}]}\end{array}$ & \multicolumn{1}{|c|}{$\begin{array}{c}\text { Exemplos de aplicação: } \\
\text { Transferência de }\end{array}$} \\
\hline TT0 & $>1000$ & Arquivos, eventos, logs \\
\hline TT1 & 1000 & Eventos, alarmes \\
\hline TT2 & 500 & Comandos de operadores \\
\hline TT3 & 100 & Interações automáticas lentas \\
\hline TT4 & 20 & Interações automáticas rápidas \\
\hline TT5 & 10 & Liberações, alterações de estado \\
\hline TT6 & 3 & Disparos (trip), bloqueios \\
\hline
\end{tabular}

Além das classes para o tempo de transferência das mensagens, a norma ainda define os requisitos para o tempo de recuperação (recovery time) tanto do aspecto da comunicação quanto para a recuperação das funcionalidades de uma determinada aplicação. Em nenhum dos casos são tolerados tempos superiores a $800 \mathrm{~ms}$ para dizer que a comunicação permanece disponível. Para atingir estes níveis de tempo, a redundância na comunicação pode ser utilizada, 
ou seja, os IEDs, neste caso, possuem duas portas de comunicação, as quais enviam e recebem dados de forma redundante [79]. Assim, caso ocorra alguma falha em um dos caminhos de transmissão de dados, o IED poderá fazer uso da outra porta de comunicação disponível, supondo que a falha não ocorre nesta também.

As classes de desempenho são definidas a seguir de acordo com o tipo de mensagem.

I. Tipo 1 - Mensagens rápidas

Este é o tipo de mensagem que carrega basicamente sinais binários, que podem ser de comando ou status, como, por exemplo, disparo (trip), partida (start), status de fechado/aberto e bloqueio.

I.a. Tipo 1A - Disparo (trip)

Para este tipo de mensagem, estão atribuídas as classes de desempenho P1 e P2 conforme Tabela V. A classe P1 é utilizada para mensagens do tipo $1 \mathrm{~A}$ que circulam dentro de uma subestação, e a classe P2, para mensagens do mesmo tipo, porém, que circulem entre subestações. 
Tabela V - Classe de desempenho tipo 1A. Fonte [13].

\begin{tabular}{|c|l|c|c|}
\hline \multirow{2}{*}{$\begin{array}{c}\text { Classe de } \\
\text { desempenho }\end{array}$} & Descrição dos requisitos & \multicolumn{2}{|c|}{$\begin{array}{c}\text { Tempo de } \\
\text { transferência }\end{array}$} \\
\cline { 2 - 4 } & Classe & ms \\
\hline P1 & $\begin{array}{l}\text { Tempo de transmissão total } \\
\text { deve ser inferior a um quarto } \\
\text { de ciclo (4ms para 60Hz). }\end{array}$ & TT6 & $\leq 3$ \\
\hline P2 & $\begin{array}{l}\text { Tempo de transmissão total } \\
\text { deve ser inferior a uma } \\
\text { metade de ciclo (8ms para } \\
60 \mathrm{~Hz}) .\end{array}$ & TT5 & $\leq 10$ \\
\hline
\end{tabular}

\section{I.b. Tipo 1B - "Outras"}

Para todas as outras mensagens rápidas importantes para interação do sistema de automação com um determinado processo, mas que não possuam requisitos tão severos quanto às mensagens de disparo, o desempenho deve estar entre o tempo de resposta de uma função de proteção (cerca de $10 \mathrm{~ms}$ ) e de um operador (cerca de $1000 \mathrm{~ms}$ ). Assim fica definida a classe de desempenho P3 como mostra a Tabela VI.

Tabela VI - Classe de desempenho tipo 1B. Fonte [13].

\begin{tabular}{|c|l|c|c|}
\hline \multirow{2}{*}{$\begin{array}{c}\text { Classe de } \\
\text { desempenho }\end{array}$} & Descrição dos requisitos & \multicolumn{2}{|c|}{$\begin{array}{c}\text { Tempo de } \\
\text { transferência }\end{array}$} \\
\cline { 3 - 4 } & & Classe & ms \\
\hline P3 & $\begin{array}{l}\text { Tempo de transmissão total } \\
\text { deve ser da ordem de um } \\
\text { ciclo }(17 \mathrm{~ms} \text { para } 60 \mathrm{~Hz}) .\end{array}$ & TT4 & $\leq 20$ \\
\hline
\end{tabular}


II. Tipo 2 - Mensagens de velocidade média

São mensagens cuja estampa de tempo de origem é importante, mas, no entanto, o tempo de transferência não é crítico. A estampa de tempo é definida pelo transmissor. A Tabela VII apresenta o tempo de transferência máximo para este tipo de mensagem.

Tabela VII - Classe de desempenho tipo 2. Fonte [13].

\begin{tabular}{|c|l|c|c|}
\hline Classe de & \multicolumn{2}{|c|}{ Descrição dos requisitos } & \multicolumn{2}{|c|}{$\begin{array}{c}\text { Tempo de } \\
\text { transferência }\end{array}$} \\
\cline { 2 - 4 } & Classe & ms \\
\hline P4 & $\begin{array}{l}\text { Tempo de transferência para } \\
\text { funções de automação. } \\
\text { Possui requisitos menos } \\
\text { severos do que aplicações de } \\
\text { proteção, mas mais severos } \\
\text { que ações de um operador. }\end{array}$ & TT3 & $\leq 100$ \\
\hline
\end{tabular}

III. Tipo 3 - Mensagens lentas

São utilizadas para funções de controle, transmissão de registros de eventos, leitura ou alteração de ajustes e apresentação de dados inerentes dos sistemas. A velocidade destas mensagens corresponde a mensagens provenientes de um operador diretamente relacionado com o tempo de resposta de um ser humano em que o tempo de reação é superior a 1 segundo. A Tabela VIII apresenta as classes de desempenho para eventos bidirecionais e unidirecionais. 
Tabela VIII - Classe de desempenho tipo 3. Fonte [13].

\begin{tabular}{|c|c|c|c|}
\hline \multirow{2}{*}{$\begin{array}{c}\text { Classe de } \\
\text { desempenho }\end{array}$} & Descrição dos requisitos & \multicolumn{2}{|c|}{$\begin{array}{c}\text { Tempo de } \\
\text { transferência }\end{array}$} \\
\cline { 3 - 4 } & Classe & ms \\
\hline P5 & $\begin{array}{l}\text { Tempo de transmissão deve } \\
\text { ser metade do tempo de } \\
\text { resposta de um operador no } \\
\text { que diz respeito a um evento } \\
\text { e sua resposta (bidirecional). }\end{array}$ & TT2 & $\leq 500$ \\
\hline P6 & $\begin{array}{l}\text { Tempo de transmissão deve } \\
\text { ser alinhado com o tempo de } \\
\text { resposta de um operador no } \\
\text { que diz respeito a um evento } \\
\text { unidirecional. }\end{array}$ & TT1 & $\leq 1000$ \\
\hline
\end{tabular}

IV. Tipo 4 - Mensagens não tratadas

Este tipo de mensagem é utilizado para amostras de sinais digitalizados por sensores e transformadores de instrumentos digitais provenientes de tecnologias de transdutores (magnético, óptico, etc.). Consiste, basicamente, de um fluxo contínuo de amostras sincronizadas. Estas amostras podem ser utilizadas em funções de proteção, e, assim, o tempo de transferência deve ser pequeno o suficiente para não impactar negativamente na aplicação destas funções. A Tabela IX apresenta as classes de desempenho deste tipo de mensagem para aplicações em funções de proteção e em outras funções. 
Tabela IX - Classe de desempenho tipo 4. Fonte [13].

\begin{tabular}{|c|l|c|c|}
\hline \multirow{2}{*}{$\begin{array}{c}\text { Classe de } \\
\text { desempenho }\end{array}$} & \multicolumn{2}{|c|}{ Descrição dos requisitos } & \multicolumn{2}{c|}{$\begin{array}{c}\text { Tempo de } \\
\text { transferência }\end{array}$} \\
\cline { 3 - 4 } & & Classe & $\mathrm{ms}$ \\
\hline $\mathrm{P}^{\mathrm{a}}$ & $\begin{array}{l}\text { Atraso aceitável para funções } \\
\text { de proteção que utilizam } \\
\text { estas amostras. }\end{array}$ & TT6 & $\leq 3$ \\
\hline $\mathrm{P}^{\mathrm{b}}$ & $\begin{array}{l}\text { Atraso aceitável para outras } \\
\text { funções que utilizam estas } \\
\text { amostras. }\end{array}$ & TT5 & $\leq 10$ \\
\hline $\begin{array}{l}\mathrm{a} \\
\mathrm{b}\end{array}$ & $\begin{array}{l}\text { equivalente à P1. } \\
\text { equivalente à P2. }\end{array}$ & \\
\hline
\end{tabular}

V. Tipo 5 - Transferência de arquivos

Este tipo de mensagem é utilizado para transferir grandes arquivos, tais como oscilografia e ajustes de IEDs. Esta classe é definida na Tabela X.

Tabela X - Classe de desempenho tipo 5. Fonte [13].

\begin{tabular}{|c|l|c|c|}
\hline \multirow{2}{*}{$\begin{array}{c}\text { Classe de } \\
\text { desempenho }\end{array}$} & Descrição dos requisitos & \multicolumn{2}{|c|}{$\begin{array}{c}\text { Tempo de } \\
\text { transferência }\end{array}$} \\
\cline { 2 - 4 } & Classe & ms \\
\hline P9 & $\begin{array}{l}\text { Tempo de transferência não } \\
\text { crítico. Arquivos utilizados } \\
\text { para análise e, no caso de } \\
\text { ajustes, requer um processo } \\
\text { de verificação cuidadoso. }\end{array}$ & TT0 & $\leq 10000$ \\
\hline
\end{tabular}


VI. Tipo 6 - Mensagens de comando e transferência de arquivos com controle de acesso

Este tipo de mensagem é usado para transferir ordens de controle através de uma interface homem-máquina (IHM) local ou remota, e que necessitam de um alto grau de segurança através de controle de acesso (e.g. senha), para garantir que somente usuários com os privilégios adequados possam realizar um determinado tipo de operação. As classes de desempenho deste tipo de mensagem possuem relação com alguns dos tipos já descritos anteriormente como definido na Tabela XI.

Tabela XI - Classe de desempenho tipo 6. Fonte [13].

\begin{tabular}{|c|c|c|c|}
\hline $\begin{array}{c}\text { Classe de } \\
\text { desempenho }\end{array}$ & \multirow[t]{2}{*}{ Descrição dos requisitos } & \multicolumn{2}{|c|}{$\begin{array}{c}\text { Tempo de } \\
\text { transferência }\end{array}$} \\
\hline & & Classe & $\mathrm{ms}$ \\
\hline $\mathrm{P} 10^{\mathrm{a}}$ & $\begin{array}{l}\text { Mensagem tipo } 3 . P 5 \text { com } \\
\text { controle de acesso. }\end{array}$ & TT2 & $\leq 500$ \\
\hline $\mathrm{P} 11^{\mathrm{b}}$ & $\begin{array}{l}\text { Mensagem tipo } 3 . P 6 \text { com } \\
\text { controle de acesso. }\end{array}$ & TT1 & $\leq 1000$ \\
\hline $\mathrm{P} 12^{\mathrm{C}}$ & $\begin{array}{l}\text { Mensagem tipo } 5 \text { com } \\
\text { controle de acesso. }\end{array}$ & TT0 & $\leq 10000$ \\
\hline \multicolumn{4}{|c|}{$\begin{array}{l}\text { equivalente à } \mathrm{P} 5 \text {. } \\
\text { equivalente à } \mathrm{P6} \text {. } \\
\text { equivalente à } \mathrm{P9} \text {. }\end{array}$} \\
\hline
\end{tabular}




\subsection{PILHA DE COMUNICAÇÃO E SERVIÇOS}

Na parte 8 da norma, é referenciado o modelo OSI (Open Systems Interconnection) [62]. Este modelo é divido em sete camadas, mostradas na Figura 3.6, e detalha os requisitos funcionais para cada uma delas. Na especificação da norma IEC 61850, no entanto, as sete camadas do modelo OSI são dividas em dois perfis distintos: Perfil de Aplicação ou Perfil-A (A-Profile - Application Profile) e Perfil de Transporte ou Perfil-T (T-Profile - Transport Profile).

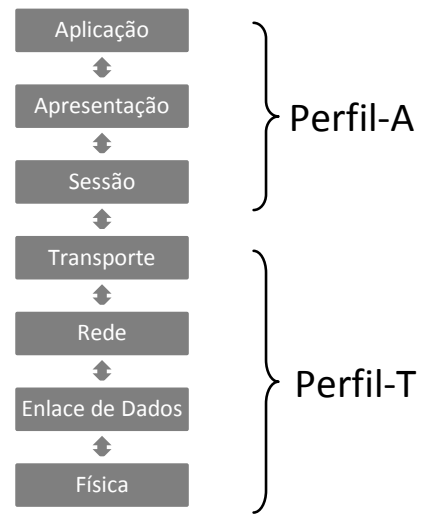

Figura 3.6 - Modelo de referência OSI e perfis de Aplicação (A) e Transporte (T).

Com o objetivo de possibilitar a troca de diferentes tipos de informações e serviços, diversas combinações de Perfil-A e Perfil-T podem ser executadas.

Na Figura 3.7, os serviços de comunicação especificados na parte 72 da norma são mostrados, bem como os tipos de mensagens, 
descritas logo a seguir, que se utilizam de tais serviços para garantir os requisitos de desempenho de cada função que faz uso delas.

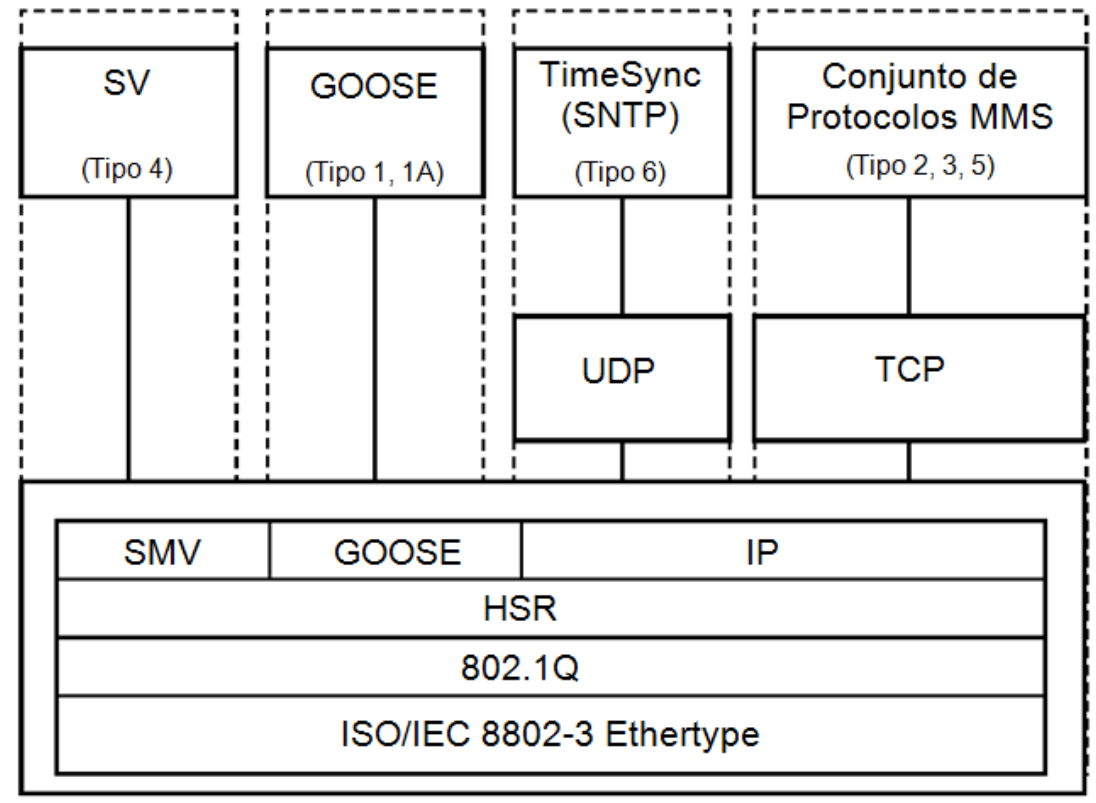

Figura 3.7 - Visão geral dos serviços de comunicação. Fonte [13].

- SV (Sampled Values): valores amostrados de corrente e tensão provenientes de transformadores de instrumentos.

- GOOSE (Generic Object Oriented Substation Event): possibilita a distribuição de dados de alta prioridade (e.g. trips) de maneira rápida e confiável.

- TimeSync: Sincronização de tempo por SNTP (Simple Network Time Protocol).

- Conjunto de protocolos MMS (Manufacturing Message Specification): serviços de requisição de informações Cliente/Servidor. 
Os serviços de mensagens GOOSE e SV possuem acesso direto à camada de enlace, para que seja possível atingir os requisitos de desempenho para as mensagens tipo $1 \mathrm{~A}$ e 4 , respectivamente. Já os tipos de mensagens 2, 3 e 5, por possuirem requisitos menos exigentes, possibilitam o uso da camada de transporte, agregando as vantagens do uso do protocolo TCP, tais como garantia de entrega e controle de congestionamento.

A mensagem GOOSE possui destaque especial na norma IEC 61850 , pois possibilita a troca de informações direta entre IEDs. A informação contida na mensagem GOOSE é configurável e transporta um conjunto de dados (dataset) que é transmistido sempre que algum dos sinais presentes neste conjunto sofrer alteração de estado. Desta maneira, o assinante terá a informação de alteração de estado do sinal e o instante em que a alteração ocorreu. Este tipo de mensagem carrega em seu cabeçalho os dados do dispositivo de origem que originou a informação, tais como nome do dispositivo, tempo do evento e endereço lógico. Esta informação é transmitida através de multicast para todos os IEDs que estiverem conectados à mesma LAN (Local Area Network) e os dispositivos, ao receberem esta mensagem, irão julgar se aquela informação é de utilidade ou não.

Como as mensagens GOOSE são transmitidas por multicast, não existe garantia de entrega. Desta forma, a norma estabelece, na parte 8 , um esquema de retransmissões constantes de mensagens, de modo a atingir um nível de confiabilidade adequado. Este processo de retransmissões é chamado heartbeat, que é ilustrado em mais detalhes na Figura 3.8. 


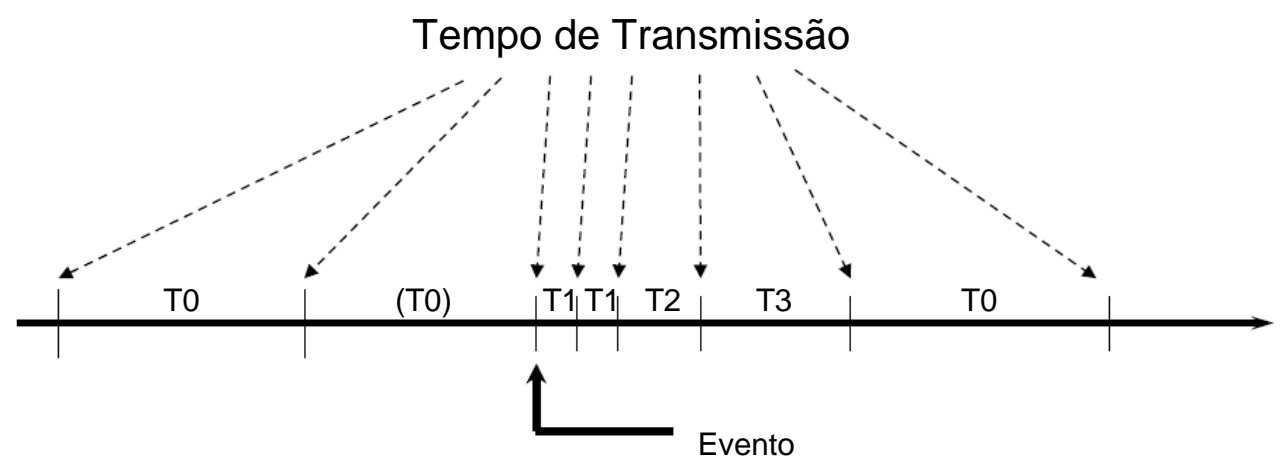

Legenda

T0 retransmissão em condições estáveis (sem evento por um longo tempo).

(T0) retransmissão em condições estáveis pode ser antecipada por um evento.

T1 período curto de retransmissão após um evento.

T2, T3 tempos de retransmissão até atingir o tempo de condição estável

Figura 3.8 - Retransmissões de um evento. Fonte [13].

O esquema de retransmissão apresentado na Figura 3.8, segundo a parte 8 da norma, pode ser usado como padrão, porém, pode variar dependendo da aplicação, sendo que em alguns casos, se for conveniente, é possível adotar publicações (envios) somente após um evento significativo. Cada mensagem, no entanto, carrega um parâmetro timeAllowedToLive que informa ao receptor o tempo máximo a aguardar pela próxima retransmissão. Neste caso, se uma nova mensagem não for recebida dentro deste intervalo de tempo, o receptor deverá assumir que a associação foi perdida.

De forma a aumentar o desempenho da rede, no que tange a latência para as mensagens transmitidas por multicast, a parte $8 \mathrm{da}$ norma também sugere o uso apropriado de endereços MAC (Media Access Control), de modo a filtrar alguns tipos de mensagens, como GOOSE e SV, de modo que estes tipos de mensagens possuam prioridade no envio e recepção. Uma outra forma de aumentar o desempenho é criar Virtual LANs (VLAN) [80]. As VLANs podem ser utilizadas para criar domínios distintos de broadcast, permitindo a 
separação de dados dentro de uma mesma LAN. Assim, os dados destinados a uma VLAN específica estarão isolados de outras VLANs, o que permite evitar sobrecarga da rede devido ao tráfego intenso de informações.

Para as mensagens MMS, os serviços adotados são do tipo cliente/servidor, ou seja, o IED atua como um cliente de uma estação supervisora, que atua como servidor. A troca de informações, neste caso, pode ser motivada pela requisição do servidor diretamente ao cliente, que, por sua vez, responde com a informação solicitada. Uma outra forma de transferência de informações MMS se dá utilizando um bloco de controle chamado Report Control Block. Este bloco monitora um dado dataset e, na ocorrência de uma alteração de estado em qualquer dos sinais presentes neste dataset, o bloco de controle envia as infomações automaticamente ao servidor, relatando a alteração de estado. A mensagem MMS, assim como apresentado na Figura 3.7, utiliza o protocolo de transporte TCP/IP, usufruindo, portanto, de garantia de entrega e está sujeita a todos os mecanismos de controle característicos deste protocolo [64].

\subsection{APLICAÇÃO DA NORMA}

Uma das vantagens na aplicação desta norma se deve ao fato dela permitir a redução de custos no projeto e instalação de sistemas de 
proteção. Esta redução de custos se deve a diversos fatores. Entre eles, pode-se destacar que a comunicação neste padrão pode ser feita diretamente entre dois dispositivos (IEDs) através de interfaces amplamente consolidadas e populares do tipo Ethernet (IEEE 802.3) [40]. Isto reflete diretamente no momento da concepção do projeto dos painéis de proteção e controle, reduzindo de forma significativa a necessidade de cabeamento, e que torna o desenvolvimento de lógicas de controle e automação mais simples de serem criadas em IEDs por meio do uso de mensagens GOOSE. A Figura 3.9 mostra o compartimento de baixa tensão de um painel de média tensão repleto de cabos de controle, provenientes de painéis adjacentes. Neste caso, estes cabos poderiam ser eliminados utilizando a IEC 61850. Além destes fatores, é importante destacar também que a interoperabilidade de dispositivos de diferentes fabricantes permite a simples expansão do sistema elétrico através da adição de novos dispositivos, independentemente do fabricante dos mesmos.

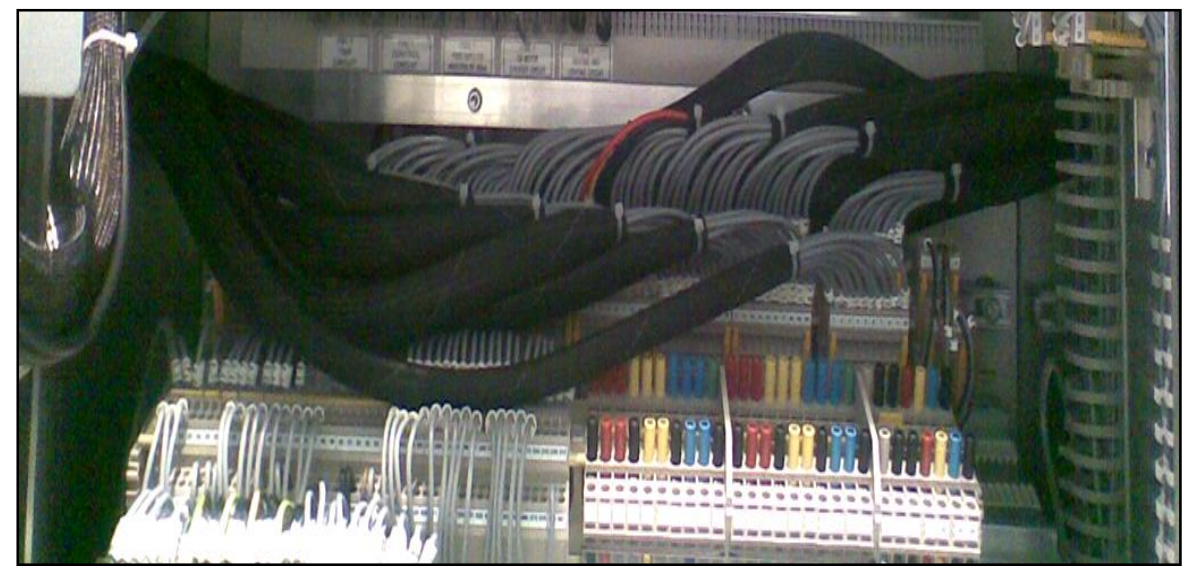

Figura 3.9 - Compartimento de baixa tensão de um painel de média tensão que não utiliza a IEC 61850. Fonte [73]. 
Para atestar que seus IEDs atendem ao que determina a norma IEC 61850, os fabricantes contratam laboratórios para certificação de seus produtos. O laboratório de maior reconhecimento mundial para certificação de dispositivos na IEC 61850 é o DNV-KEMA. Este laboratório é independente e é capaz de emitir certificações de nível A. As companhias que utilizam seus próprios laboratórios para esta finalidade, caso aprovados pela UCAlug (Utilities Communication Architecture - International Users Group), instituição responsável por autorizar os laboratórios de teste a emitirem os certificados de conformidade [81], estão autorizados a emitir certificações nível B [82]. A parte 10 da norma define testes de conformidade para os aspectos funcionais e de desempenho. A Figura 3.10 apresenta um trecho extraído de um certificado emitido pelo DNV-KEMA, que atesta que o produto em questão não demonstrou nenhuma não conformidade durante os testes e, em seguida, cita as partes da norma as quais o produto foi submetido a testes.

Issuedbr. KEMAき

The product has not shown to be non-conforming to:

IEC 61850-6, 7-1, 7-2, 7-3, 7-4 and 8-1

Communication networks and systems in substations

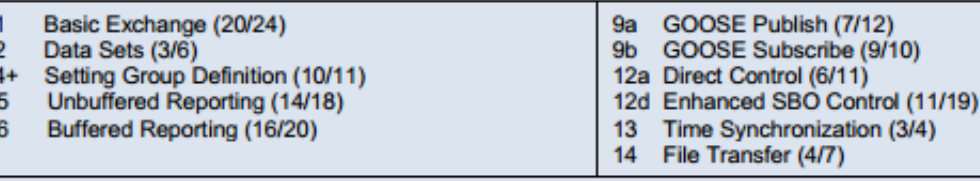

Figura 3.10 - Trecho extraído de um certificado de conformidade. Fonte [73]. 
A Figura 3.11 apresenta equipamentos que foram usados em um teste de conformidade realizado pelo DNV-KEMA em 2010, a pedido de um fabricante, no intuito de certificar um conjunto de IEDs e cubículos de média tensão isolados a ar.

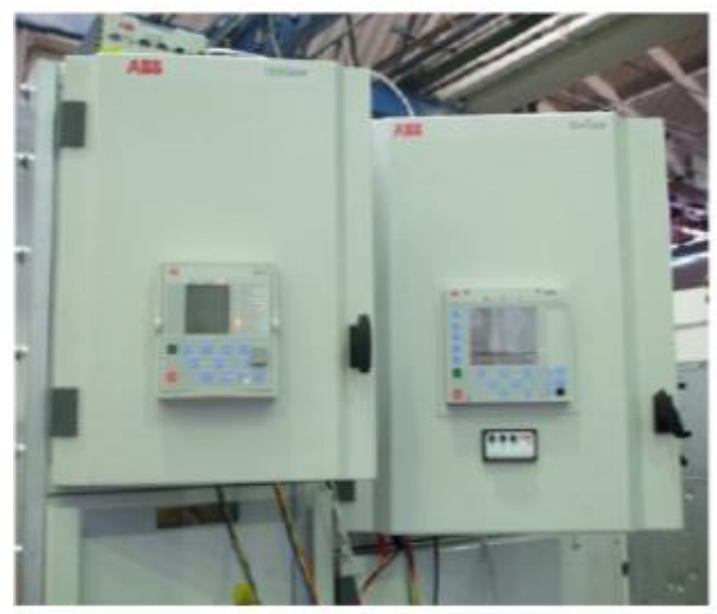

IEDs

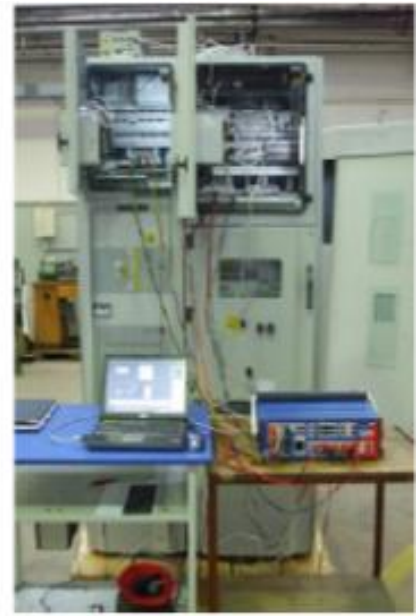

Equipamentos de teste

Figura 3.11 - Teste de conformidade realizado no KEMA.

Dentre os diversos ensaios realizados, o teste referenciando na Figura 3.11 chegou à conclusão que para o esquema de proteção de falha de disjuntor, usando mensagens GOOSE, ao invés de utilizar cabos de interligação entre entradas e saídas binárias dos IEDs, a atuação da proteção foi de $12 \mathrm{~ms}$ a $17 \mathrm{~ms}$ mais rápida, comprovando um dos benefícios que a IEC 61850 possibilita. Este ganho em desempenho é possível, pois o tempo para processamento das informações de comunicação é inferior ao tempo para codificação e decodificação dos sinais lógicos. No entanto, existem dificuldades na realização dos testes. Pois para determinar o tempo de transferência dos sinais sem interferir no hardware no 
IED a ser testado é necessário fazer uma estimativa do tempo de processamento da lógica implementada no IED, o que faz com que estes testes, se tornem problemas de difícil solução.

Graças às características da norma discutidas neste capítulo, a mesma tem sido citada como base para a estrutura semântica comum que é necessária nas redes elétricas inteligentes [32]. Existem esforços inclusive para aumentar a área de abrangência da IEC 61850, no sentido de integrá-la com normas usadas para medidores [83], com destaque para a IEC 62056 [84]. Estes esforços são fundamentados no fato que outros protocolos definem o número de bytes que devem ser transmitidos, mas eles não definem como os dados devem ser organizados em dispositivos, enquanto que a norma IEC 61850 fornece tal definição.

Devido ao destaque e importância desta norma, no próximo capítulo, será apresentada a simulação de um SAS baseado na mesma. 


\section{SIMULAÇÃO PROPOSTA}

Este capítulo visa a simulação de uma rede de comunicação de um SAS, empregando o protocolo IEC 61850 e parâmetros obtidos em testes reais com IEDs, de modo a explorar os limites operativos da estrutura. Em outras palavras, tal simulação de uma rede elétrica inteligente permite verificar a confiabilidade no transporte de informação, em função da latência e do número de dispositivos que nela operam.

\subsection{SISTEMAS DE AUTOMAÇÃO DE SUBESTAÇÕES}

As subestações desempenham um papel crítico no sistema de potência, pois realizam uma importante tarefa para os sistemas de geração, transmissão e distribuição onde a tensão é transformada de alta para baixa e vice-versa. Todos os dispositivos em uma subestação são controlados, protegidos e monitorados pelo Sistema de Automação de Subestações (SAS - Substation Automation System) que é responsável por coletar informações dos equipamentos de potência (nível de processos) e desempenhar ações sobre estes elementos. 
A demanda por uma melhor qualidade de energia e a evolução das redes elétricas inteligentes são os fatores mais significativos para a expansão do SAS. O custo de interrupções no fornecimento de energia elétrica está aumentado e as companhias de energia elétrica querem reduzir tais ocorrências, oferecendo uma melhor qualidade de fornecimento. A automação de subestações tem um papel crítico para esta finalidade. Além disso, um dos motivos mais importantes para a adoção do SAS está também relacionado a introdução de dispositivos que possam fornecer dados de modo, a evitar a tomada de decisões errôneas, especialmente em situações críticas.

A utilização do SAS começou em meados dos anos 1980 e, desde então, vem aumentando para: i) atender aos requisitos do mercado, visando a queda nos custos totais; ii) permitir uma operação altamente efetiva próxima dos limites suportados pelos equipamentos utilizados na subestação; iii) otimizar os custos de manutenção [85]. Nestes sistemas, a rede de comunicação é um elemento fundamental e o desempenho desta pode ter um impacto crítico no processo de controle. Nas décadas passadas, novos padrões de comunicação foram desenvolvidos e alguns também foram modernizados. A partir da década de 1990, os fabricantes de dispositivos para as redes destes sistemas começaram a utilizar o padrão Ethernet, os protocolos TCP/IP e métodos proprietários para comunicação.

Além de comunicação, o SAS é caracterizado por algumas funções básicas. Estas funções podem ser classificadas em monitoramento, controle, registros e proteção, e sua estrutura pode ser dividida em três níveis [86]: nível da estação (station level), nível do vão (bay level) e nível de processo (process level). A Figura 4.1 apresenta esta classificação. 
O nível de processo é o nível inferior do SAS, também conhecido como nível 0 , e é onde os equipamentos de potência estão localizados, tais como sensores e atuadores, que são necessários ao monitoramento e operação do sistema.

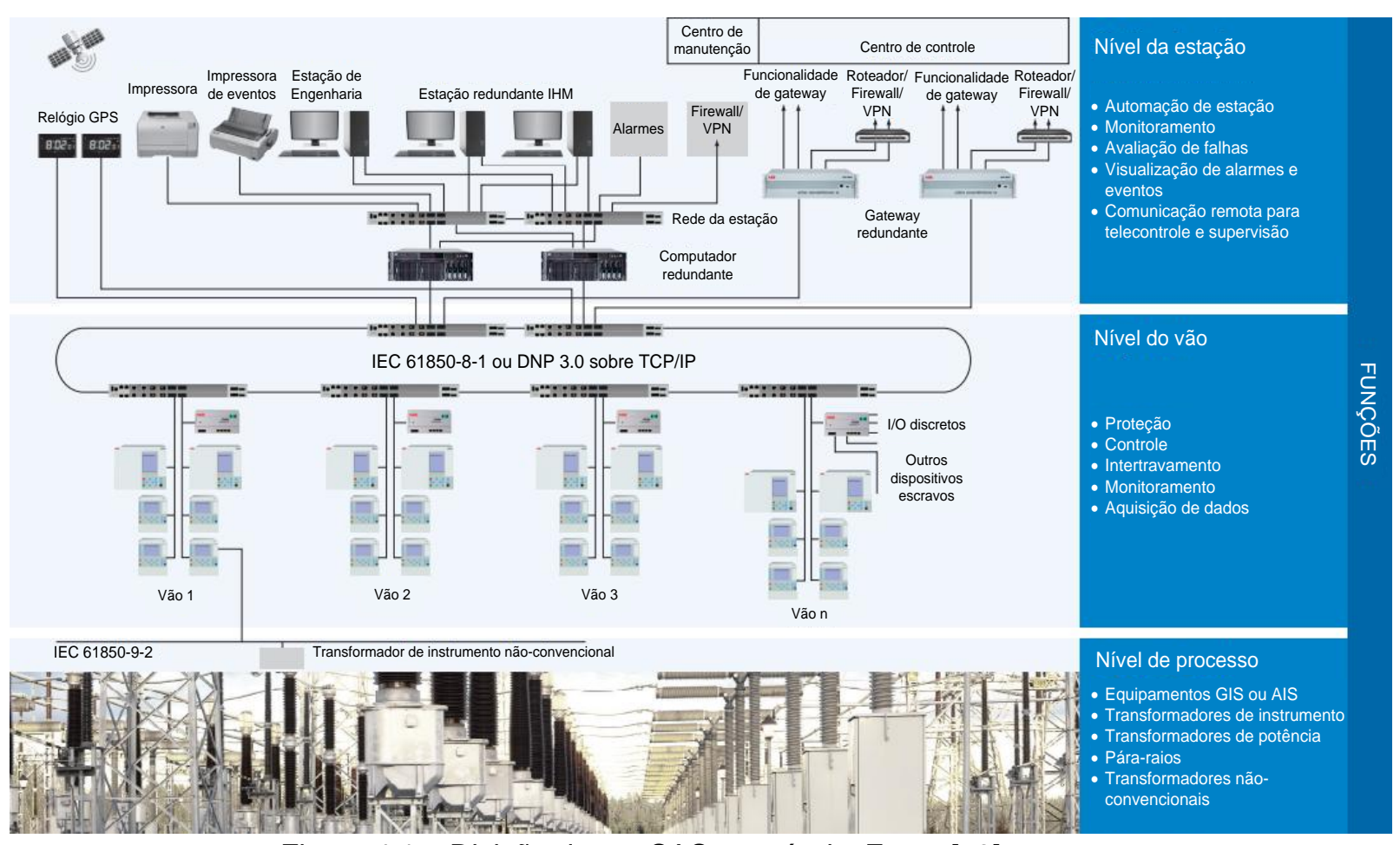

Figura 4.1 - Divisão de um SAS por níveis. Fonte [73].

O nível do vão é o nível intermediário, também conhecido como nível 1, em que os equipamentos de proteção e controle estão localizados. Estes dispositivos geralmente estão cabeados aos dispositivos do nível inferior, e os dados transferidos por estes cabos consistem basicamente de entradas ou saídas digitais e analógicas, tais como as saídas de transformadores de tensão e corrente e controle de disparo (trip) de relés de proteção. 
O nível de estação é o nível superior, também conhecido como nível 2, em que se encontram os computadores supervisores, interfaces homem-máquina (IHM), gateways e equipamentos de telecomunicação para conexões com o centro de controle do sistema (COS).

A norma IEC 61850 trouxe alguns avanços para a estrutura do SAS, particularmente no que se refere ao cabeamento dos dispositivos do nível do vão junto aos equipamentos do nível de processo. A Figura 4.2 apresenta a diferença entre a estrutura de um SAS convencional e o previsto pela IEC 61850 para as futuras subestações.

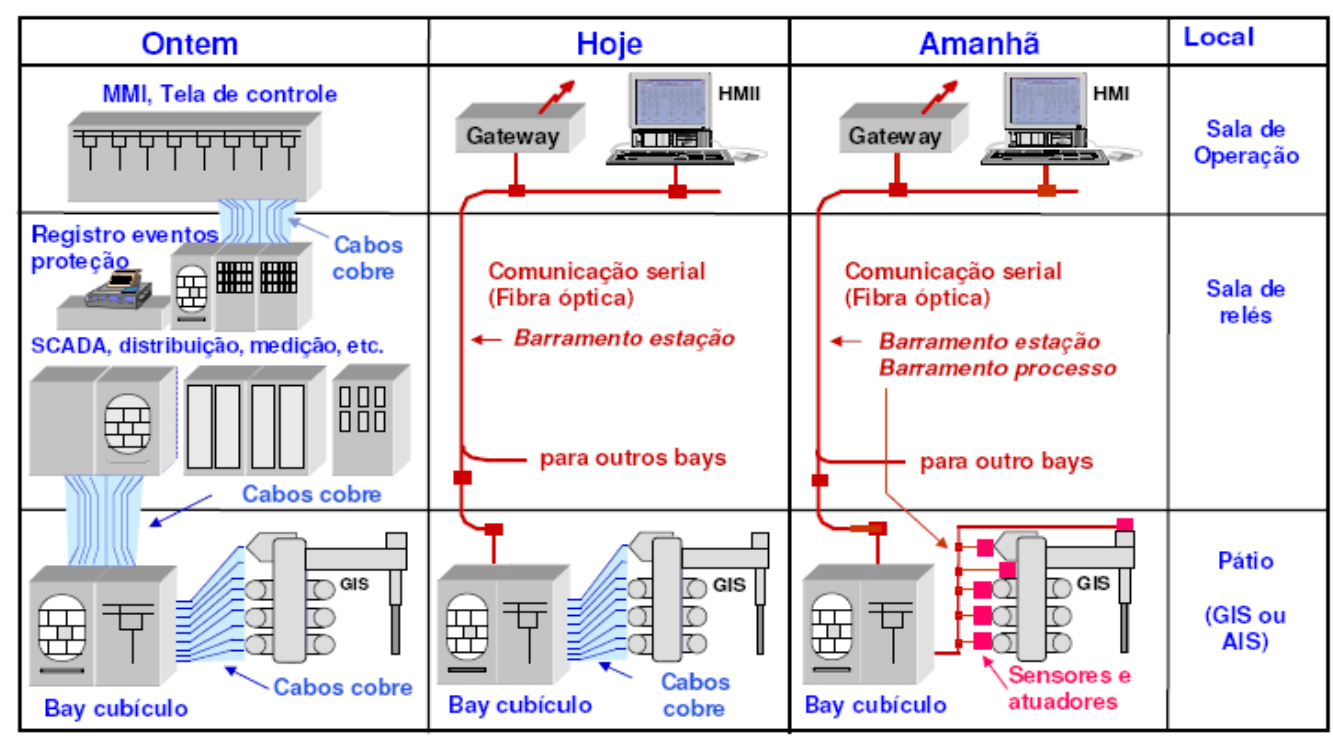

Figura 4.2 - Atualidades e tendências com o uso da IEC 61850 em subestações. Fonte [73].

Em redes elétricas inteligentes, a utilização da nova geração de relés de proteção e controle no SAS é de fundamental importância. Os IEDs, permitem a implementação de lógicas flexíveis, esquemas 
avançados de proteção, e, fundamentalmente, integrar diversas funções de proteção em um único dispositivo [84]. O aumento no uso deste tipo de dispositivo fez também crescer a demanda pelo uso de comunicação, incluindo a comunicação entre relé e central supervisória, entre relé e outros equipamentos de subestações e entre relés.

\subsection{DEFINIÇÃO DOS CENÁRIOS A SEREM SIMULADOS}

Com o aumento do uso de comunicação baseada na norma IEC 61850 para uso em SAS, surgiram questionamentos sobre a confiabilidade dos sistemas. Por este motivo, foram realizados trabalhos nesta área com o intuito de avaliar a confiabilidade dos mesmos, e criar uma base de consulta para aplicações e projetos. Neste contexto, [87] utiliza um sistema de simulação em tempo real (RTDS - Real Time Digital Simulator) para verificar o comportamento de mensagens GOOSE e SV em situações anormais, utilizando IEDs de dois fabricantes distintos. Ao final é concluído que a programação correta dos IEDs é de grande importância para que os dispositivos possam responder adequadamente às anormalidades. Ainda, em [88], as mensagens são modeladas em um software de simulação de redes e dá-se enfoque ao uso de SV para o caso de uma pequena subestação. O artigo é concluído afirmando que para o caso simulado, 
considerando apenas nove dispositivos, o padrão Ethernet é suficiente para trafegar as informações de forma confiável, incluindo o tráfego de SV.

Além dos artigos citados, há também o trabalho realizado em [66], onde os pesquisadores utilizam IEDs e softwares de carregamento da rede para avaliar a interoperabilidade, latência e confiabilidade do sistema. Com este trabalho, os autores puderam estabelecer metodologias, baseadas na parte 10 da norma IEC 61850, e propuseram o uso de ferramentas de software para testes de redes que utilizam esta norma. Na conclusão, são citados os problemas encontrados nos testes, tais como desempenho inaceitável de alguns IEDs, dificuldades na configuração e integração dos cenários de teste e problemas nos equipamentos de infraestrutura de rede.

Neste trabalho, a abordagem é diferente da utilizada nos artigos citados, não somente no que tange a simulação, mas também se diferencia nas aplicações a serem simuladas como será apresentado ao longo deste capítulo.

Conforme evidenciado nos artigos [66][87][88], a confiabilidade de um SAS, cujo sistema de proteção e controle está baseado na IEC 61850 , é de suma importância. É fator preponderante para tal que a rede de comunicação funcione adequadamente, de modo que a troca de sinais entre os IEDs se dê sem problemas. Isso ocorre porque esta troca de sinais é feita através de uma rede de comunicação. Por isso, muitas vezes no momento da especificação do projeto de uma subestação, o cliente se preocupa com o desempenho desta rede em situações extremas, ou seja, sempre surge dúvida em relação aos limites operativos da estrutura de rede a ser implementada no SAS da subestação para garantir que a 
confiabilidade do sistema de proteção e controle seja mantida, mesmo na piores condições.

As dúvidas mais comuns são com relação ao número máximo de mensagens que podem ser trocadas pelos IEDs sem comprometer significativamente o tempo de resposta da rede, a confiabilidade no transporte de pacotes e a quantidade de informação que é trafegada na rede durante um evento tal como um curto-circuito.

Algumas aplicações, como é o caso de sistemas de descarte de cargas (load shedding), requerem tráfego constante de pacotes contendo informações de corrente, tensão e potência. Nestas aplicações, o intervalo em que o tráfego destas informações deve ocorrer é muito pequeno, da ordem de alguns milissegundos. Isto permite que o sistema possa analisar variações no carregamento do sistema e tomar ações para mitigar estes distúrbios de forma suficientemente rápida, evitando o colapso da rede.

O descarte de cargas é bastante utilizado no sistema elétrico de potência, seja para controle de demanda, seja para estabilidade do sistema. No entanto, existem diversos mecanismos de operação. Por exemplo, no Sistema Interligado Nacional (SIN), existe o Esquema Regional de Alívio de Carga (ERAC) [89]. Este sistema estabelece cinco estágios de subfrequência, sendo que para cada estágio está atribuído um montante de potência a ser descartada do sistema, com o objetivo de manter a estabilidade do mesmo.

Dada a importância do sistema de descarte de cargas, esta é uma das situações a ser explorada nas simulações. No entanto, este sistema possui princípio de funcionamento diferente do ERAC, que é basedo em frequência. O sistema proposto neste trabalho é baseado na comunicação IEC 61850 com troca de mensagens GOOSE. Nele, 
- IED responsável pelo gerenciamento do descarte de cargas recebe os dados de potência dos outros IEDs e calcula o balanço de potência, que é o resultado da diferença entre potência fornecida e consumida em uma determina barra. A potência fornecida pode ser proveniente de diversas fontes, como, um gerador ou um transformador de potência. Entretanto, estes elementos possuem limites no fornecimento de potência, podendo ser o limite de demanda contratada ou mesmo o limite térmico do próprio equipamento. Caso a potência consumida exceda este limite, o gerenciador de descarte executa o procedimento de descarte de cargas, de acordo com as classes de prioridade, de forma a reestabelecer o balanço de potência.

Complementando esta análise, é verificada também uma situação corriqueira de curto-circuito. Durante tal condição, sinais GOOSE podem ser enviados para realizar esquemas de seletividade lógica, ou até mesmo para garantir a extinção de um curto-circuito, no caso de uma falha de disjuntor. Entretanto, para simular o pior caso possível, é assumida uma condição onde todos os IEDs de proteção estão detectando curto-circuitos independentes, porém, que ocorrem no mesmo instante. 


\subsection{SOFTWARE DE SIMULAÇÃO DE REDE DE PACOTES}

O software utilizado para executar as simulações, o NS-2 (Network Simulator 2) [90], é um simulador de eventos discretos que foi criado através do projeto VINT (Virtual InterNetwork Testbed) financiado pela DARPA (Defense Advanced Research Projects Agency). Grande parte de seu sucesso se deve ao fato de se tratar de um software gratuito, de código fonte aberto, o que permite aos usuários a personalização das configurações e ajustes, de forma que o software contemple as funcionalidades necessárias. Este simulador ainda possui, implementado em seu código fonte, diversas interfaces de rede, protocolos e caracterizações de tráfego, o que possibilita a criação de simulações de forma rápida.

Além disso, o NS-2 possui uma estrutura de codificação baseada em scripts OTCL, o que agiliza o processo de criação de simulações. Através destes scripts é definida a topologia de rede, os protocolos a serem utilizados, a forma como estes protocolos devem se comportar e quais resultados o simulador deverá gerar como saída.

Conforme citado, o NS-2 é um simulador de eventos discretos. Portanto, o avanço de tempo depende da temporização dos eventos, a qual é mantida por um scheduler, e os eventos são iniciados e finalizados conforme definido no script de simulação.

Por estes motivos, pela familiaridade com o software e por sua popularidade, o que facilita a resolução de eventuais dúvidas que 
surjam com relação a sua operação, o NS-2 foi escolhido para as simulações deste trabalho.

Os passos para definição de uma simulação no NS-2 podem ser enumerados da seguinte forma:

1) Inicialização do simulador;

2) Definição de nós, enlaces, filas e topologia;

3) Definição de agentes e aplicações;

4) Monitoramento dos dados;

5) Definição dos dados a serem coletados.

4.4. DEFINIÇÃO DA ARQUITETURA E PARÂMETROS DA SIMULAÇÃO

O diagrama unifilar da subestação proposta para a simulação das situações descritas anteriormente e a estrutura do respectivo SAS são apresentados na Figura 4.3. Para realizar a simulação proposta neste trabalho, a estrutura apresentada na Figura 4.3 precisou ser modelada no software NS-2. O modelo resultante é apresentado na Figura 4.4. 


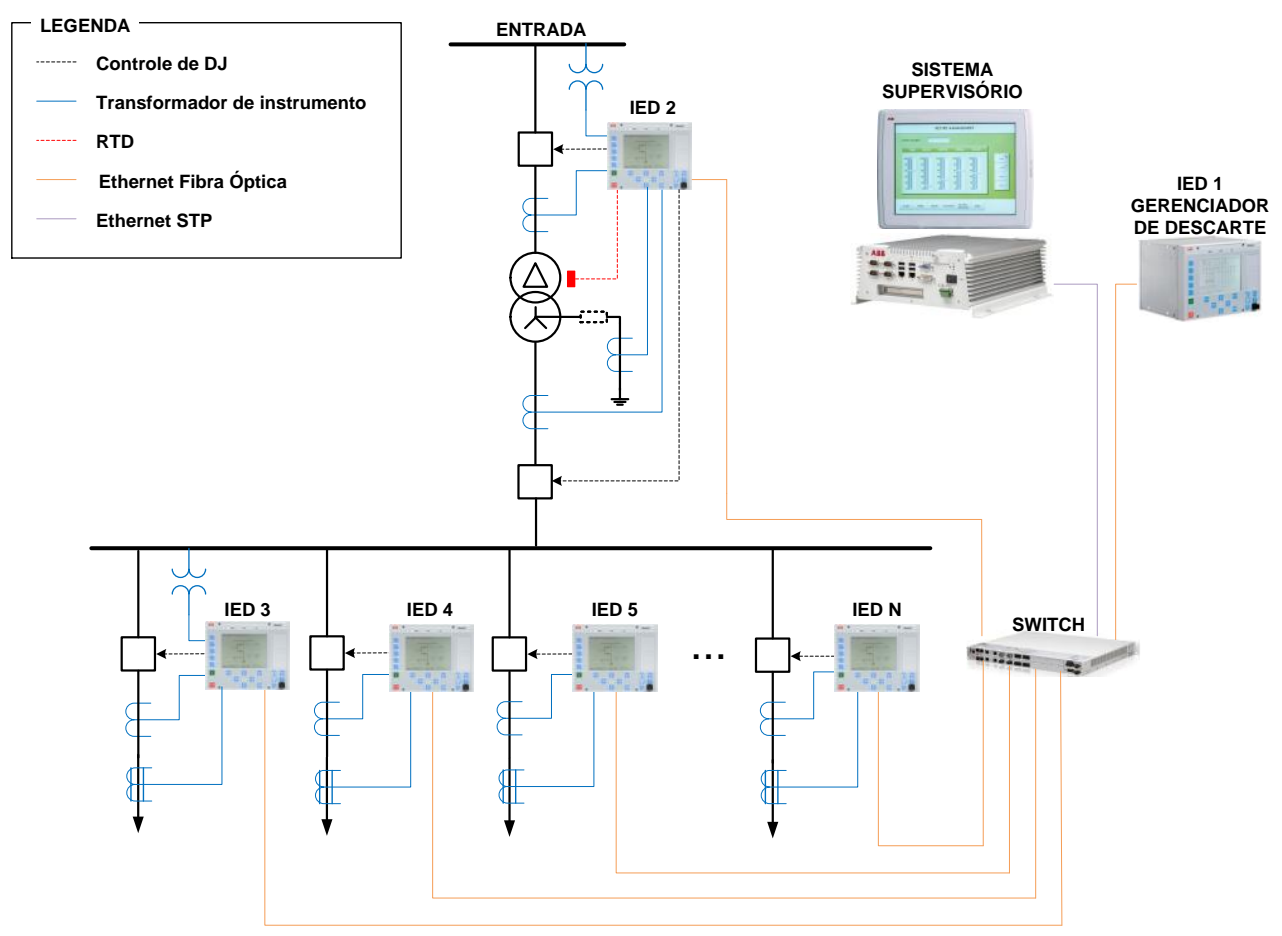

Figura 4.3 - Diagrama unifilar e estrutura do SAS simulado.

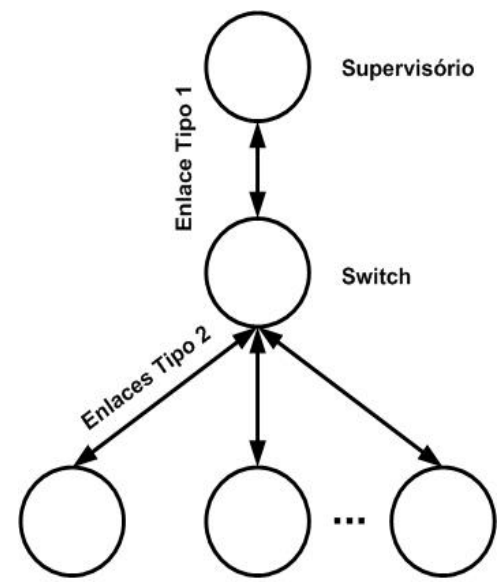

IEDs

Figura 4.4 - Topologia de rede de comunicação da simulação.

Conforme descrito na Figura 4.4, os enlaces utilizados na simulação foram divididos em dois tipos. O primeiro enlace faz a interligação 
entre o supervisório e o switch, enquanto que o enlace do tipo 2 faz a interligação entre o switch e os IEDs. Os enlaces são do tipo Ethernet de 100 Mbps full duplex, configuração que é tipicamente utilizada em subestações. O tempo de latência dos enlaces é calculado como descrito em [91], como mostra a Equação 4.1, e varia de acordo com o número de IEDs e tamanho dos pacotes, além de levar em conta também a latência interna do switch. Nesta simulação, o sistema supervisório requisita informações aos IEDs, simulando uma troca de mensagens MMS através de pacotes do tipo TCP, e os IEDs, por sua vez, realizam o multicast de pacotes GOOSE a todos os dispositivos conectados ao switch com exceção do supervisório, que se encontra em outro grupo de rede.

$$
L_{\text {pior caso }}=\frac{F S . N}{B R}+L_{S W}
$$

em que,

FS é o tamanho do pacote a ser transmitido em bits;

$\mathrm{N}$ é o número de IEDs na mesma rede;

BR é a taxa de transmissão de dados do enlace;

Lsw é a latência interna do switch.

Para tornar a simulação compatível com uma situação real, foram utilizados dados obtidos através de testes realizados em fevereiro de 2012 no laboratório de relés de média tensão da ABB Brasil, onde foi criada uma estrutura simplificada do SAS mostrado na Figura 4.3. Nestes testes, foram utilizados apenas 2 IEDs e um computador para simular o sistema supervisório, de modo a realizar as medições de tráfego na rede, utilizando o software ITT Explorer da ABB. As 
medições foram coletadas para o sistema de descarte de cargas e para a situação de curto-circuitos simultâneos. A Figura 4.5 apresenta os equipamentos utilizados em laboratório para coleta de dados e a forma com que estavam conectados em rede.

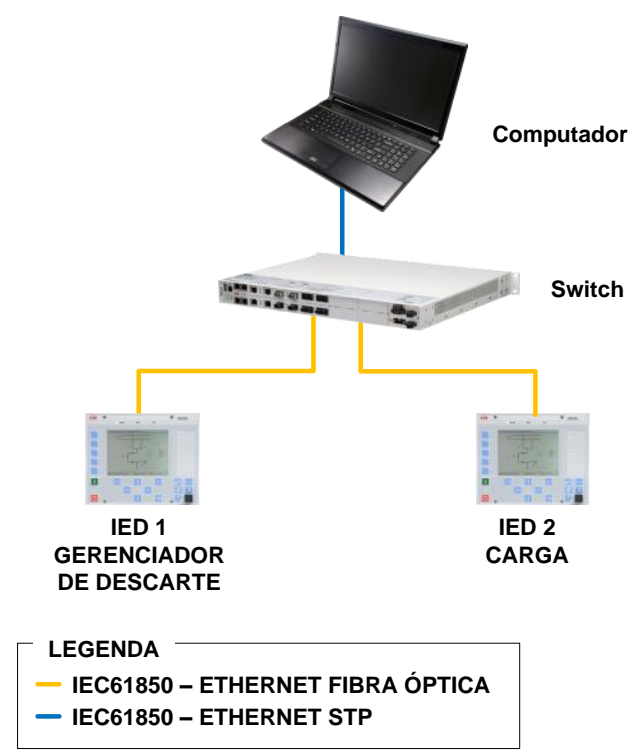

Figura 4.5 - Equipamentos usados no laboratório para coleta de dados.

Nos testes efetuados, o tamanho do maior dos pacotes Ethernet medidos, incluindo cabeçalho e payload, foi de 160 bytes para pacotes GOOSE contendo valores de potência e 156 bytes para pacotes GOOSE que transportam sinal de trip de proteção. Para pacotes MMS, o tamanho do maior pacote medido foi de 159 bytes, com exceção de pacotes de keep alive utilizados para monitorar a conectividade do dispositivo na rede, com tamanho de 40 bytes e intervalo entre transferências na ordem de segundos. $O$ tamanho dos pacotes pode variar de acordo com o valor da variável de informação a ser transportada. Contudo esta variação não é 
significativa se comparada ao tamanho total do pacote, o que não influencia diretamente nos resultados da simulação.

Para simulação do tráfego de dados entre IEDs e supervisório, foi utilizado um modelo de fila $\mathrm{M} / \mathrm{M} / 1$ [92] com característica de um processo de Poisson e média de chegada de 8 pacotes $(3$ correntes de fase, 1 corrente residual, 3 tensões de fase e 1 tensão residual) por ciclo $(60 \mathrm{~Hz})$. Este modelo de fila é utilizado por se tratar de uma rede com um único servidor, em que ocorre importantes variações no tempo de serviço. Ainda, foi considerado que as requisições de dados partem do sistema supervisório, e, logo, os dados são enviados um a um e não através de um único dataset. Este tráfego de pacotes MMS foi utilizado em todas as simulações cujos resultados são apresentados na seção 4.5, mantendo os parâmetros descritos como fixos. Os pacotes GOOSE não são representados com o modelo $\mathrm{M} / \mathrm{M} / 1$ e são enviados considerando a situação operacional da simulação - ocorrência de um evento de curtocircuito e envio de dados de potência para descarte de cargas - que é característica da norma IEC61850 e estabelece retransmissões em tempos definidos (heartbeats). Além disso, pacotes GOOSE são transmitidos por multicast, diferentemente dos pacotes MMS que foram modelados por $M / M / 1$, pois, neste caso, os clientes são homogêneos. Em outras palavras, o sistema possui o mesmo tempo de serviço e o mesmo tamanho de pacotes. O tempo de simulação total utilizado foi de 0,5 s para a simulação do descarte de cargas que é um cenário mais dinâmico e 15s para a simulação do curtocircuito simultâneo que é um cenário onde os eventos ocorrem mais espaçados no tempo, sendo que o início do tráfego ocorre após $0,1 \mathrm{~s}$ do início da simulação para ambos os casos.

Os resultados dos dois casos simulados são apresentados a seguir. 


\subsection{RESULTADOS DA SIMULAÇÃO}

Para o descarte de cargas, os pacotes GOOSE, contendo a informação de potência dos IEDs, seguem o estabelecido na Figura 3.8, porém, são gerados em intervalos constantes de $1 \mathrm{~ms}$. Neste caso, a maior preocupação é garantir que a quantidade de IEDs a ser utilizada não exceda a capacidade de transferência de dados da rede.

Com o intuito de encontrar o número estimado de IEDs para o qual a capacidade de transmissão de dados dos enlaces fosse atingida, foi utilizada a Equação 4.2, considerando somente o tráfego de pacotes GOOSE.

$$
C=N \cdot Q \cdot P
$$

Onde,

C é a capacidade de transferência de dados em um enlace, dado em bytes/s.

$\mathrm{N}$ é a quantidade de IEDs.

$Q$ é a quantidade de pacotes gerados por IED por segundo.

$P$ é o tamanho de um pacote em bytes.

Logo, se considerarmos a vazão de $100 \mathrm{Mb} / \mathrm{s}$ temos:

$$
\begin{gathered}
\frac{100.10^{6}}{8}=N .1000 .160 \\
N=78,125 \text { IEDs }
\end{gathered}
$$


Desta forma, sabe-se que o número máximo de IEDs que poderia ser considerado para não extrapolar o limite da rede seria de cerca de 78 IEDs. Como além dos pacotes GOOSE existe também o tráfego dos pacotes MMS, o número de IEDs pode ser menor.

O primeiro resultado obtido através da simulação foi a quantidade de pacotes na fila para situações de tráfego de pacotes GOOSE com intervalo entre transmissões de $1 \mathrm{~ms}$. Neste caso, optou-se por simular os casos com 10, 40, 60, 78 e 79 IEDs, de acordo com a Figura 4.6. A partir desta figura, é possível notar que, para a simulação com 79 IEDs, o número de pacotes na fila segue uma característica linear e crescente, o que resultará no preenchimento da capacidade do buffer do switch ${ }^{13} \mathrm{e}$, consequentemente, levará ao descarte de pacotes. A ocorrência deste fato resultaria na perda de confiabilidade do sistema, fazendo com que informações críticas sejam ignoradas. Para os demais casos, o número de pacotes na fila permanece estável, abaixo de 90 pacotes, pois, a capacidade de transmissão de dados é maior do que o fluxo de dados gerado.

\footnotetext{
${ }^{13}$ Para o switch utilizado a capacidade do buffer é de $25 \mathrm{Mb}$, cerca de 19,5 mil pacotes de 160 bytes.
} 


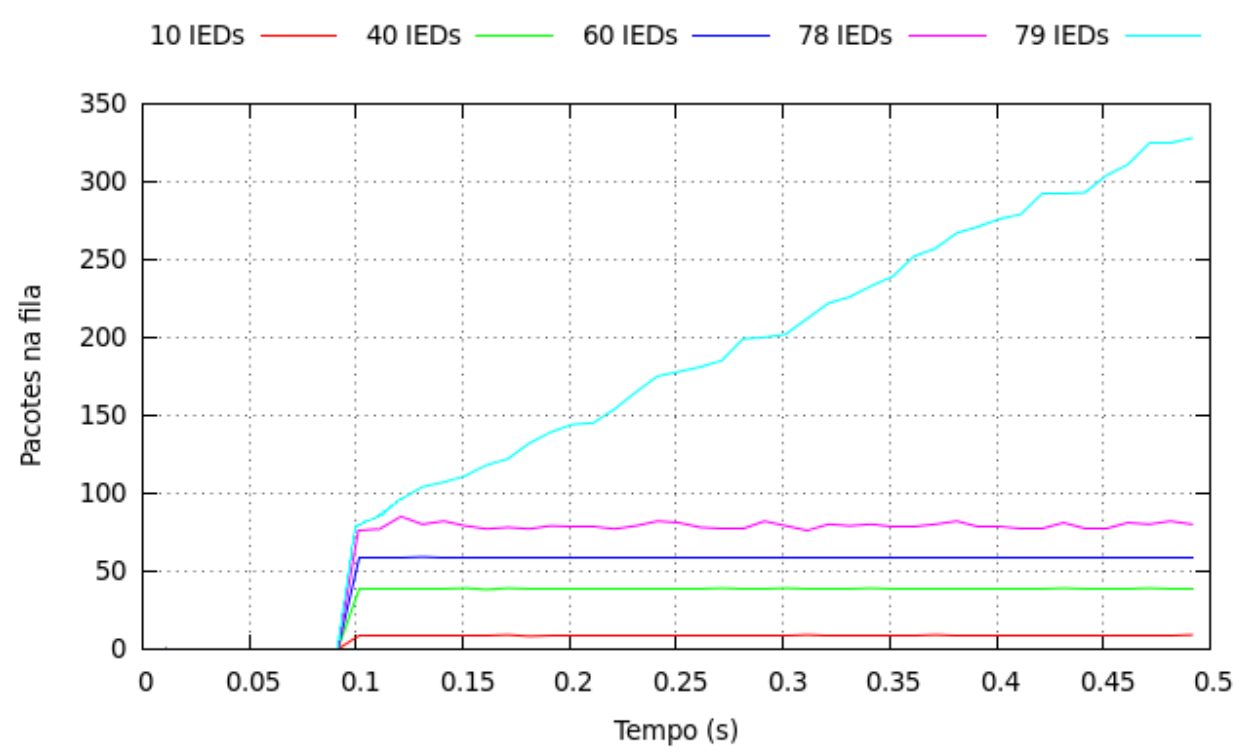

Figura 4.6 - Número de pacotes na fila.

Outra situação avaliada diz respeito ao tempo de latência dos pacotes como mostrado na Figura 4.7. Nesta simulação, a situação com 79 IEDs é descartada, pois a capacidade de transferência de dados do enlace é atingida e os pacotes são armazenados na fila, resultando em um tempo de latência com característica crescente. Através dos resultados apresentados nesta figura, é possível verificar que o tempo de latência máximo verificado fica em torno de 2,1 ms. Este valor atende aos requisitos mais exigentes da norma IEC 61850 utilizado para pacotes do tipo 1A para a classe P1, que é de $4 \mathrm{~ms}$ considerando o tempo de transferência do sinal na rede e o tempo de empilhamento e desempilhamento da informação no buffer dos dispositivos.

Através dos dados obtidos, foi monitorada também vazão de dados nos enlaces como mostra a Figura 4.8. Nela, é possível notar que, para a situação em que foram utilizados 78 IEDs, a vazão de dados atinge a capacidade de transmissão de dados do enlace. 


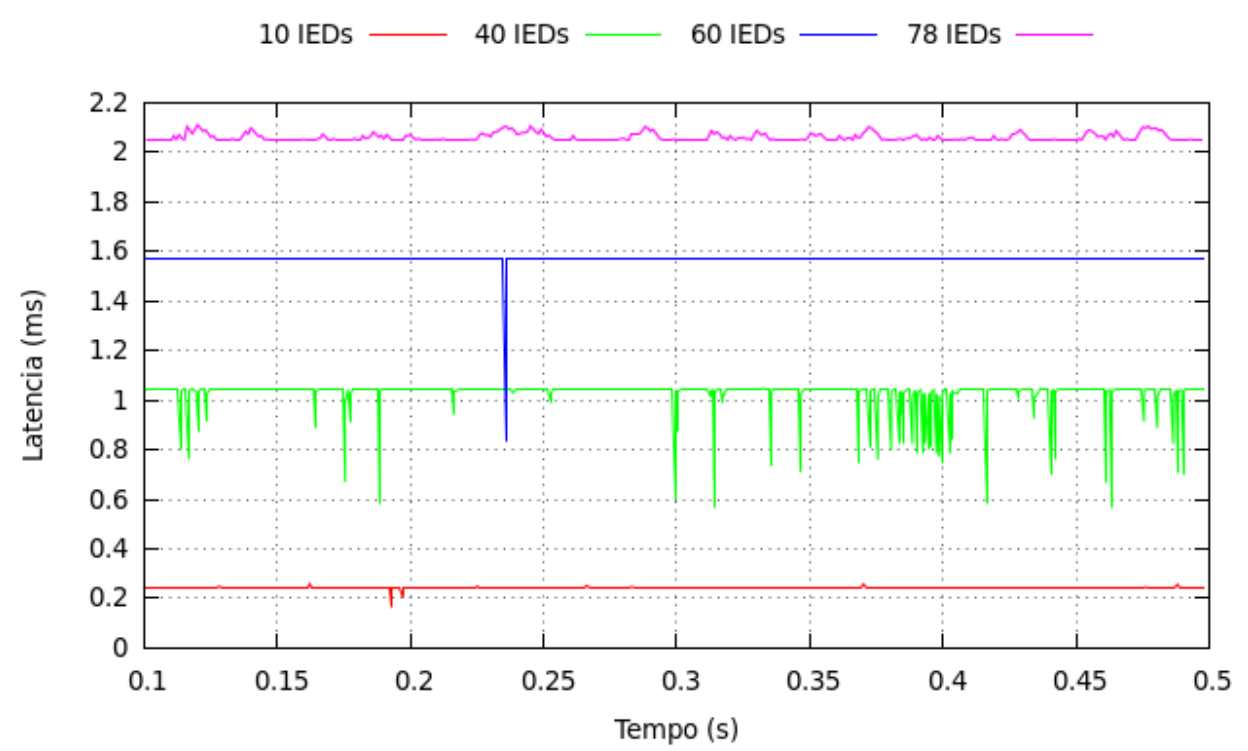

Figura 4.7 - Latência nos enlaces.

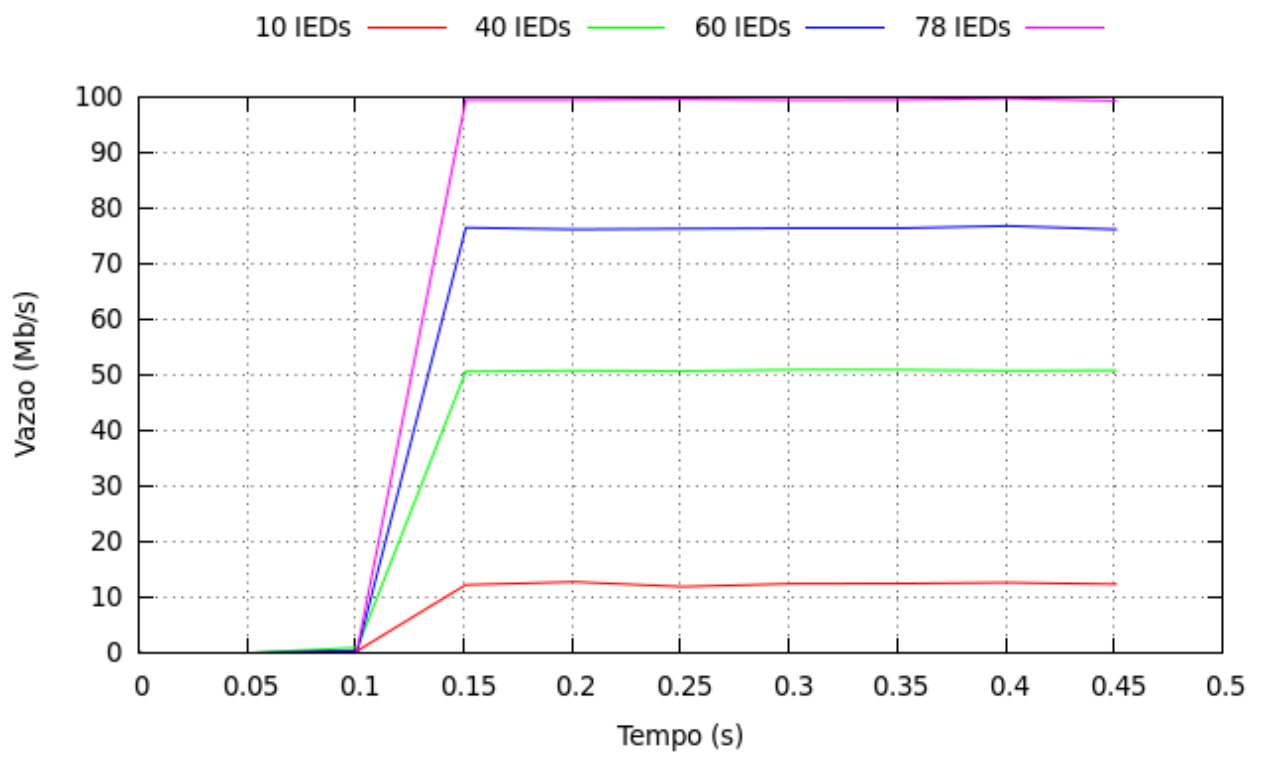

Figura 4.8 - Vazão de dados.

Para o cenário de curto-circuito, considerou-se eventos simultâneos em todos os alimentadores protegidos pelos IEDs, seguindo 0 
esquema de retransmissões apresentado na Figura 3.8, em que os tempos considerados foram:

$$
\begin{gathered}
T 1=2 m s ; T 2=10 m s ; T 3=100 m s \\
T 0=1000 m s-(T 1+T 2+T 3)=888 m s
\end{gathered}
$$

Os tempos escolhidos são justamente os implementados nos IEDs usados nos testes de laboratório.

Neste caso, o fator crítico está ligado à latência e não diretamente à capacidade de transmissão de dados, pois, durante um evento de curto-circuito simultâneo, a tendência é que todos os IEDs também enviem sinais GOOSE ao mesmo tempo.

Para atender aos requisitos de tempo de transferência de pacotes do tipo $1 \mathrm{~A}$ para a classe $\mathrm{P} 1$, a latência medida na simulação deve ficar abaixo de $4 \mathrm{~ms}$. Para isso, foi utilizado o processo de bissecção ${ }^{14}$, considerando que o número de IEDs máximo para atender a exigência de $4 \mathrm{~ms}$ estaria entre 100 e 200 IEDs. O valor encontrado foi de 155 IEDs como mostra a Figura 4.9.

Outra análise realizada para este caso teve como objetivo comprovar que a capacidade de transmissão de dados do enlace não seria problema como mostra a Figura 4.10. Neste caso, é possível verificar os picos de vazão que tem curta duração e o tráfego gerado pelos pacotes MMS em menor escala, porém distribuído ao longo de todo o tempo da simulação.

\footnotetext{
${ }^{14} \mathrm{O}$ processo de bissecção consiste em dividir o intervalo onde as raízes de uma função estão localizadas através do seu ponto médio. Assim, o processo pode ser repetido até que o valor do erro seja aceitável.
} 


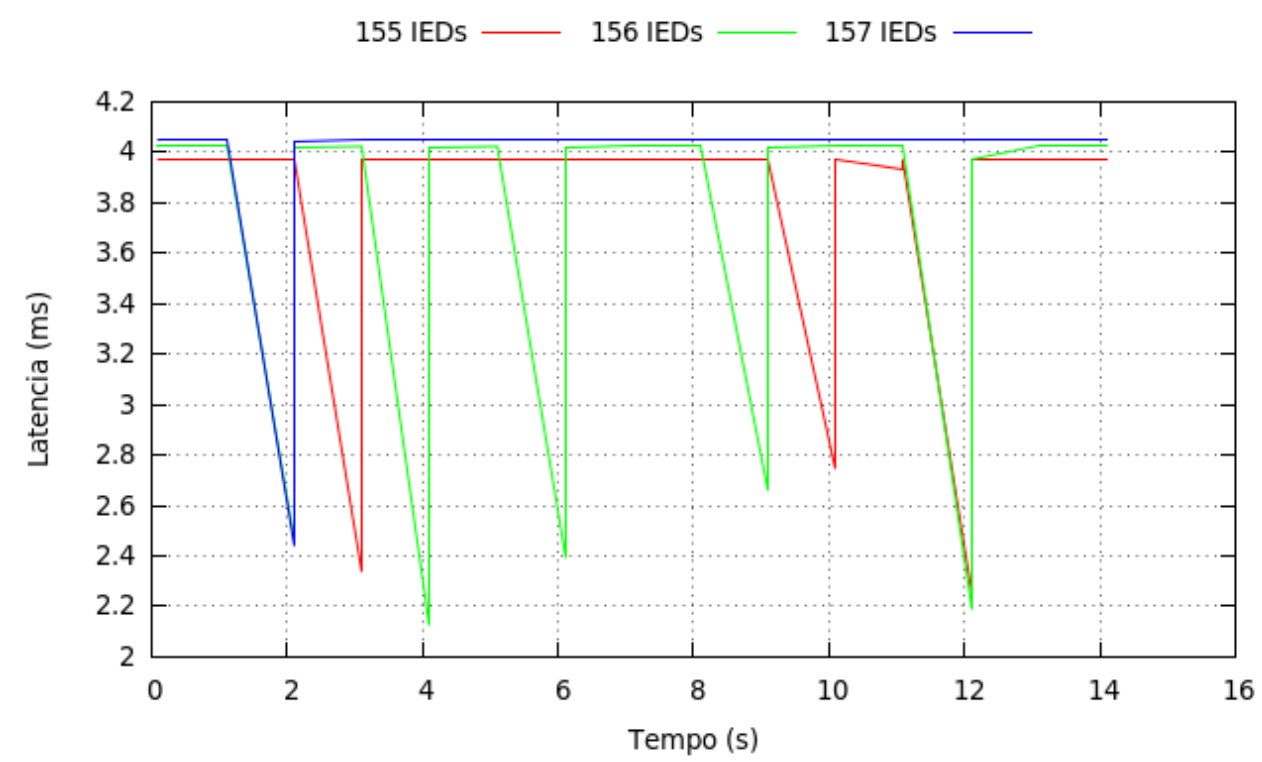

Figura 4.9 - Latência nos enlaces no caso de curto-circuitos simultâneos.

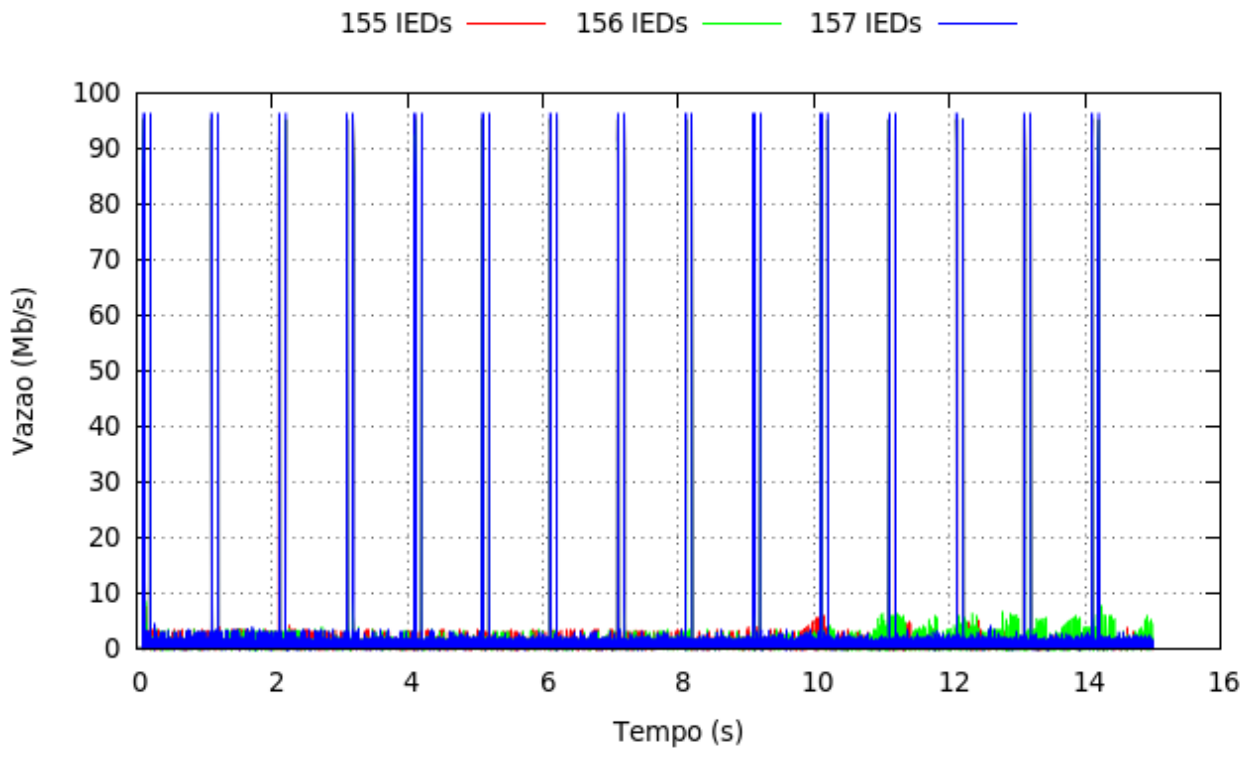

Figura 4.10 - Vazão de dados no caso de curto-circuitos simultâneos.

Os picos de vazão na Figura 4.10 decorrem da geração dos eventos de curto-circuito e do mecanismo de retransmissão das mensagens 
GOOSE (vide Figura 3.8). Sendo que, após o pico, o tráfego registrado é somente o das mensagens MMS.

\subsection{CONSIDERAÇÕES ADICIONAIS ACERCA DA SIMULAÇÃO}

Em redes IEC 61850, são utilizados switches que possuem a capacidade de gerenciar a qualidade de serviço (QoS - IEEE 802.1p) e criar VLANs. Estes recursos podem ser utilizados para dar prioridade a determinados tipos de pacotes e para isolar determinadas partes da LAN do restante dos dispositivos. No caso de pacotes GOOSE, utilizando QoS, estes pacotes recebem prioridade de envio e recebimento em detrimento de outros e, utilizando VLANs, é possível dividir os IEDs em grupos de rede privadas, fazendo com que os pacotes GOOSE sejam transmitidos via multicast a um número menor de dispositivos. Estes recursos podem ser utilizados para garantir os requisitos da norma no que tange o tempo de transferência determinado para as mensagens.

No entanto, com base nos sistemas de mercado, principalmente em projetos implentados na área de industrial, os recursos de QoS e VLAN não costumam ser utilizados. Como o intuito desta simulação é avaliar a pior situação possível para os pacotes GOOSE, estes recursos não foram considerados. 
No cômputo geral, a partir das situações simuladas, foi possível explorar alguns limites de um SAS para dois tipos de aplicações: i) demanda de fluxo de dados intenso e; ii) demanda de transferência de pacotes em intervalos maiores. Para as aplicações que demandam um fluxo maior de dados, foi possível verificar que, para um número de 79 IEDs, a capacidade de transmissão da rede foi saturada. Consequentemente, neste caso, deve-se utilizar os recursos de QoS e VLAN, se necessário for, ultrapassar o número de 78 IEDs para que a capacidade de transferência de dados dos enlaces não seja excedida. No segundo caso, para a situação de curto-circuito simultâneo, o valor encontrado foi de 155 IEDs para que o tempo de latência não ultrapasse solicitado pela norma IEC 61850.

Dados os resultados obtidos, é possível concluir que a norma IEC 61850 pode atender satisfatoriamente às aplicações de redes elétricas inteligentes nos contextos tratados. 


\section{CONCLUSÕES}

O desenvolvimento de redes elétricas inteligentes não advém somente da forte necessidade de integrar fontes de energia renováveis ao sistema e possibilitar o uso de veículos elétricos em larga escala, mas também representa uma oportunidade singular para aumentar a eficiência e aprimorar a infraestrutura da rede elétrica já existente. Assim, apesar de potencial revolucionário, estas redes irão se originar de uma evolução das tecnologias atuais, fruto do aprimoramento e gradual melhoria das mesmas. Além disso, a concepção destas redes não será baseada sobre uma única opção, mas sim na combinação de várias tecnologias. Portanto, dado o potencial de tal conceito e a pluralidade das técnicas envolvidas em sua implantação, não é de se estranhar que ela tenha se tornado um dos principais tópicos de estudo entre os acadêmicos e a indústria. No entanto, os últimos relatórios da EIA, têm indicado um forte aumento na exploração de óleo de xisto para produção de energia nos Estados Unidos. Este aumento pode trazer novidades para o setor energético nos próximos anos.

Neste trabalho, em particular, foram levantadas as motivações que estão por trás das redes elétricas inteligentes e alguns dos desafios relacionadas à sua implantação, no que tange os aspectos técnicos e normativos. As tecnologias já existentes e as que devem ser desenvolvidas nos próximos anos podem ajudar a transpor desafios, como a redução na emissão de $\mathrm{CO}_{2}$ e o aumento da capacidade dos sistemas elétricos através da otimização de recursos. 
Pode-se dizer que os assuntos abordados nos capítulos 1 a 3 são adequados para embasar os princípios das redes elétricas inteligentes, desde sua motivação, até as tecnologias de comunicação que estão sendo apontadas para uso nestas redes, como é o caso do capítulo 3, dedicado à norma IEC 61850.

Através das simulações propostas, foi possível avaliar o desempenho no uso da IEC 61850 para automação de subestações em situações extremas, porém, factíveis. Os casos simulados são aplicações típicas de redes inteligentes e podem ser estendidos para outras situações, topologias e quantidades de dispositivos, de acordo com necessidades específicas. No mercado de concessionárias de energia, a aceitação da norma IEC 61850 tem sido bastante positiva, principalmente no sentido de integrar os dispositivos em diferentes níveis do sistema, o que reafirma o potencial desta norma. Além disso, o conceito de redes elétricas inteligentes tem tido forte destaque nas ações de concessionárias e fabricantes de equipamentos para sistemas de potência nos últimos anos. Na indústria, fazendo algumas exceções, a aceitação da norma tem sido um pouco mais morosa. Sob esta ótica, as contribuições deste trabalho são importantes e servem para assegurar a confiabilidade dos sistemas baseados na IEC 61850.

Os arquivos de simulação e os resultados deste trabalho podem ser de grande utilidade para o dimensionamento de sistemas de automação de subestação, particularmente, para aplicações de descarte de carga que utilizam redes de comunicação padrão IEC 61850. Isto porque é possível simular situações em que a quantidade de IEDs e a topologia de rede sejam diferentes, através da alteração de apenas alguns parâmetros. Deste modo, a melhor utilização dos recursos é possível, especialmente tratando-se dos 
gerenciadores de descarte de cargas, que possuem um hardware diferenciado, o que resultaria em redução de custos para grandes projetos.

Para trabalhos futuros é possível avaliar a integração de valores amostrados (SV) na simulação, utilizando, neste caso, os dados medidos através de dispositivos que atendam à parte 9 da norma IEC 61850. Esta é uma tendência de mercado nos próximos anos para os projetos de sistemas de automação de subestações. 


\section{REFERÊNCIAS}

[1] J. V. De Putte e R. Short, "Battle of the Grids," Greenpeace International, Amsterdam, 2011.

[2] Hughes, Thomas P. Networks of Power: Electrification in Western Society 1880-1930. Baltimore: Johns Hopkins University Press, 1993.

[3] W. L. de Sousa, "Impacto Ambiental de Hidrelétricas: Uma Análise Comparativa de Duas Abordagens" [dissertação], UFRJ, Rio de Janeiro, 2000.

[4] L. Quaino, "Lei ambiental tira 100 mil megawatts de energia do país, diz MME" G1 Economia, 26/08/2013. [Online]. Disponível: http://g1.globo.com/economia/noticia/2013/08/leiambiental-tira-100-mil-megawatts-de-energia-do-pais-dizmme.html. [Acesso em 12/09/2013].

[5] U.S. Energy Information Administration, "International Energy Outlook 2013," Report Number: DOE/EIA-0484, Washington, 2013.

[6] U.S. Energy Information Administration, "Energy Technology Perspectives 2012: Pathways to a Clean Energy System (International Energy Agency)" OECD/EIA Publisihing, 2012.

[7] Empresa de Pesquisa Energética - EPE, "Anuário estatístico de energia elétrica 2011," Rio de Janeiro, 2011. 
[8] Brasil. Ministério de Minas e Energia. Plano Nacional de Energia 2030 / Ministério de Minas e Energia; colaboração Empresa de Pesquisa Energética. Brasília : MME : EPE, 2007.

[9] Brasil, Ministério de Minas e Energia, Empresa de Pesquisa Energética. Plano Decenal de Expansão de Energia $2021 /$ Ministério de Minas e Energia. Empresa de Pesquisa Energética. Brasília: MME/EPE, 2012

[10] ExxonMobil, "2012 The Outlook for Energy: A View to 2040," Irving, 2012.

[11] IEEE, "1815 ${ }^{\mathrm{TM}}-2012$ - IEEE Standard for Electric Power Systems Communications-Distributed Network Protocol (DNP3)", New York, 2012.

[12] International Electrotechnical Commission, "IEC 60870 Telecontrol equipment and systems," Genebra, 2006.

[13] International Electrotechnical Commission, "IEC 61850 Communication networks and systems for power utility automation," Genebra, 2013.

[14] US Department of Energy, "2010 Smart Grid System Report". Report to Congress, February 2012. [Online] Disponível: http://energy.gov/sites/prod/files/2010\%20Smart\%20Grid\%20S ystem\%20Report.pdf. [Acesso em 15/09/2013].

[15] Michael T. Burr, "Reliability demands drive automation investments," Public Utilities Fortnightly, Technology Corridor department, 01/11/2003. [Online] Disponível: http://www.fortnightly.com/fortnightly/2003/11/technology- 
corridor. [Acesso em 15/09/2013].

[16] Amin, S.M. ; Wollenberg, B.F. "Toward a smart grid: power delivery for the 21st century". IEEE Power and Energy Magazine (Volume:3, Issue: 5 ), 12/09/2005.

[17] Douglas A. A. Garcia; Francisco E. Duzzi Jr. "Aspectos de evolução do smart grid nas redes de distribuição," O Setor Elétrico, Distribuição de Energia. Ed. 75, 2012. [Online] Disponível:

http://www.osetoreletrico.com.br/web/documentos/fasciculos/E d75_fasc_distribuicao_cap3.pdf. [Acesso em 15/09/2013].

[18] C. W. Gellings, "The Smart Grid: Enabling Energy Efficiency and Demand Response" CRC Press, 2009.

[19] European technology platform for the electricity networks of the future "Smart Grids". [Online]. Disponível: http://www.smartgrids.eu. [Acesso em 25/09/2012].

[20] H. Sui, W. Lee, "An AMI based measurement and control system in smart distribution grid," em IEEE Industrial and Commercial Power Systems Technical Conference (I\&CPS), Baltimore, 2011.

[21] M. Erol-Kantarci, H. T. Mouftah, "Supply and Load Management for the Smart Distribution Grid Using Wireless Networks," em Japan-Egypt Conference on Electronics, Communications and Computers (JEC-ECC), Alexandria, 2012.

[22] M. Vaziri, S. Vadhva, T. Oneal, M. Johnson, "Smart Grid, Distributed Generation, and Standards," em IEEE Power and 
Energy Society General Meeting, San Diego, 2011.

[23] J. Stragier, L. Hauttekeete, L. De Marez, "Introducing Smart Grids in Residential Contexts: Consumers' Perception of Smart Household Appliances," em IEEE Innovative Technologies for an Efficient and Reliable Electricity Supply (CITRES), Waltham, 2010.

[24] Z. Jiang, F. Li, W. Qiao, et al., "A Vision of Smart Transmission Grids," em IEEE Power \& Energy Society General Meeting, Calgary, 2009.

[25] N. Katie, V. Marijanovie, I. Stefani, "SMART GRID SOLUTIONS IN DISTRIBUTION NETWORKS COST/BENEFIT ANALYSIS," em China International Conference on Electricity Distribution (CICED), Nanjing, 2010.

[26] P. Li, X. Li, J. Chen, J. Chen, L. Fei, "To Strengthen the Construction of Smart Grid, To Enhance the Leaping Development of New Energy Power Generation," em International Conference on Electrical Machines and Systems (ICEMS), Beijing, 2011.

[27] S. M. Amin, "Smart Grid Security, Privacy, and Resilient Architectures: Opportunities and Challenges," em IEEE Power and Energy Society General Meeting, San Diego, 2012.

[28] Enel, "Telegestore - Italy". [Online]. Disponível: http://www.enel.com/enGB/innovation/smart_grids/smart_metering/telegestore/. [Acesso em 12/09/2013]. 
[29] U.S. Department Of Energy , "Understanding the Benefits of the Smart Grid", Junho 2010. [Online]. Disponível: http://www.netl.doe.gov/smartgrid/referenceshelf/whitepapers/ 06.18.2010_Understanding\%20Smart\%20Grid\%20Benefits.pd f. [Acesso em 25/09/2013].

[30] Agência Nacional de Energia Elétrica - ANEEL, "Relatórios do Sistema de Apoio a Decisão," 0507 2012. [Online]. Disponível: $\quad$ http://www.aneel.gov.br/area.cfm?idarea=550. [Acesso em 05/07/2012].

[31] Agência Nacional de Energia Elétrica - ANEEL, "Audiência Pública 043/2010," 2010. [Online]. Disponível: http://www.aneel.gov.br/aplicacoes/audiencia/dspListaDetalhe. cfm?attAnoAud=2010\&attldeFasAud=435\&id_area=13\&attAno FasAud=2010. [Acesso em 07/09/2011].

[32] Smartgrid News, "ANEEL aprova regras para facilitar a geração de energia nas unidades consumidoras," 18/04/2012. [Online]. Disponível: http://smartgridnews.com.br/aneelaprova-regras-para-facilitar-a-geracao-de-energia-nasunidades-consumidoras/. [Acesso em 30/06/2012].

[33] AES Eletropaulo, "AES ELETROPAULO ANUNCIA O MAIOR PROJETO DE SMART GRID DO PAÍS", 30/04/2013. [Online]. Disponível: http://aesbrasilsustentabilidade.com.br/pt/noticias/item/aeseletropaulo-anuncia-o-maior-projeto-de-smart-grid-dopais.html. [Acesso em 20/09/2013].

[34] M. G. Kallitsis, G. Michailidis, M. Devetsikiotis "A Framework for Optimizing Measurement-based Power Distribution under 
Communication Network Constraints," em IEEE International Conference on Smart Grid Communications, Gaithersburg, 2010.

[35] IEEE, "IEEE 802.11-2012 IEEE Standard for Information Technology - Telecommunications and information exchange between systems. Part 11: Wireless LAN Medium Access Control (MAC) and Physical Layer (PHY) Specifications", New York, 2011.

[36] "Mesh Networks Research Group," [Online]. Disponível: http://www.mesh-networks.org/. [Acesso em 21/07/2012].

[37] M. Souryal, C. Gentile, D. Griffith, D. Cypher, N. Golmie "A Methodology to Evaluate Wireless Technologies for the Smart Grid," em IEEE International Conference on Smart Grid Communications, Gaithersburg, 2010.

[38] B. Bjelajac, B. Lichtensteiger, C. Müller e C. Wietfeld, RF Mesh Systems for Smart Metering: System Architecture and Performance, IEEE International Conference on Smart Grid Communications (SmartGridComm), 2010, pp. 379-384.

[39] P. Yi, A. Iwayemi, C. Zhou, "Developing ZigBee Deployment Guideline Under WiFi Interference for Smart Grid Applications," em IEEE Transactions on Smart Grid, Vol. 2, $1^{\text {a }}$ Edição, 2011.

[40] IEEE, "IEEE 802.15.4-2011 IEEE Standard for Local and metropolitan area networks - Part 15.4: Low-Rate Wireless Personal Area Networks (LR-WPANs)", New York, 2011. 
[41] California Independent System Operator, "Demand Response \& Proxy Demand Resource - Frequently Asked Questions," 24/06/2011. [Online]. Disponível: http://www.caiso.com/271e/271ee8df2c760.pdf. [Acesso em 29/07/2012].

[42] IEEE, "IEEE 802.16-2012 IEEE Standard for Air Interface for Broadband Wireless Access Systems", New York, 2012.

[43] IEEE, "IEEE Std 1901-2010 - IEEE Standard for Broadband over Power Line Networks: Medium Access Control and Physical Layer Specifications," [Online]. Disponível: http://grouper.ieee.org/groups/1901/. [Acesso em 21/07/2012].

[44] U. Braun, "Bridging the gap with Broadband Powerline (BPL) technology," em IEEE PES International Conference and Exhibition on Innovative Smart Grid Technologies, Manchester, 2011.

[45] ANSI, ANSI T1.413-1998 - Network and Customer Installation Interfaces - Asymmetric Digital Subscriber Line (ADSL) Metallic Interface, 1998..

[46] Society of Cable Telecommunications Engineers, SCTE 222012 - Data-Over-Cable Service Interface Specification DOCSIS, Exton, 2012.

[47] 3GPP, 3rd Generation Partnership Project - Technical Specification Group Radio Access Network, Valbonne, 2011.

[48] ETSI, EN 301347 - General Packet Radio Service (GPRS), 1999. 
[49] Newton-Evans Research Company. "Market Trends Digest," Março 2011. [Online]. Disponível: http://www.newtonevans.com/mtdigest/mtd1q11.pdf. [Acesso em 2109 2013].

[50] International Electrotechnical Commission, "IEC 62056 Electricity metering - Data exchange for meter reading, tariff and load control".

[51] American National Standard, "ANSI C12.18-2006 - Protocol Specification for ANSI Type 2 Optical Port", Rosslyn, 2006.

[52] EIA standard RS-232-C: Interface between Data Terminal Equipment and Data Communication Equipment Employing Serial Binary Data Interchange. Washington: Electronic Industries Association. Engineering Dept. 1969.

[53] K. D. Craemer, G. Deconinck, "Analysis of State-of-the-art Smart Metering Communication Standards," em Young Researchers Symposium (YRS), Leuven, 2010.

[54] S. Feuerhahn, M. Zillgith, C. Wittwer, C. Wietfeld. "Comparison of the Communication Protocols DLMS/COSEM, SML and IEC 61850 for Smart Metering Applications," em IEEE International Conference on Smart Grid Communications (SmartGridComm), Brussels, 2011.

[55] International Electrotechnical Commission, "IEC Smart Grid Standardization Roadmap," Edição 1, 2009.

[56] International Electrotechnical Commission, "IEC TR 62357 Power system control and associated communications Reference architecture for object models, services and 
protocols," Genebra, 2012.

[57] International Electrotechnical Commission, "IEC 61970 Energy management system application program interface (EMS-API)," Genebra, 2005.

[58] International Electrotechnical Commission, "IEC 61968 Application integration at electric utilities - System interfaces for distribution management," Genebra, 2003.

[59] International Electrotechnical Commission, "IEC 62351 Power systems management and associated information exchange - Data and communications security," Genebra, 2007.

[60] International Electrotechnical Commission, "IEC 61508 Functional safety of electrical/electronic/programmable electronic safety-related systems," Genebra, 2010.

[61] DNP - Distributed Network Protocol. [Online]. Disponível: http://www.dnp.org/. [Acesso em 21/09/2013].

[62] International Organization for Standardization, "ISO/IEC 74981 - Open Systems Interconnection -- Basic Reference Model: The Basic Model" Genebra, 1994.

[63] Electronic Industries Association. EIA RS-485: Standard for electrical characteristics of generators and receivers for use in balanced digital multipoint systems. Washington, 1983.

[64] RFC 793 "Transmission Control Protocol", 1981. [Online]. Disponível: http://www.ietf.org/rfc/rfc793.txt. [Acesso em 21/09/2012]. 
[65] RFC 768 "User Datagram Protocol", 1980. [Online]. Disponível: http://tools.ietf.org/rfc/rfc768.txt. [Acesso em 21/09/2012].

[66] G. Manassero Jr., E. L. Pellini, E. C. Senger, R. M. Nakagomi, "IEC61850 based systems - Functional testing and interoperability issues," em IEEE Transactions on Industrial Informatics, Vol. 9, Issue: 3, 2013.

[67] R. Hamrén, "Using IEC 61850 for remote disturbance analysis," Master Thesis in Computer Science, Mälardalen University, Östersund, 2007.

[68] J. Bergmann, C. Glomb, J. Götz, et al., "Scalability of Smart Grid Protocols," em IEEE International Conference on Smart Grid Communications, Gaithersburg, 2010.

[69] Y. Yan, Y. Qian, H. Sharif, D. Tipper, "A Survey on Smart Grid Communication Infrastructures: Motivations, Requirements and Challenges," em IEEE Communications Surveys \& Tutorials, Vol. 15, No. 1, 2013.

[70] International Electrotechnical Commission, "IEC 61850 Communication networks and systems in substations," Genebra, 2003.

[71] T. S. Sidhu, S. Injeti, M. Kanabar e P. Parikh, "Packet Scheduling of GOOSE Messages in IEC 61850 based Substation Intelligent Electronic Devices (IEDs)," em IEEE Power and Energy Society General Meeting, Minneapolis, 2010. 
[72] W3C - Extensible Markup Language (XML) 1.0. [Online]. Disponível: http://www.w3.org/TR/REC-xml/. [Acesso em 25/09/2013].

[73] Apresentação sobre IEC 61850. ABB, 2010.

[74] Institute of Electrical and Electronics Engineers, "C37.2 - IEEE Standard Electrical Power System Device Function Numbers and Contact Designations," New York, 2008.

[75] International Organization for Standardization, "ISO 8601 Data elements and interchange formats - Information interchange - Representation of dates and times," 2004.

[76] Navstar GPS Space Segment/Navigation User Interfaces Global Positioning Systems Directorate, Systems Engineering \& Integration, Interface Specification IS-GPS-200, 2012. [Online] Disponível: http://www.gps.gov/technical/icwg/lSGPS-200G.pdf. [Acesso em 07/2013].

[77] IEEE - Institute of Electrical and Electronics Engineers, IEEE C93.4-2012 - IEEE Standard for Power-Line Carrier LineTuning Equipment ( $30 \mathrm{kHz}$ to $500 \mathrm{kHz}$ ) Associated with Power Transmission Lines, New York, 2013.

[78] Cigré SC34 WG 34-35.11. Protection Using Telecommunications, TB 13, 2000.

[79] International Electrotechnical Commission, "IEC 62439 Industrial communication networks - High availability automation networks," Genebra, 2012.

[80] IEEE - Institute of Electrical and Electronics Engineers, IEEE 
802.1Q-2011 - IEEE Standard for Local and metropolitan area networks--Media Access Control (MAC) Bridges and Virtual Bridged Local Area Networks, New York, 2011.

[81] UCA International Users Group, "About UCAlug". [Online]. Disponível: http://www.ucaiug.org/aboutUCAlug/default.aspx. [Acesso em 0809 2013].

[82] DNV-KEMA, "Conformance testing". [Online]. Disponível: http://www.dnvkema.com/services/moc/inc/conformancetesting.aspx. [Acesso em 0809 2013].

[83] N. Liu, J. Chen, H. Luo e W. Liu, "A Preliminary Communication Model of Smart Meter Based on IEC 61850," em Power and Energy Engineering Conference (APPEEC), Wuhan, 2011.

[84] IEC - International Electrotechnical Commission, IEC 62056 Electricity metering - Data exchange for meter reading, Genebra, 2002.

[85] G. Leishman e M. Thakur, "Standardization of Distribution Protection System Based on the New Generation of Microprocessor Relays," em 60th Annual Conference for Protective Relay Engineers, College Station, 2007.

[86] S. Roostaee, R. Hooshmand, M. Ataei, "Substation Automation System Using IEC 61850," em The 5th International Power Engineering and Optimization Conference (PEOCO2011), Selangor, 2011.

[87] D.S. Ouellette, M.D. Desjardine, P.A. Forsyth, "Using a Real Time Digital Simulator to Affect the Quality of IEC 61850 
GOOSE and Sampled Value Data," em IET International Conference on Developments in Power System Protection, Manchester, 2010.

[88] T. S. Sidhu, Y. Yin, "Modelling and Simulation for Performance Evaluation of IEC61850-Based Substation Communication Systems," em IEEE Transactions on Power Delivery, 2007.

[89] Agência Nacional de Energia Elétrica, "Resolução Normativa ANEEL n. 367", 02/06/2009.

[90] "The Network Simulator - ns-2," [Online]. Disponível: http://www.isi.edu/nsnam/ns/. [Acesso em 12/02/2012].

[91] Ruggedcom, "Latency on a Switched Ethernet Network," [Online].

Disponível: http://www.ruggedcom.com/pdfs/application_notes/latency_on _a_switched_ethernet_network.pdf. [Acesso em 03/2012].

[92] Y. Raghunath, A. Sravani, "Performance Measures for Internet Server by Using M/M/m Queueing Model," em IJRET, 2012. 